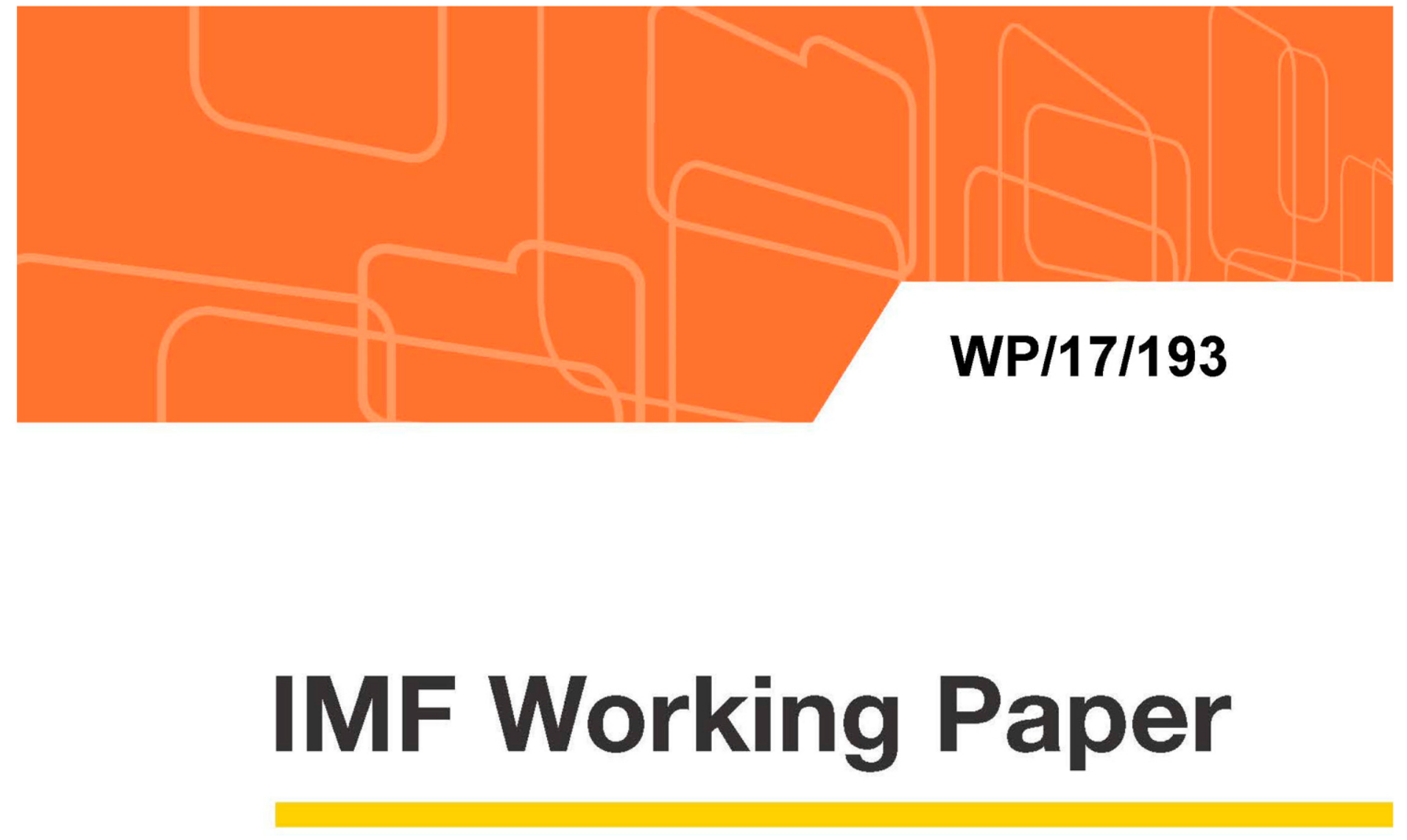

\title{
How Important is the Global Financial Cycle? Evidence from Capital Flows
}

by Eugenio Cerutti, Stijn Claessens and Andrew K. Rose

IMF Working Papers describe research in progress by the authors and are published to elicit comments and to encourage debate. The views expressed in IMF Working Papers are those of the authors and do not necessarily represent the views of the IMF, its Executive Board, or IMF management.

$$
\text { I N T E R N A T I O N A L M O N E T A R Y F U N D }
$$




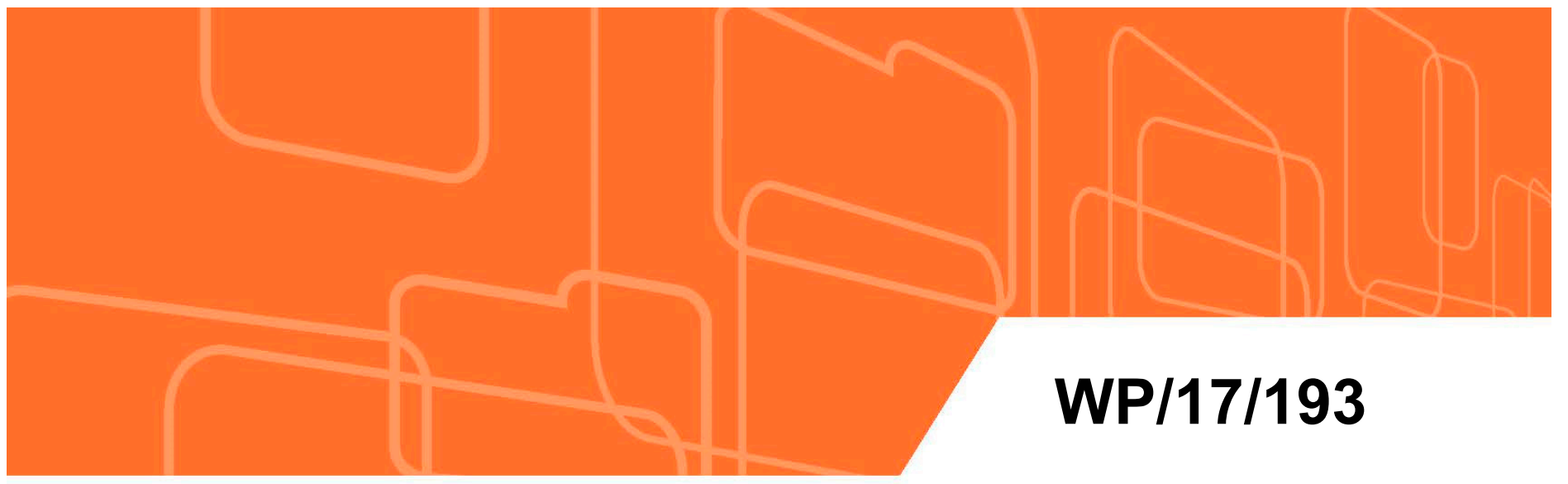

\title{
IMF Working Paper
}

\section{How Important is the Global Financial Cycle? Evidence from Capital Flows}

\author{
by Eugenio Cerutti, Stijn Claessens and Andrew K. Rose
}

IMF Working Papers describe research in progress by the authors and are published to elicit comments and to encourage debate. The views expressed in IMF Working Papers are those of the authors and do not necessarily represent the views of the IMF, its Executive Board, or IMF management.

$$
\text { I N T E R N A T | O N A L M O N E T A R Y F U N D }
$$




\title{
IMF Working Paper
}

Research Department

\section{How Important is the Global Financial Cycle?}

\author{
Evidence from Capital Flows* \\ Prepared by Eugenio Cerutti, Stijn Claessens and Andrew K. Rose
}

Authorized for distribution by Maurice Obstfeld

September 2017

\section{IMF Working Papers describe research in progress by the authors and are published to elicit comments and to encourage debate. The views expressed in IMF Working Papers are those of the authors and do not necessarily represent the views of the IMF, its Executive Board, or IMF management.}

\begin{abstract}
This study quantifies the importance of a Global Financial Cycle (GFCy) for capital flows. We use capital flow data dis-aggregated by direction and type between 1990Q1 and 2015Q4 for 85 countries, and conventional techniques, models and metrics. Since the GFCy is an unobservable concept, we use two methods to represent it: directly observable variables in center economies often linked to it, such as the VIX; and indirect manifestations, proxied by common dynamic factors extracted from actual capital flows. Our evidence seems mostly inconsistent with a significant and conspicuous GFCy; both methods combined rarely explain more than a quarter of the variation in capital flows. Succinctly, most variation in capital flows does not seem to be the result of common shocks nor stem from observables in a central country like the United States.
\end{abstract}

JEL Classification Numbers: F32; F36; F65; G15

Keywords: empirical; data; center; country; panel; fit; VIX; equity; bonds; FDI; credit.

Authors’ E-Mail Address: ECerutti@,imf.org, Stijn.Claessens@,bis.org, ARose@haas.berkeley.edu

\footnotetext{
* We thank Nathan Converse and Carmen Reinhart for providing data, and Tamim Bayoumi, Olivier Blanchard, Antoine Bouveret, Steve Davis, Robin Koepke, Maurice Obstfeld, David Reeb, Hyun Song Shin, Anand Srinivasan, Johan Sulaeman, Shang-Jin Wei and workshop participants at ABFER and NUS for comments. Rose thanks the National University of Singapore for hospitality during the course of this research. A current version of the paper, the data set and key output are freely available at Rose's website. All opinions expressed in this paper are those of the authors, and not of the institutions they are affiliated with.
} 


\section{Contents}

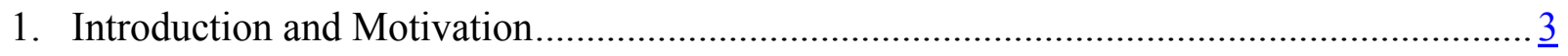

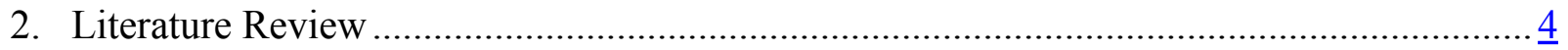

3. Identifying the GFCy: Data, Methodology and a First Look .......................................... 9

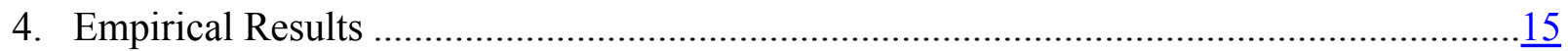





\section{Tables}

1. Importance of Common Phenomena for Goodness of Fit in Panel Regressions ................. $\underline{31}$

2. Importance of Common Phenomena for Goodness of Fit in Panel Regressions ..................31

3. Country-Heterogeneous Responses to Common Phenomena in Panel Regressions............. $\underline{32}$

\section{Figures}

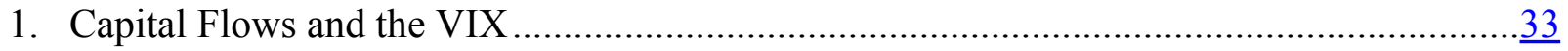

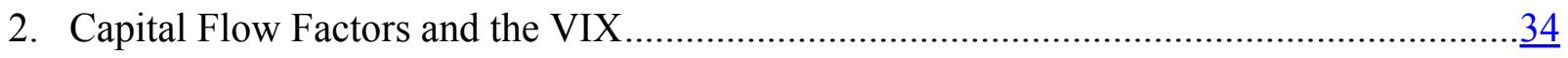

3. Capital Inflow Factors: Advanced and Emerging Economies ......................................

4. Fear Measures and Factors from Asset/Commodity Prices .......................................... 36

5. Fit of Country Time-Series Capital Flow Regressions ....................................................37

6. Fit of Country Time-Series Capital Flow Regressions ................................................ 38

7. Fit of Country Time-Series Capital Flow Regressions ................................................

8. Fit of Country Time-Series Capital Flow Regressions ................................................. 40

9. Fit of Country Time-Series Capital Flow Regressions ................................................ 41

10. Capital Flows (\%GDP) around quarters when VIX close $>30$.......................................

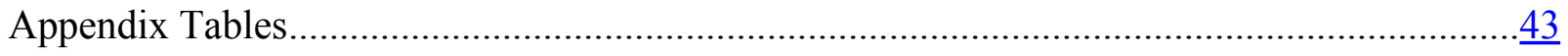

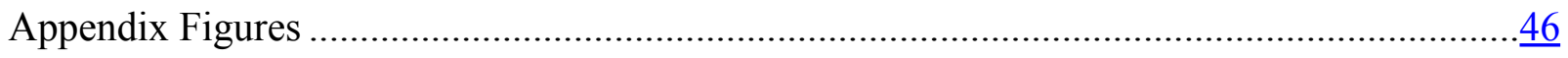


"Risky asset prices around the globe, from stocks to corporate bonds, have a strong common component. So do capital flows ... Global financial cycles are associated with surges and retrenchments in capital flows, booms and busts in asset prices and crises. The picture emerging is that of a world with powerful global financial cycles characterized by large common movements in asset prices, gross flows, and leverage ... The global financial cycle can be related to monetary conditions in the centre country and to changes in risk aversion and uncertainty ... capital flows, especially credit flows, are largely driven by a global factor ..."

-- Rey (2013, pp 1-2)

\section{Introduction and Motivation}

This paper seeks to quantify the importance of a Global Financial Cycle (hereafter GFCy), particularly for the variation in international capital flows. ${ }^{1}$ The concept of an important GFCy is closely identified with the work of Rey, who writes:

"There is a global financial cycle in capital flows, asset prices, and in credit growth. This cycle comoves with the VIX, a measure of uncertainty and risk aversion of the markets."

-- Rey (2013, abstract)

"Large gross cross-border flows are moving in tandem across countries regardless of the exchange rate regime, they tend to rise in periods of low volatility and risk aversion and decrease in periods of high volatility and risk aversion, as measured by the VIX ... There is a global financial cycle."

-Passari and Rey (2015, p 693)

The interest in the GFCy is certainly not confined to Rey and her co-authors. For instance, Forbes and Warnock (2012) write:

"Global factors, especially global risk, are significantly associated with extreme capital flow episodes. ... Our analysis indicates that waves of capital flows are primarily associated with global factors. Global risk, which incorporates both risk aversion and economic uncertainty, is the only variable that consistently predicts each type of capital flow episode; an increase in global risk is associated with more stops and retrenchments and fewer surges and flight. ... most domestic factors only have a limited correlation with capital flow volatility ... global factors, and especially global risk, are key to understanding periods of extreme capital flows by domestic and foreign investors. Increases in global risk predict sudden stops in capital flows by foreigners and retrenchments in capital flows by domestic investors ..."

As reflected in a growing literature, it is easy to motivate research on the GFCy. Suppose that the GFCy explains much of the variation in capital flows, particularly for small and emerging economies. In this case, it becomes more difficult for policy-makers in these countries to manage their economics as the GFCy, driven by common shocks including factors emanating from the center, leads to large capital flows fluctuations (exogenous from the viewpoint of the small and/or emerging countries). They could insulate their economies against the GFCy (with capital controls, macro-prudential instruments and the like), but also give up some of the benefits of international financial integration. As Rey (2015, pp 9-10) writes:

\footnotetext{
${ }^{1}$ We use "GFCy" since "GFC" is commonly used to refer to the Global Financial Crisis of 2008-09. Since the GFCy can manifest itself also in ways other than capital flows, we separately analyze in a forthcoming companion paper the behavior of domestic asset prices and credit growth across countries.
} 
"As capital flows respond to US monetary policy, they may not be appropriate for the cyclical conditions of many economies. For some countries, the Global Financial Cycle can lead to excessive credit growth in boom times and excessive retrenchment in bad times. ... The Global Financial Cycle can be associated with surges and dry outs in capital flows, booms and busts in asset prices and crises... The empirical results on capital flows, leverage and credit growth are suggestive of an international credit channel or risk-taking channel and point towards financial stability issues."

However, if the GFCy does not explain most or even much of the variation in capital flows, then the policy authorities in small and/or emerging countries have greater degrees of freedom to manage their economies, at least in terms of the impact of the GFCy on capital flow fluctuations. For this reason, quantifying the importance of the GFCy for capital flows, our chief concern in this paper, is important. We emphasize at the outset that our approach is conventional, by design. Thus, our data sets, techniques, capital flow models and statistical metrics are widely used and plain-vanilla. The focus of this paper is on empirical results, not on our data or methodology.

In the next section, we review related empirical literature, which also helps explain our methodological approach; section 3 introduces our data. The heart of the paper is in section 4 which presents our empirical results; we end with a brief summary and conclusion.

\section{Literature Review}

In our investigation, we draw on two strands of literature that have analyzed the GFCy implicitly or explicitly. One strand involves traditional "push-pull" analyses which try to explain capital flows with global "push" (i.e., source country) and "pull" (i.e., recipient country) factors. The other strand documents the (degree of) commonality in global financial developments, including capital flows, credit creation, and domestic asset prices, using factor models and structural times-series models (often variants of VARs). We use elements of both strands in such a way that our exploration maximally favors the quantitative importance of the GFCy for international capital flows. Since the literature has also documented differences by type, source and destination of capital flows as well as period of time, we explore the robustness of our results to variations in these dimensions as well.

\section{$\underline{\text { Push-Pull }}$}

The first strand of literature, started by Calvo et al. $(1993,1996)$, mainly uses panel regressions to investigate the relative roles of push and pull factors in driving capital flows. Recent contributions include Fratzscher (2011), Forbes and Warnock (2012), Broner et al. (2013), Bruno and Shin (2015a), and Cerutti, Claessens, and Ratnovski (2017). Koepke (2015) provides a recent review of some 40 papers; see also IMF (2014). While results vary, typically a worsening in global risk conditions, as measured by the VIX, is found to lower capital flows, especially to emerging markets. ${ }^{2}$ Evidence on US monetary policy is more mixed. Some papers find capital flows respond negatively to a tightening in US monetary policy, more so for portfolio bond and equity flows; others find monetary policy variables are not always

\footnotetext{
${ }^{2}$ Flows to some advanced countries have occasionally been found to increase due to a flight to safety.
} 
significant, or do not consistently have the same sign (e.g., Cerutti, et al. 2015), with some even finding opposite signs (e.g., Correa et al. 2016 find banking flows increase for some countries when US interest rates rise, in part related to the relative level of riskiness comparing US nonbank borrowers and those countries' borrowers).

The explanatory power of these push variables is typically limited, in absolute terms and sometimes also relative to pull variables (when those are included). Bruno and Shin (2015b) investigate banking flows to 46 countries using BIS data and find that "local factors account for only a modest amount of the variation and global factors account for an overwhelming part of the variation," but they report overall $\mathrm{R}^{2} \mathrm{~s}$ of .1 or less. Similarly, Forbes and Warnock (2012, p244) state in an endnote that it is difficult to fit capital flows: "For example, in a simple logit specification, the pseudo-R2 is only .04 for flight episodes, increasing to $.07, .13$, and .15 for surges, retrenchments, and stops, respectively." Cerutti et al. (2017), regressing a panel of banking flows on domestic factors, spreads, and global measures, report $\mathrm{R}^{2} \mathrm{~s}$ less than .1, even when including, besides US VIX and other US measures, conditions in other funding areas (UK, Japan, EMU). Only when including various pull variables as well as country fixed effects, do their $\mathrm{R}^{2} \mathrm{~s}$ exceed .5. It seems reasonable to conclude that capital flows are difficult to model empirically in general, especially using only push variables. ${ }^{3}$

\section{Factor Models and VARs}

The second strand is more recent and limited; it is exemplified by Rey (2013). In her Jackson Hole paper, Rey first documents the (negative) correlations between (various types of) capital flows and the VIX, both globally and for various sub-regions, varying between -.06 and .28. Conditional on other push factors (world short term real interest rate and growth), correlations rise slightly, peaking at -.36 for debt flows to Central and Eastern Europe, and -.34 for equity flows to East Asia. She then documents, using principal components analysis, the presence of a large single common factor among various asset prices from many countries (some 850), where the first common factor in turn shows a relatively high, negative correlation (about .25) with the VIX. Building on her earlier work with Miranda Agrippino (2015), she then shows, using a VAR (and a BVAR), dynamic relations running from monetary policy in the United States to the VIX, and then on to bank leverage, capital flows and credit, with final effects on US GDP and deflator (which are last in the ordering in the VAR). In the VAR, she explains $4-17 \%$ of the variation in VIX by shocks to the Federal Funds rate, and in the BVAR, about $14 \%$ of the variation in capital flows to banks and $6 \%$ of debt flows to non-banks by US monetary policy.

A paper along the same lines is Bruno and Shin (2015a). The paper uses a small scale VAR to study the impact of US monetary policy on leverage and the VIX, and consequently on capital flows over the period 1995Q4-2007Q4. Their ordering of variables in the VAR is similar to that used by Miranda Agrippino and Rey (2015): 1) Federal Funds rate; 2) broker dealer leverage; 3) BIS banking flows; 4) VIX; and 5) US dollar REER. They then show that US monetary

\footnotetext{
${ }^{3}$ As also noted by Koepke (2015): "A historical perspective suggests that the recent literature may have overemphasized the importance of cyclical factors at the expense of longer-term structural trends." See also the April 2016 IMF World Economic Outlook.
} 
policy eventually leaves its mark on the US dollar exchange rate and capital flows funded by the US dollar. The quantitative importance of the global (and other) factors is, however, not noted. ${ }^{4}$

Variations, by Type of Flow, Country, Source and Over Time

Both strands, especially the first one, recognize that sensitivities to global factors can vary between inflows and outflows, between gross and net flows, and by flow type. While the typical focus is on inflows, outflows can also be sensitive to global factors. Not surprisingly, outflows tend to increase when global interest rates rise. At the same time, increases in global risk reduce the probability of outflow-driven stops - maybe signaling capital repatriation by domestic investors in such circumstances (Calderón and Kubota, 2013). Even when gross inflows and outflows are volatile, net flows will be less volatile if the two offset each other. ${ }^{5}$ Since this offset is more common for advanced countries than for emerging markets, in part as the private sector in advanced countries typically has larger gross foreign asset positions, global factors are typically more important for the latter (see further IMF (2013) and Forbes and Warnock (2012); Broner et al. (2013) provides a comprehensive study).

The impact of global factors may also vary across flow type, i.e., bank (credit) flows, equity and bond portfolio flows, foreign direct investment, vs. other flows (the latter includes a broad residual array of transactions and holdings between residents and non-residents). A common finding is that portfolio flows and credit react more to global factors than FDI flows do. ${ }^{6}$ Related, sensitivities can vary by maturity (short vs. long) and currency (US dollar vs. others; foreign vs. local currency). All this argues against sweeping generalizations, in the spirit of Claessens et al. (1995) and others. And given these differences, as the composition of capital flows changes, the aggregate exposures to global factors will likely vary both over time and across countries. ${ }^{7}$

\footnotetext{
${ }^{4}$ When not considering the effects on capital flows in a smaller, four variables VAR, they conduct a variance decomposition. It shows that US monetary policy shocks account for almost $30 \%$ of the variance of VIX index and between $10 \%$ and $20 \%$ of the variance of leverage of US broker dealers at horizons longer than 10 quarters. In contrast, monetary policy shocks are less important drivers of the variance of the US dollar REER. Their variance decomposition reveals a considerable degree of interactions between the variables in their model, and points to the importance of the leverage cycle of the global banks as a key determinant of the transmission of monetary policy shocks.

${ }^{5}$ Terminology is important here. In balance-of-payments terminology, inflows and outflows are net items themselves, and can be positive and negative, since they involve both buying and selling transactions by foreigners (non-residents) in case of inflows and domestic agents (residents) in case of outflows, respectively. Net capital flows can be defined as the net of the two gross flows - that is gross inflows minus gross outflows, and then satisfy the identity that the current account deficit equals the sum of net flows and changes in official reserves. For more on the resident vs. non-resident and in- vs. outflows distinctions and a four-way based classification of gross capital flows, see Forbes and Warnock (2012).

${ }^{6}$ Koepke (2015). Also see Contessi et al. (2013), which comprehensively studies the second moments and cyclical properties of disaggregated gross flows.

${ }^{7}$ Milesi-Ferretti and Tille (2011) and Lane and Milesi-Ferretti (2017) document the large shifts and cross-country heterogeneity in flows post-GFC. Notably, flows intermediated through banks have been arguably replaced by
} 
Research has tried to assess whether shifts come along with variations in the importance of specific drivers. Avdjiev et al. (2017a) find that the impact of global risk has increased post-GFC for international bonds flows and declined for cross-border loan flows. They also report greater sensitivities to US monetary policy, driven mainly by behavioral shifts, with better-capitalized banking systems experiencing smaller rises in sensitivities and larger increases in international lending shares. McCauley et al. (2015), focusing on credit denominated in US dollars, find that unconventional monetary policy helped the partial shift from borrowing away from global banks and towards bonds. Cerutti et al. (2017) show that changes in banking system conditions since the GFC have affected the importance of US and European drivers of bank flows.

Variations in countries' general exposure to global factors have been studied in both strands of the literature mentioned. Unsurprisingly, more open countries (in both real and financial terms) experience greater effects. Bruno and Shin (2015b) find that global factors have a larger impact than local factors in more financially open countries with bigger banking flows. They report, when using a model with global and local variables, that for countries subject to large bank inflows, the $\mathrm{R}^{2}$ (of 0.21 ) is 3.6 times higher than for a model with just local variables (still, in countries with lower banking inflows, global factors explain somewhat more than local factors). They find differences, in how much global factors explain, to be small between developing and developed countries, but larger between countries with high and low measures of law and order. Calderón and Kubota (2013) document, however, only small differences in how capital flows to emerging markets and advanced countries vary in their sensitivity to global factors.

There is less research on how recipient type and source characteristics affect the sensitivities of flows to global factors, and related domestic responses. Using gross capital inflows during 1996-2014 for 85 countries at a quarterly frequency, Avdjiev et al. (2017b) show that capital flows into banks and corporations decline both in advanced economies and emerging markets when the VIX rises, as do flows to emerging markets' sovereigns, but not to advanced economies' sovereigns. Baskayay et al. (2017) show for one country that, through fluctuations in capital flows, local banks are especially affected by global factors, with a lower VIX leading to lower local borrowing rates and greater credit supply, explaining up to $40 \%$ of cyclical credit growth. ${ }^{8}$ Some papers study the role of global factors given the source of

corporate bond financing (Shin 2013). The post-GFC substitution of bank lending for debt securities, however, seems to have been at the aggregate level more a phenomenon among advanced economies' borrowers rather than among emerging countries' borrowers, as the latter increased their borrowing in both bank loans and debt securities (Cerutti and Hong 2017).

${ }^{8}$ Igan and Tan (2015) investigate the associations between capital inflows and credit growth, breaking down flows by type and destination (household or corporate). They find non-FDI inflows to boost credit growth and increase the likelihood of credit booms in both household and corporate sectors, with the composition of inflows to matter more than recipient country's financial system characteristics for household credit growth, while for corporate credit growth, both the composition and the financial system's characteristics matter. Lane and McQuade (2013) perform a similar study and find that domestic credit growth in European countries is strongly related to net debt inflows but not to net equity inflows. Neither paper, however, studies the role of push and pull factors. Blanchard 
financing. Raddatz and Schmukler (2012) and Puy (2016) document that fund flows - in particular to and from emerging markets - are pro-cyclical with financial conditions at home, often independent of borrowing countries' variables. Jotikasthira et al. (2012) find that funding shocks in funds' domiciles - typically advanced countries - can translate into fire sales (and purchases) for countries included in global mutual funds' portfolios - in particular, emerging markets. Cerutti et al. (2015) show capital flows to emerging markets that rely more on mutual funds or international banks to be more sensitive - at least in the short-term - to global factors.

Lastly, a number of papers have investigated cross-country differences in the independence of domestic monetary policy, the "dilemma vs. trilemma" issue first raised by Rey (2013), typically focusing on the determinants of interest rates. While Han and Wei (2016) find that a flexible exchange rate by itself does not confer monetary policy autonomy, Klein and Shambaugh (2015) find that a moderately flexible exchange rate does confer monetary policy autonomy, though partial capital controls do not. And Obstfeld et al. (2017) highlight that the transmission of global financial shocks is magnified under fixed exchange rates relative to more flexible regimes. Aizenman et al. (2016) also find that economies that pursue greater exchange rate stability and financial openness face stronger links with center economies' monetary policies. Han and Wei (2016) find that a flexible exchange rate regime confers monetary policy autonomy when the center country raises its interest rate, but not when it lowers its rate (in their words, "fear of floating" mostly takes the form of "fear of appreciation"); capital controls provide insulation to countries even when the center lowers its rate. Ghosh et al. (2014) find that while global factors act as "gatekeepers" in determining the timing of capital flow surges, local macroeconomic variables determine the magnitudes. More case-based analyses also find that capital flows can vary across countries during periods of global financial stress, but it has proven harder to explain such differences. ${ }^{9}$

Overall, the properties of different types of flows remain an area of ongoing research and debate, as are the relationships between global factors to domestic financial and economic developments and cross-country differences in the sensitivities of capital flows and domestic developments to various global factors. Few of the papers in either strand, however, have analyzed the relative importance of global factors, the main objective of this paper.

et al. (2015), studying the effects of flows on macroeconomic variables in a model where domestic bond and other assets (e.g., stocks and bank deposits) are imperfect substitutes, find exogenous bond flows to have small negative effects on output, and non-bond flows to have positive effects.

\footnotetext{
${ }^{9}$ Sahay et al. (2014) and Ahmed et al. (2014) show that while most emerging markets experienced outflows during the 2013 "taper tantrum," some were less affected. Prachi et al. (2014) and Ahmed et al. (2014) find that countries with better macroeconomic fundamentals suffered less deterioration in exchange rates, equity prices and bond yields during the period. In contrast, Aizenman et al. (2014) find a sharper deterioration of financial conditions in robust emerging markets compared with fragile ones, at least over the following 24 hours. Similarly, Eichengreen and Gupta (2014) do not find better fundamentals to provide insulation. Rather, larger and more liquid financial markets experienced more pressures, possibly as investors could better rebalance portfolios there.
} 


\section{Identifying the GFCy: Data, Methodology and a First Look}

The chief objective of this paper is to quantify the importance of the GFCy for capital flows; we seek to understand what proportion of the variation in capital flows is explained by the GFCy. To do this, we must be able to measure the GFCy. In this section, we explain the strategy we employ and explore the data we use.

\section{Strategy}

Our goal is to identify the GFCy, an intrinsically unobservable variable. We are guided by the idea that if the GFCy is consequential for capital flows, it should drive a high proportion of the fluctuations in most types of capital flows, in many places, much of the time. ${ }^{10}$ For the purposes of this paper, we define the GFCy as (high) commonality in financial conditions, manifest in capital flows, driven by observable global determinants. Accordingly, and in the spirit of finding robust evidence, we proceed in two ways, investigating both measurable variables from center countries and commonality.

First, we examine the role of directly observable "fundamental" GFCy drivers, centercountry macroeconomic and financial determinants of capital flows. But which variables, and for which center-countries? Our reading of the literature delivers a relatively strong consensus; the VIX is widely considered the favorite direct measure, most closely related to the GFCy. Still, in an effort to be conservative, we cast a wide net, since we are keenly aware that choosing the wrong measures or center-countries could lead us to under-estimate the importance of the GFCy. Accordingly, we also include other measures used as drivers in the literature, both for the United States and other potential center economies.

We proceed conservatively by also taking an indirect approach; we examine observable manifestations of the GFCy via the commonality of capital flows. There is a host of reasons why capital flows could behave similarly across countries at a point in time, and the GFCy is certainly one of them. ${ }^{11}$ If we ascribe all common movements in capital flows to the GFCy, we thereby develop an upper bound for the importance of the GFCy on capital flows. Accordingly, we use factor analytic methods to extract common factors in capital flows and use those as manifestations of the GFCy. Finally, in an effort to be extra conservative, we combine both

\footnotetext{
${ }^{10}$ Consistent with this, Passari and Rey $(2015, \mathrm{p}$ 679) write "Stylized Fact 1 : There is a clear pattern of comovement of gross capital flows, of leverage of the banking sector, of credit creation and of risky asset prices (stocks, corporate bonds) across countries. This is the global financial cycle. Rey (2013) shows that gross inflows across geographical areas and across asset classes (credit, portfolio debt and equity, FDI) are overwhelmingly positively correlated."

11 Other candidate explanations include demand determinants as well as other common factors unrelated to center economies. The latter could include oil and other commodity prices, provided they move exogenously and in some way affect capital flows across many countries. More generally, besides investor sentiment ("irrational exuberance or pessimism"), sunspots or contagion could drive capital flows. All these possibilities are captured in our second approach.
} 
methods.

\section{Data: Center Country Variables}

The most discussed and plausible center country is the United States, and whenever we include variables, we include US measures. ${ }^{12}$ However, the European Economic and Monetary Union (EMU) is also a potential generator of fluctuations in the GFCy; the same is also true (perhaps less plausibly) of the UK. ${ }^{13}$ Accordingly, as a robustness check, in some of our analysis we include variables from both Europe and the UK, as well as the US. This is limiting, since EMU only began in 1999Q1, necessarily reducing the span of study for certain variables (such as Eurozone interest rates).

We start with the consensus GFCy measure, the VIX (ticker symbol for the Chicago Board Options Exchange (CBOE) volatility index). It measures the implied near-term volatility of S\&P 500 index options, calculated and published by the CBOE. We use the last VIX reading of each quarter, downloaded from Bloomberg. ${ }^{14}$ The VIX is extensively used as a measure of the GFCy. For instance, it is explicitly identified by Passari and Rey $(2015$, p683) as "our proxy for the global financial cycle". ${ }^{15}$ However, we do not restrict ourselves to purely US volatility measures; we also use a German analogue, the VDAX which began trading in 1992 (now replaced by the VDAX-NEW), and check that our results are robust to using the VSTOXX, which began in 1999 with EMU; and the British analogue (IVI, which measures volatility of the underlying FTSE 100 index) after 2000. ${ }^{16}$ These VIX-analogues are also end-of-quarter measures

\footnotetext{
12 This is consistent with the literature. For instance, Miranda Agrippino and Rey (2015) write "... monetary conditions are partly dictated by the monetary policy of the center country (the US) even for countries operating within a flexible exchange rate regime ..." US variables are used as global/center-country proxies by many, among others: Avdjiev et al. (2016): Bruno and Shin (2015a, b); Cerutti et al. (2017); Forbes and Warnock (2012); Ghosh et al. (2014); Passari and Rey (2015); and Rey (2013, 2015).

${ }^{13}$ A point made by Cerutti et al. (2017).

${ }^{14}$ More details are available at http://www.cboe.com/products/vix-index-volatility/vix-options-and-futures/vixindex, including the VIX's relationship with the VXO (which preceded the VIX until 2003).

${ }^{15}$ Passari and Rey (2015, p 685, emphasis added) add "... we investigate whether cross sectionally, the sensitivities of the local stock market and of credit growth to the global financial cycle (proxied by the VIX) are affected by the exchange rate regime ..." and later (p693, emphasis added): "Large gross cross-border flows are moving in tandem across countries regardless of the exchange rate regime, they tend to rise in periods of low volatility and risk aversion and decrease in periods of high volatility and risk aversion, as measured by the VIX..." Also, the abstract of Rey (2013, emphasis added) includes: "There is a global financial cycle in capital flows, asset process, and in credit growth. This cycle co-moves with the VIX, a measure of uncertainty and risk aversion of the markets." Koepke (2015, pp 19-27) states "...mature economy interest rates and global risk aversion are unambiguously external in nature and have significant explanatory power for capital flows movements ... There is very robust evidence that both types of portfolio flows are strongly affected by global risk aversion ... There is robust evidence that banking flows respond negatively to an increase in global risk aversion ..." The VIX is used extensively, including by Avdjiev et al. (2016); Bruno and Shin (2015a, b); Cerutti et al. (2017); Fratzscher (2012); and IMF (2014). Forbes and Warnock (2012) use a closely correlated predecessor, the VXO.
}

${ }^{16}$ The (time-series) correlation between the VDAX and the VSTOXX is .9. 
obtained from Bloomberg.

As with the choice of center country, we try to be conservative by considering other observable center-country "fundamentals" above and beyond measures of stock market volatility. We use seven other standard variables: a) the nominal policy interest rate (the Federal Funds rate for the United States; the UK Base rate, and the Euro Area deposit facility rate, all end of period and obtained from Haver); b) the ex post real policy interest rate, measured as the nominal rate minus the ex post year over year realized CPI inflation rate (inflation is obtained from IFSTSUB and GDS); $c$ ) the TED spread (measured as the end of period three month LIBOR minus the government rate; for the latter, we use the Treasury bill rate for the United States, the Gilt rate for the UK and the Government AAA bill rate for EMU); d) the yield curve slope (measured as the end of period ten-year minus the three-month government rates); e) GDP growth (obtained from IMF WEO); f) the growth in the real effective exchange rate (REER, measured as the quarter over quarter percentage change in the IMF's CPI-based real effective exchange rate); and g) M2 growth (measured as year over year growth in local currency, obtained from Haver). ${ }^{17}$

\section{Data: Capital Flows}

For capital flow data, we rely on conventional series from the balance of payments on four types of dis-aggregated capital flows: Foreign Direct Investment ("FDI"), Portfolio Equity Investment ("Equity"), Portfolio Debt Investments ("Debt"), and Bank Credit ("Credit"; occasionally we sum portfolio equity and portfolio debt flows for an overall measure of portfolio flows). ${ }^{18}$ All these series come from the IMF BOP Statistics. We have data on both inflows and outflows, and all are expressed as percentages of GDP. Our panel data set is unbalanced, and runs from 1990Q1 through 2015Q4 (since we are interested in quantifying the GFCy over recent history, and as data are of lower quality in earlier periods). We have data on 85 countries; they are listed in appendix Table A1. ${ }^{19}$ In much of what follows, we focus on a set

\footnotetext{
${ }^{17}$ Our variables cover those widely used in the literature, e.g., as surveyed by Koepke (2015). Still, a number of other fundamentals has also been suggested to us, and we have added all without altering the conclusions that follow. For instance, at the urging of Johan Sulaeman, we included Shiller's cyclically-adjusted price/earnings ratio, without substantive success. Maury Obstfeld and Robin Koepke encouraged us to include the US corporate Baa bond yield relative to the 10-year T-bond yield; this addition also has little substantive effect. Finally, we included credit growth for each of the three large economies (US, UK, and EMU), again without changing our conclusions. Summary results for these are available at Rose's website.

${ }^{18}$ Bank credit is a subset of other investment liabilities, more specifically "other investment liabilities, of which borrowers are banks." It is not part of portfolio investment flows, and it captures loans, currency and deposits, trade credits, and other liabilities from non-residents against resident banks (defined as deposit-taking institutions).

${ }^{19}$ We began to winnow down our sample from approximately 140 countries for which we have data since the 1990s. We chose to retain only countries that reported in 2015 data by type of capital flow, and had series for at least a decade on a quarterly basis. In an effort to ensure precision, two versions of the data set have been
} 
of 63 "small" countries by excluding other plausible center-countries (USA, UK, actual/future members of EMU, and Japan). ${ }^{20}$ We have checked and corrected the data set using standard techniques.

Figure 1 provides a quick informal peek at the relationships between the standard GFCy proxy (the VIX) and capital flows. It shows scatters of capital flows (on the y-axis, measured as a percentage of GDP) against the VIX; eight plots are provided for the two directions (in- and outflows) and four types of capital flows. Each scatter includes observations for the five dozens of countries and hundred time-periods, without conditioning for any influences at all, so the plots should be interpreted cautiously. Still, there is no indication of strong relationships between capital flows and the VIX for any type/direction of flow. While Figure 1 has some nontrivial outliers, the same non-result characterizes the data when constrained to smaller values (Figure A1 in the appendix, an analogue for capital flows of less than five percent of GDP, delivers a similar message). Of course, both figures implicitly gloss over many other sources of variation that can be controlled for, so we do not take the negative message from the raw data too seriously. ${ }^{21}$

\section{Factors}

Our indirect method of measuring the GFCy is through common movements in capital flows, for which we use factor analysis. Since there is no obvious way to estimate commonality, we estimate common factors in a large number of ways -180 , to be precise - to check that our results are not sensitive to minor perturbations in the methodology or sample.

We begin our analysis using 1990Q1-2015Q4 to provide a reasonable span of recent data. However, we also generate our factors using 1996Q1-2015Q4 since that increases the fraction of countries with complete series and restricts the GFCy impact to be estimated over a period of time when arguably financial globalization had its most influence. Similarly, we also generate our factors using data from different groups of countries, to allow for the possibility that phenomena common to advanced economies may not be the same as those relevant for emerging markets. We therefore use three sets of countries: advanced economies; emerging markets; and a mix of advanced and emerging economies, all listed in an appendix Table A1. ${ }^{22}$

\footnotetext{
generated separately and matched; the data have also been checked for errors using standard techniques, and a number of outliers have been checked by hand.

${ }^{20}$ We refer to these as "countries" for convenience, recognizing that some are not, e.g., Hong Kong switched from being a British dependency to a special administrative region.

${ }^{21}$ The second stylized fact of Passari and Rey $(2015, \mathrm{p} 680)$ is that "Indices of market fear (such as the VIX, the VSTOXX, the VFTSE or the VNKY) tend to co-move negatively with gross cross-border flows ..."

${ }^{22}$ Our set of (6) advanced economies excludes large and safe-haven economies (EMU, Japan, Switzerland, UK, and US) so as to focus attention on economies unlikely to be the source of the GFCy; our set of (15) emerging markets are the $\mathrm{MSCl}$ members with weights greater than 1\%; and our set of advanced/emerging economies are those (10)
} 
Given specific samples of time and countries, we then construct factors for each direction (capital flows either into or out of a country) and type of capital flow. We use five types of capital flows (FDI, debt, equity, credit, and portfolio debt+equity) flows. For each set of data, we then estimate common factors in three ways. First, we estimate a dynamic factor model with a single lag and extract an unobserved factor from the largest eigenvalue, following, e.g., Miranda Agrippino and Rey (2015). ${ }^{23}$ Second, we estimate a dynamic factor model with two lags, and again extract a single factor from the largest eigenvalue; we do this to check sensitivity to the exact lag length. Third, and again for comparison, we estimate a traditional static factor model and again extract a single factor from the largest eigenvalue. We thus obtain 180 factors, one for each of the (two) samples of time, (three) sets of countries, (two) directions and (five) types of capital flows, and (three) estimation methods. To check that the results are insensitive to our forms of factor analysis, we also use the global factors provided by Miranda Agrippino and Rey (2015).

\section{A First Look at the Factors}

A ubiquitous GFCy should drive fluctuations in most capital flows for most countries to a significant degree. This should be manifest in our dynamic factors, which should display much commonality. Accordingly, it is useful to look at the factors extracted from capital flows. ${ }^{24}$ Figure 2 displays a matrix of scatterplots which graph factors against each other. Eight factors are portrayed; one for each of the two capital flow directions (in/outflows) and each of the four main types (FDI/debt/equity/credit); all the factors were estimated using a dynamic factor model for advanced economies between 1990Q1 and 2015Q4 using a single lag. The horizontal axis at the extreme left is the date, so that the column on the extreme left contains simple time-series plots. The column next to the date contains the VIX, the standard direct measure of the GFCy. Each of the scatterplots contains over one hundred points, one for each quarterly observation for our 26-year span.

If the GFCy drives most of the variation in most types and directions of capital flows, then one would expect the eight factors (which measure cross-country commonality in capital flows, and thus include variation due to the GFCy) to be reasonably positively correlated with each other in the scatterplots of Figure 2. If the VIX is highly correlated with the GFCy, it should also be highly correlated with the factors. While some of the scatterplots display positively

\footnotetext{
largest economies that are unlikely to be the source of the GFCy (and so exclude China/EMU/Japan/UK/US). Members of each group are listed in Table A1.

${ }^{23}$ In using a single lag as our default, we follow Miranda Agrippino and Rey (2015). We estimate our (non-linear) dynamic factor models with the Berndt-Hall-Hall-Hausman (BHHH) technique for a maximum of 20 iterations (allowing for more iterations has essentially no effect on the resulting factors).

${ }^{24}$ Figure A2 provides a matrix of scatterplots which directly compares FDI inflows for six small advanced economies and the dynamic factor extracted from the same countries (using a single lag); Figure A3 is the analogue for a dozen emerging markets. Both figures indicate limited commonality in capital flows across countries, an issue for the GFCy.
} 
correlated data (particularly among the outflow factors), most of the scatter plots are clouds without any clear shape. Another striking feature of Figure 2 is that the VIX is not particularly strongly related to any of the factors extracted from capital flows. Of the eight scatters between the VIX and capital flow factors, all have correlations smaller than .5, and three are negatively correlated. Only three of the eight correlation coefficients are significantly different from zero; two of these are actually positive (FDI inflows, .41, and FDI outflows, .34), while one is negative (Debt inflows, -.29 ). ${ }^{25}$

Figure 2 portrays factors extracted from advanced economies, though much of the interest in the literature lies in the drivers of capital flows to emerging markets. Accordingly, Figure 3 portrays factors extracted from (four types of) capital inflows, and implicitly compares factors derived from capital flows to advanced economies and from flows to emerging economies. If capital flows into advanced and emerging economies are driven by similar phenomena - such as the GFCy - this would be manifest in positively correlated scatterplots, particularly those that compare factors derived from advanced and emerging economies for the same type of capital inflow. While this characterizes the FDI common factors (the correlation coefficient is .66), the three other factors are only modestly correlated (the coefficients are $.01, .18$, and -.01 for Debt/Equity/Credit respectively).

Figures 2 and 3 compare factors extracted from capital flows. However, the literature makes it clear that the GFCy should manifest itself in other phenomena as well, including asset and commodity prices. It is also worth investigating the analogues to the VIX in other potential center countries. All this is pursued in Figure 4, which includes four factors extracted from stock returns and another from commodity prices as well as the VIX and its counterparts for the UK (IVI) and Germany (VDAX). We display both the long-sample and short-sample stock market factors provided by Miranda Agrippino and Rey (MAR). ${ }^{26}$ We also include factors extracted from the (national) $\mathrm{MSCl}$ stock returns of the advanced and emerging market economies, and another extracted from the levels of commodity prices. ${ }^{27}$ While the two factors extracted by MAR are, not surprisingly, strongly correlated to each other (.78), there are few strong positive correlations with other price factors.

Appendix Figure A4 examines the effects of different modeling assumptions for the

\footnotetext{
${ }^{25}$ Recently, the relationship between the VIX and the GFCy has been questioned (Shin 2016 and Cerutti et al. 2017).

${ }^{26}$ Miranda Agrippino and Rey use monthly data in a dynamic factor model for over 800 risky assets between 1990 and 2012; we simply average their monthly factors to derive quarterly factors. They also use a smaller number of risky assets (still in excess of 300) to estimate a comparable factor model on a longer sample between 1975 and 2010. We use both the short- and long-sample factors from Miranda Agrippino and Rey provided at the former's website. We note that the role of globalization in affecting the degree of commonality in asset prices has often been assessed in the context of testing formal asset price models (see Bekaert et al. 2017 for a review).

${ }^{27}$ For the latter, a dynamic factor model is estimated from World Bank GEM data from the energy, fats and oils, grains, and metals and minerals indices.
} 
factor models. It shows scatters for capital inflow factors for advanced economies derived from three statistical models: dynamic factor models with both one and two lags, and static factor models. The exact lag length used in a dynamic factor model does not seem to make a large impact on the results, but using a static factor model delivers factors only loosely correlated with those of dynamic factor models. It seems reasonable to set the one-lag dynamic factor as our default. ${ }^{28}$

The evidence from Figures 2-4 suggests that the factors extracted from different types and directions of capital flows are not strongly related with the VIX or with each other. One would imagine that a substantive GFCy should result in capital flows that are correlated with the VIX, the standard proxy used in the literature for the GFCy; and that capital flows to various countries should be related to each other. ${ }^{29}$ The more important the GFCy is, the tighter these relationships should be. So the limited relationships between factors extracted from capital flows and the VIX as well as the limited relationships among capital flows revealed in our admittedly quick examination of the data are not easy to reconcile with an important GFCy for capital flows. Since our analysis to this point has been informal - scatter-plots and correlations - we now turn to a more formal statistical examination.

\section{Empirical Results}

\section{$\underline{\text { Panel Regressions }}$}

We begin our analysis by estimating regressions where capital flows are pooled across countries but disaggregated by direction and type. As a first exercise, we begin without any country-specific time-varying regressors at all. Instead, we project capital flows on a comprehensive set of time fixed effects, common across countries. We do this to assess the quantitative importance of all possible global phenomena (such as the GFCy), thus working (temporarily) under the assumption that these shocks have an equal impact on all countries. In particular, for a particular direction and type of capital flow, we start with estimating a panel regression with least squares:

$$
\text { CAPFLOW }_{\mathrm{d}, \mathrm{e}, \mathrm{i}, \mathrm{t}}=\left\{\phi_{\mathrm{i}}\right\}+\left\{\theta_{\mathrm{t}}\right\}+\varepsilon_{\mathrm{d}, \mathrm{e}, \mathrm{i}, \mathrm{t}} \quad \text { across } i, t
$$

\footnotetext{
${ }^{28}$ Figures 2 and 3 present factors extracted from capital flow quantities while Figure 4 presents factors extracted from risky asset prices. Do the $P$ and $Q$ factors line up? This is explored in Figure A5, which presents four capital inflow factors taken from Figure 2 along with four price factors taken from Figure 4, all for advanced economies. There are no tight relationships between the factors extracted from prices and quantities.

${ }^{29}$ For instance, Passari and Rey $(2015, \mathrm{p}$ 682) write "There are striking commonalities in movements in credit, leverage, gross flows, risky asset prices across countries. All these variables are found to co-move negatively with the VIX and other indices of market volatility and risk aversion." While Rey (2013, pp 1-2) writes "... the characteristics of capital flows (gross and net), show impressive co-movement in gross flows and ... relate to global factors, as proxied in particular by the VIX ..."
} 
where:

- CAPFLOW ${ }_{d, e, i, t}$ represents a capital flow of direction $d$, type $e$ vis-a-vis country $i$ in quarter $t$, as a percentage of GDP of country $i$.

- $\left\{\phi_{\mathrm{i}}\right\}$ and $\left\{\theta_{\mathrm{t}}\right\}$ are comprehensive sets of country- and time-specific fixed effects, and

- $\varepsilon$ represents all other determinants of capital flows.

We estimate (1) pooling data across all the countries for which the regressand is available for the entire period of time, 1990Q1-2015Q4. Our results are presented in Table 1, which has eight rows corresponding to the two directions $(d)$ and four types $(e)$ of capital flows. The two left-hand columns of Table 1 presents two familiar measures of goodness of fit when equation (1) is estimated over the entire sample, the within and overall $R^{2}$ measures. ${ }^{30}$ All sixteen of these goodness of fit measures are low. The same is true if the data set is extended to the countries which have complete series available only back through 1996Q1; the results are tabulated in the middle two columns of Table 1 . The result is also similar when the estimation is restricted to small economies, as shown by the two columns at the extreme right of Table 1. Succinctly, global phenomena specific to a period of time - such as the GFCy - do not seem to have an important effect on capital flows, even if not modeled explicitly, so long as their impact is restricted to have the same effect on all countries.

Table 1 is not particularly revealing, however, for at least two reasons. First, there is no explicit modelling of economic shocks such as the GFCy; instead, the effects of all common phenomena, including the GFCy, are absorbed by the time fixed effects. Second, the response of one particular country's capital flows to a common shock is assumed to be the same as the response of all other countries. We unpack these assumptions in two steps: first, we remove the time effects from (1) and substitute time-varying common phenomena; and next, we allow responses to the latter to vary by country.

We begin by removing the time fixed effects from (1) and replacing them with a standard set of "push" regressors used to model capital flows. ${ }^{31}$ In particular, we use contemporary US values of eight key variables: a) VIX; b) real GDP growth rate; c) nominal policy rate; d) real policy rate; e) TED spread; f) yield curve slope; g) REER change; and h) M2 growth. Above and beyond the eight variables and using country fixed-effects, we include two dynamic factors extracted from capital flows, each matching the direction and type of capital flow of the regressand; one is extracted from capital flows to/from advanced economies, the other from capital flows to/from emerging economies. ${ }^{32}$ We note that the factors include all sources of commonality in capital flows, whether driven by the GFCy or not. As with equation

\footnotetext{
${ }^{30}$ The within $R^{2}$ corresponds to deviations from estimated country-specific averages, while the overall $R^{2}$ is derived from the model fitted to both country- and time-fixed effects.

${ }^{31}$ Omitting "pull" factors and regressand dynamics allows us to establish the maximal impact of the GFCy.

32 Thus, the FDI inflow dynamic factors are used as regressors when the regressand is the country-specific FDI inflows, etc.
} 
(1), we estimate our regressions with least squares, pooling across countries with data available over the entire timespan, and again dis-aggregated by direction and type of capital flow:

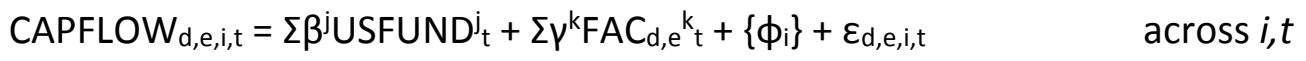

where:

- $\quad$ USFUND ${ }_{t}$ is the value of one of the eight US variables indexed by $j$, and

- $F A C_{d, e}{ }^{k}$ is the value of one of the two dynamic capital flow factors (one for advanced economies, one for emerging markets, both estimated with one lag) indexed by $k$.

Results are tabulated in Table 2. Again, there are eight rows of results, one for each direction and type of capital flow. Both within and overall $R^{2}$ measure of goodness of fit are presented, though they are (as in Table 1 ) typically close. The results at the extreme left-hand side show the results when equation (2) is estimated for small countries. The results are necessarily worse than those of Table 1 (since time effects are more flexible than any set of common time-varying regressors), and show that the standard push factors account for only a small fraction of the variation in capital flows. These results are essentially unchanged when the Miranda Agrippino-Rey factors are substituted for our default factors. ${ }^{33}$ In the second column from the right, we add a single quarterly lag of each of the US factors; this improves the goodness of fit, but only marginally. At the extreme right, we add four lags of the US variables; again, this makes only a small difference to the goodness of fit.

We conclude that standard center-country variables do not seem to explain much of the variation in capital flows, so long as the responsiveness to these phenomena is constrained to be identical across countries. Accordingly, we next allow the effects of center-country variables on capital flows to vary by country. We retain both dynamic capital flow factors (as always, matching direction/type of capital flow) and country-specific fixed effects. But now we allow for the possibility of country-specific effects of US variables (both contemporary and lagged) on capital flows. ${ }^{34}$ As with equations (1)-(2), we estimate our regressions with least squares, disaggregated by direction and type of capital flow:

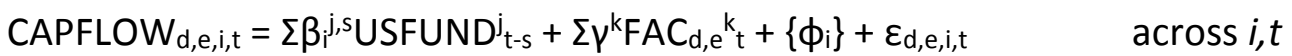

where:

- USFUND' $\mathrm{j}_{\mathrm{t}-\mathrm{s}}$ is the $\mathrm{s}^{\text {th }}$ lag of US variable $j$.

Results are estimated with least squares for small countries and are tabulated in Table 3.

The left-hand column of Table 3 contains results when (3) is estimated with a single US

\footnotetext{
33 The factors of Miranda Agrippino and Rey are not available for the entire sample period, so the two left-hand columns of Table 2 are estimated on slightly different samples of time.

${ }^{34}$ Including the time-effects allows us to drop capital flow and asset price factors from the right-hand side, since any common effects of these would be absorbed by the time-effects.
} 
variable, namely contemporaneous values of the VIX (along with common capital-flow factors and country-specific fixed effects). The results are similar to those of Table 1; capital flows are not much determined by center-country phenomena, even when allowing each country to respond differently to the VIX. To test for delayed responsiveness of capital flows to the VIX, we successively add one and then four lags of the VIX (all with country-specific coefficients) in the middle columns of Table 3; this does not change the fit of the panel equations very much, and the maximum $\mathrm{R}^{2}$ remains less than .15 .

To check whether the poor fit of the equations in the left-center of Table 3 is due to our focus on the VIX, on the right side of Table 3, we allow for country-specific slopes for all eight US variables, not simply for the VIX only. That is, we let each country respond differently to the a) nominal, and b) real policy interest rates, c) TED spread, d) yield curve slope, e) output growth, f) growth of broad money, g) REER change, and h) VIX. In the column second from the right, we allow all these eight US variables to have country-specific slopes; in the extreme right column, we allow both the contemporary and a single lag of all eight US variables to have country-specific slopes. At this point, the equations obviously start to fit better, though in no case does the $\mathrm{R}^{2}$ approach .5. Further, this improvement comes with a profligate parameterization. The best fitting equation in Table 3 is that for FDI inflows, which has a within $R^{2}$ of .42 but over 300 regressors! This equation is estimated with only $5.8(\approx 2016 / 349)$ observations per coefficient, and has an overall $R^{2}$ of just $.08 .^{35}$ We return to the issue of free parameters below.

Histograms of $\overline{\mathrm{R}}^{2}$ Measures from National Capital Flow Equations

It seems that panel regressions do not offer a particularly good fit in the sense of explaining much of the variation in capital flows across countries and time, even allowing for either common or idiosyncratic national responses to a variety of contemporary and lagged center-country variables and factors. That said, the goodness of fit measures tabulated in Tables 1-3 are overall summary statistics that could potentially mask considerable variation across countries. Some of the literature reviewed indeed suggests that the importance of the GFCy varies by country (e.g. because of different exchange rate regimes). It is conceivable that center country variables explain much of the variation for a number of countries' capital flows, but little variation for others. We now investigate that possibility by running regressions for individual countries. We do this only for small countries as these are most likely most affected by the GFCy. Like equations (1)-(3), our equations are estimated with least squares, disaggregated by direction and type of capital flow. However, unlike equations (1)-(3), we estimate our regressions country by country, instead of pooling across countries:



Thus, for each small country in our sample with capital flow data, we estimate up to ten timeseries capital flow equations (potentially one for each of the two directions and five types of

\footnotetext{
35 The estimates of Table 3 include only observations for small countries; results are similar when all countries are included.
} 
capital flows: FDI/debt/equity/credit/portfolio debt+equity). Our interest is restricted to the goodness of fit of these equations. Since we have dozens of small countries, we simply provide histograms of the $\bar{R}^{2}$ s. We focus on (adjusted) $\bar{R}^{2}$ rather than $R^{2}$ to provide a penalty for overparameterization of the model; since $\mathrm{R}^{2}$ necessarily rises with the addition of regressors, one can always "model" capital flows well (in-sample) with enough regressors. We note that this penalty is small, since $\overline{\mathrm{R}}^{2}$ still rises when a regressor is added with a t-statistic exceeding one in absolute value; we also show that our results are robust to using $\mathrm{R}^{2}$. We note in passing that such measures are the standard used in push-pull regression results (e.g., Bruno and Shin, 2015a; Avdjiev, et al. 2017a).

We begin by estimating (4) with the standard eight US variables (the VIX, nominal and real policy rates, the TED spread, yield curve slope, output growth, REER change, and M2 growth), and two dynamic capital flow factors (advanced and emerging markets, both estimated with a single lag and matched to the direction and type of capital flow). We estimate (4) with these variables and factors using the time-series variation for a particular country/direction/type of capital flow combination provided there is any non-trivial time-series data (it need not be the entire 1990Q1-2015Q4 span), and record the $\overline{\mathrm{R}}^{2}$ for each combination. ${ }^{36}$ We then present the resulting set of $\overline{\mathrm{R}}^{2}$ statistics graphically; our default results are presented in Figure 5.

Figure 5 contains twelve small histograms, each presenting $\overline{\mathrm{R}}^{2}$ statistics for a set of national capital flow equations. The top-left histogram presents all the (598) $\overline{\mathrm{R}}^{2}$ values that we estimate for all combinations of countries, directions and types of capital flows. Clearly most of these time-series regressions fit poorly; the mean $\overline{\mathrm{R}}^{2}$ is only .12, over a quarter of $\overline{\mathrm{R}}^{2} \mathrm{~s}$ are negative, and only a few exceed .5. This pattern is widespread across different subsets. Across the top row of Figure 5 to the right are analogous histograms which cover capital flow regressions for inflow, outflows, and portfolio flows respectively; all three are similar to the top-left histogram. In the two rows below are a set of eight histograms presenting $\overline{\mathrm{R}}^{2} \mathrm{~s}$ for capital flows by direction and type. FDI inflows are the easiest capital flows to model statistically, a pattern we find consistently throughout our research, but even there the mean $\overline{\mathrm{R}}^{2}$ is only $.25 .{ }^{37}$ Thus the evidence from the dozen histograms of Figure 5 indicates that conventional time-series models of capital flows do not fit small countries well, even when incorporating eight center-country variables and two capital flow factors. ${ }^{38}$ Given that the GFCy should be present in both the variables (particularly the VIX) and the capital flow factors, it is hard to reconcile this evidence with a GFCy that explains much variation in capital flows for many countries.

\footnotetext{
${ }^{36}$ We ignore models estimated with less than ten degrees of freedom; there are few of these.

${ }^{37}$ We note in passing the inconsistency between our results on FDI and the typically weaker results in the literature, as surveyed in Koepke (2015).

${ }^{38}$ Comparable results for large economies (other than the United States) look similarly unpromising.
} 
The sensitivity of these results is explored in Figures A6-A15; these are analogues to Figure 5 , but each perturbs an aspect of the methodology. Figure $A 6$ is analogous to Figure 5 but presents conventional measures of $\mathrm{R}^{2}$ without adjusting the statistic for degrees of freedom. The results are similar; the typical goodness of fit is poor, with the mean $\mathrm{R}^{2}$ less than .25. Figure $A 7$ removes the US variables, while retaining the two capital flow factors. Figure $A 8$ restricts the sample to small countries with complete sets of time-series capital flow data, from 1990Q1 through 2015Q4. Figure A9 restricts the sample to the countries with above-median capital mobility, as gauged by the Chinn-Ito index of financial openness. ${ }^{39}$ Figure A10 restricts the sample to countries with per capita annual real GDP of at least $\$ 5,000 .{ }^{40}$ Figure $A 11$ adds four quarterly lags of the VIX to the regressors of (4), while Figure A12 adds a quarterly lag of all eight US variables to the contemporaneous values. Finally, Figure A13 adds contemporaneous values of the eight British and Eurozone variables to the eight US variables, though this restricts the time-series span to 2000Q1-2015Q4. ${ }^{41}$

None of the nine appendix variations on Figure 5 alters our view substantively; as with the straightforward estimates of equation (4), national capital flow equations typically fit the time-series data poorly, even when traditional proxies of the GFCy (like the VIX) are augmented with other center-country variables as well as capital flow factors. It is easy to find exceptions of course, given the large number of countries, directions and types of capital flows, but those are ... exceptions, which do not rise to the level of a systemic presence of a GFCy.

The histograms in Figure 5 persuade us that center-country phenomena and common factors do not explain much of the time-series variation in capital flows, and the evidence of Figures A6-A13 suggest to us that this conclusion is robust. We consider the histograms to be compelling presentations of the fit of our many time-series capital flow regressions. But histograms are also a somewhat inefficient way to convey the many $\overline{\mathrm{R}}^{2}$ statistics; a more concise way is through box plots.

Box Plots of $\overline{\mathrm{R}}^{2}$ Measures

Consider the top-left panel of Figure 6, more particularly its top row. This contains a wealth of information on the goodness of fit when FDI inflows (measured, as always, as a percentage of recipient's GDP) are regressed on an intercept, capital flow factors for both advanced and emerging market economies, and the standard eight contemporary US

\footnotetext{
${ }^{39}$ More details on the Chinn-Ito index are available at http://web.pdx.edu/ ito/Chinn-Ito_website.htm.

40 The GDP per capita series is in constant 2011 international \$ adjusted for PPP deviations, and is taken from the World Bank's World Development Indicators (mnemonic NY.GDP.PCAP.PP.KD).

${ }^{41}$ Appendix Figure A14 substitutes the natural logarithm of the VIX for its level; the results are inconsequentially different from Figure 5, so we stick to the level of the VIX. Appendix Figure A15 is the same as Figure 5 but with a top row of histograms for net capital flows, in the same order as the gross flows below; the absence of novel results for net flows is the reason we stick to gross flows below.
} 
variables. ${ }^{42}$ As in Figure 5, a separate time-series regression is estimated for each of the small economies with a sufficiently long series of data on capital flows (not necessarily for all of 1990Q1-2015Q4). Since there are 63 such countries in our sample, this delivers a distribution of goodness of fit measures. The (horizontal) box plot presents information on the distribution of the adjusted- $R^{2}$ statistics across the country time-series regressions. The box extends from the $25^{\text {th }}$ to $75^{\text {th }}$ percentiles of the $\overline{\mathrm{R}}^{2}$ statistics, with the median marked by a vertical bar. The whiskers extend out to the "adjacent values," defined as the most extreme values within $150 \%$ of the interquartile range of the nearest quartile; outliers are individually marked. Immediately below the box plot for FDI inflows are the analogue box plots for Debt, Equity and Credit inflows; immediately below those are the analogues for capital outflows. For continuity and ease of comparison, a vertical line is marked at . 25 for each set of box plots, a notional benchmark.

What is the message from these box plots? The boxes in the top-left panel of Figure 6 are all located well to the left; seven of the eight interquartile boxes lie below the .25 marker. So while there are the occasional outliers to the right - those clearly marked observations where a particular country has a capital flow that is well modelled by the eleven coefficients in equation (4) - the majority of the equations fit poorly. ${ }^{43}$

Immediately below the box plots in the top-left panel of Figure 6 are box-plots for $\mathrm{R}^{2}$ statistics computed analogously (instead of the $\overline{\mathrm{R}}^{2}$ values in the top-left panel); these show that the exact choice of statistics makes little difference. The two panels in the middle are constructed similarly, but restrict the sample to countries with complete time series available over the entire 26 years. The two panels on the right are again similar to those on the left, but drop all eight US variables from the estimation. All six panels of box plots in Figure 6 look similar; the GFCy does not seem to explain much variation in capital flows in that it cannot be modelled well with the ten time-varying regressors of (4).

Figures 7-9 contain a large number of box plot panels with further robustness checks, all constructed similarly to those of Figure 6 . Thus Figure 7 changes the specification of (4). The top-left panel drops the factors from the right-hand side of (4); the top-middle substitutes static for dynamic factors; the top-right substitutes the dynamic factors estimated by Miranda Agrippon and Rey for our dynamic factors. The bottom-left box plots add 4 lags of the VIX to the right-hand side of (4), while the bottom-middle panel adds a single lag of all eight US variables as regressors. In the bottom-right of Figure 7 contemporary values of all eight variables for both the UK and the EMU are added (thereby restricting the time-series span of the data). None of these changes leads to a really dramatic improvement in the quality of the fits. The highest $\overline{\mathrm{R}}^{2}$ statistics are in the bottom-right, when 24 US, British, and European

\footnotetext{
${ }^{42}$ As always, the included factors are matched to the type of capital inflow (so that FDI inflow factors are used to model FDI capital inflows, and are estimated over the entire 26 -year period with a single lag).

${ }^{43}$ This is, of course, unsurprising since the data underlying the top-left panel of Figure 6 is drawn from that of Figure 5.
} 
variables are used, along with two factors extracted from capital flows, to model the 64 observations available since 2000Q1. Even in this case a reasonable median $\overline{\mathrm{R}}^{2}$ is .25 , and there are plenty of negative statistics. ${ }^{44}$

Figure 8 changes the sample in a number of ways to ensure that the results are robust. The top-left panel implicitly splits the sample into two by allowing each of the 8 US variables to have a different coefficient from 2009Q1 onwards, following Avdjiev et al. (2017a). ${ }^{45}$ The bottom-left panel drops outlier observations, defined as those where the residual lies more than 2.5 standard errors from the mean. The top-middle panel drops all observations where capital flows exceed $8 \%$ of GDP; the bottom-middle panel winsorizes all observations at $5 \%$ of GDP. At the top-right, advanced economies are dropped from the sample leaving only developing and emerging markets, while observations between 1990Q1 and 199504 are dropped in the bottom-right. None of these perturbations alters the results substantially.

Finally, to examine findings in the literature that the impact of the GFCy varies by country characteristics, Figure 9 splits the sample on the basis of a number of criteria. In the top-left panel, we drop observations which have below-median levels of financial openness, using the Chinn-Ito measure, while in the bottom-left, observations are dropped for countries with annual real GDP per capital below $\$ 5,000$. In the top-middle, results are portrayed using only countries from East/Central Asia, the Pacific and Europe; the panel below contains results for the other countries. The panels on the right of Figure 9 use the Reinhart-Rogoff annual data on exchange rate regimes to split the sample; countries on top have relatively flexible exchange rates, either floating (managed or freely) or in bands (crawling or moving). The box-plots on the bottom have more rigid regimes, being in currency unions, boards, or pegs (crawling or not). ${ }^{46}$ Our results do not seem particularly sensitive to the exact region or exchange rate regime: the GFCy is quantitatively not so important. ${ }^{47}$

\section{Event Study}

The evidence that we have presented thus far indicates that center-country phenomena, captured by the VIX or other variables, do not typically explain much variation in capital flows. This is true even when the empirical models are augmented by factors that

\footnotetext{
${ }^{44}$ Using US and Euro-zone (but not British) variables leads to similar results.

${ }^{45}$ Breaking the sample at 2008Q1 instead of 2009Q1 changes the results insubstantially.

${ }^{46}$ We currently only have annual exchange rate regime data, so all four quarters of the year are matched to the single respective annual Reinhart-Rogoff observation.

47 The focus in this paper has been on the relationship between the GFCy and capital flows. Figure A16 provides an informal peek at the GFCy and credit growth. It is an analogue to Figure 6, reporting box plots of goodness of fit, but when real credit growth replaces capital flows as the regressand in equation (4), with appropriate dynamic factors. Real credit growth seems to be slightly more linked to the GFCy than most types of capital flows, with a median $\mathrm{R}^{2}$ of about 0.3 . We are pursuing developments in credit, along with asset prices, in a companion paper.
} 
reflect the common movements of capital flows. Perhaps though, the GFCy is more important during brief periods of crisis than in more typical and longer tranquil times? We investigate this hypothesis briefly with some event studies of sub-periods of global financial stress. ${ }^{48}$

To define periods of stress, we focus on periods when the VIX is high. During our 26year sample, the VIX ended the quarter above 30 on eight occasions; we treat these as the events portrayed in Figure 10. ${ }^{49}$ We then plot some of the key movements of capital flows for our sample of (63) small countries during the twelve quarters on either side of the periods with high VIX values.

Consider the top-left graph in Figure 10. Starting at the extreme left of the graph, the solid middle line traces out the average size of FDI inflows (relative to GDP) beginning twelve quarters before the event, then progressing, as the eye moves to the right, through the event and twelve quarters afterwards. The dashed lines above and below trace out the $(5,95)$ confidence intervals for FDI inflows. There is little action in inflows of FDI capital during the periods immediately before, during, and after heightened values of the VIX. The three graphs to the right in the top of Figure 10 are analogous but cover inflows of portfolio debt, portfolio equity, and credit; analogous outflows are portrayed in the bottom row. All eight graphs of Figure 10 deliver the same message; capital flows do not seem to change systematically and significantly during periods around high VIX values. There are some small changes in flows, but no statistically significant movements.

The results of Figure 10 are robust to minor changes in the empirics. For instance, appendix Figure A17 replaces the (eight) events when the VIX exceeded 30 with (nineteen) events when the VIX ended the quarter exceeding 25. Little of statistical or economic significance seems to change when we use this lower threshold to mark periods of market fear; capital flows just do not seem to change systematically during these periods of market stress. The same is true when we look at the (dozen) periods when the VIX rose by more 5, as shown in Figure A18; at the (seven) quarters when the average (not just the end-of-quarter) value of the VIX exceeded 30, portrayed in Figure A19; or at the (seven) quarters when the US\$ real effective exchange rate appreciated more than 3.5\% (Figure A20). We conclude that periods of financial stress - that is, high and/or rapidly rising values of the VIX or the dollar - do not seem to be systematically associated with unusual capital flow movements (at the quarterly frequency) across our sample of countries. If the former are associated with critical moments in the GFCy, then they are not closely linked to capital flows.

\footnotetext{
${ }^{48}$ It can well be the case that global events, including the ones we study here, affect capital flows in the very shortrun. Since we use capital flow data from balance-of-payments statistics, however, we are limited to quarterly data. Still, even if the GFCy matters a lot for short periods of time occasionally, our point remains that the GFCy isn't typically very important from a broader perspective for capital flows.

49 This is not an obvious statement, since we could plausible apply a window around events, to avoid overlap. The VIX closed above 30 on 1998Q3, 2001Q3, 2002Q3, 2008Q3, 2008Q4, 2009Q1, 2010Q2, and 2011Q3; clearly the extended volatility around the global financial crisis of 2008-09 could reasonably be handled in different ways. When we use a one-year exclusion window around the $>30$ VIX events of Figure 10 , our results are similar.
} 


\section{Coefficients}

Our emphasis in this paper diverges from most of the literature in that we focus on the quantitative importance of the GFCy for determining capital flows; we care about an equation's goodness of fit, rather than the sign, size and significance of its coefficient estimates. This biases our approach towards finding an important GFCy, since a particular model of capital flows may fit well statistically, without intuitively-signed, plausibly-sized coefficients. Indeed, in our analysis above we have not even discussed the sign or size of the coefficient estimates (this would be difficult, since we have estimated literally thousands of capital flow equations). We nevertheless provide a little direct evidence on the matter by tabulating coefficient estimates from (4) in appendix Table A3 for capital flows into five emerging markets. While we do not take these estimates particularly seriously - in part because of the specific choices of countries and models estimated, we note that the coefficients and their significance levels vary dramatically across countries and capital flow types. In general, for example, results confirm the literature's general findings (see Koepke 2015) that portfolio flows, especially debt flows, tend to co-move negatively with the VIX more so than other types of capital flows. Nevertheless, the analogous scatter plots of actual against fitted capital flows for these countries, which are portrayed in appendix Figure A21, confirm our general result of limited explanatory power. ${ }^{50}$

\section{Conclusion}

Our goal in this paper has been not to praise the Global Financial Cycle (GFCy), nor to bury it, but merely to quantify it; we are interested in its relevance for understanding capital flows. We have done this quantification with a variety of techniques, including panel regressions, national capital flow equations, and event studies. Our data and statistical metrics are as conventional as our models and techniques, falling well within the bounds of the existing literature. We use a broad approach to quantify the GFCy, measuring it both directly via conventional center-country variables like the VIX, and indirectly via commonality in capital flows extracted from dynamic factor models. Nevertheless, it has been difficult to find consistent manifestations of the GFCy in capital flows, something that is puzzling for a phenomenon viewed by some as conspicuous and significant. More importantly, we find little evidence that the GFCy explains systematically as much as a quarter of the variation in capital flows.

As the measures that we use simply do not explain much variation in capital flows, we are left skeptical of the general quantitative importance of the GFCy in understanding capital

\footnotetext{
${ }^{50}$ As we portray estimates for twenty capital inflows in Table A3 and Figure A21, some equations (e.g., Brazilian FDI) inevitably fit better than others (e.g., Brazilian credit). While acknowledging this, our interest lies in the general importance of the GFCy, for many capital flows and countries, and we prefer not to focus on one type of capital flow for a particular country (even ignoring bizarre coefficients).
} 
flows. This is especially true since we have been conservative in that: a) we ignore implausible coefficient estimates; and b) we attribute all explanatory power associated with both centercountry variables and commonality to the GFCy, even if the true source lies elsewhere. Our conclusion is, surprisingly, consistent with the literature, which is more concerned with, e.g., estimating coefficients for global interest rates and risk measures than on understanding their quantitative importance for the variation in capital flows. The main message from our analysis is that the empirical importance of the Global Financial Cycle in determining capital flows is limited, smaller than typically implied by the literature.

Caveats are naturally appropriate. Our empirics are based on conventional models of capital flows that we estimated in straightforward ways with standard data and evaluate with traditional statistics. Future work can plausibly extend our research on any or all of these dimensions. For instance, a claim that the GFCy explains a high proportion of capital flow variation for a particular set of countries or time periods could be evaluated with out-of-sample statistical techniques. Perhaps the country is an inappropriate unit of analysis? Our approach could also be extended to consider non-linear effects of the GFCy on capital flows. Most of our models have no intrinsic dynamics (unlike, e.g., VARs) so that the GFCy explains the same variation at all horizons, another feature that might be worth exploring. We have also ignored endogenous domestic responses to the GFCy, another aspect of the issue worth exploring. Indeed, we have eschewed all domestic influences on capital flows; including these determinants seems likely to reduce the effects of the GFCy further. More generally, our results focus on the potential impact of the GFCy on capital flows, so it could be the case that countries also face the impact of the GFCy in other important variables, such as domestic asset prices or credit. Finally, our analysis was conducted at the quarterly frequency. The GFCy could be more important for capital flows at higher frequencies for short periods of time. Still, the fact that any such effects do not show up strongly at the quarterly frequency simply reinforces our message that the GFCy is not a very important determinant of capital flows.

The conclusion that the Global Financial Cycle is not that important in understanding capital flows leads to important policy messages which become clear once one considers two possibilities. Suppose that most of the variation in capital flows that most countries experience most of the time is explained by center-country phenomena through the GFCy. In this case, as Rey and her co-authors have ably pointed out, a peripheral country may consider the benefits of financial integration as less than the risks introduced by (volatile) capital flows driven by exogenous events taking place in larger center countries. If this is the case, the country may choose to insulate itself from the GFCy with, for example, capital controls, macro-prudential policies, and the like, or seek to avail itself of (self)-insurance mechanisms. In contrast however, if, as our results suggest, the GFCy explains only a small fraction of the variation in capital flows, then more idiosyncratic phenomena necessarily explain capital flows. To the extent these are idiosyncratic foreign phenomena, it will be difficult to put in place systematic policies that screen "good" from "bad" capital flows, and the country is thus more likely to give up the gains of international financial integration as it tries to insulate itself. And, regardless, it may be more natural to identify much of this idiosyncrasy with domestic phenomena, making it incumbent on the policy authorities of countries in the periphery to take ownership and 
responsibility for these. Since the potential impact of the GFCy can show up in other variables (e.g., domestic asset prices and credit), however, more analysis is needed before reaching policy conclusions. 


\section{References}

Avdjiev, Stefan Leonardo Gambacorta, Linda S. Goldberg and Stefano Schiaffi (2017a) "The shifting drivers of international capital flows," mimeo, Bank for International Settlements.

Avdjiev, Stefan, Bryan Hardy, Sebnem Kalemli-Ozcan and Luis Serven (2017b) "Gross Capital Flows into Banks, Corporates and Sovereigns" CEPR Discussion Paper DP11,806

Ahmed, Shaghil, Coulibaly Brahima, Zlate Andrei (2014) "International Financial Spillovers to Emerging Market Economies: How Important Are Economic Variables?" Board of Governors of the Federal Reserve System Working Paper D2015-37.

Aizenman, Joshua, Mahir Binici, and Michael M. Hutchison (2014) "The Transmission of Federal Reserve Tapering News to Emerging Financial Markets,” NBER Working Paper No. 19,980.

Aizenman, Joshua, Menzie D. Chinn, and Hiro Ito (2016) "Monetary Policy Spillovers and the Trilemma in the New Normal," NBER Working Paper No. 21,128.

Baskayay, Yusuf Soner, Julian di Giovanni, Sebnem Kalemli-Ozcan, and Mehmet Fatih Ulu (2017), International Spillovers and Local Credit Cycles, NBER Working Paper No. 23,149.

Bekaert, Geert Campbell R. Harvey, Andrea Kiguel, and Xiaozheng Wang (2016) "Globalization and Asset Returns" Annual Review of Financial Economics 8, 221-288.

Blanchard, Olivier, Jonathan D. Ostry, Atish R. Ghosh, and Marcos Chamon (2015) "Are Capital Inflows Expansionary or Contractionary? Theory, Policy Implications, and Some Evidence," NBER Working Paper No. 21,619.

Broner, Fernando, Tatiana Didier, Aitor Erce, and Sergio L. Schmukler (2013) "Gross Capital Flows: Dynamics and Crises" Journal of Monetary Economics 60, 113-33.

Bruno, Valentina and Hyun Song Shin (2015a) "Capita flows and the Risk-Taking channel of Monetary Policy" Journal of Monetary Economics 71, 119-132.

Bruno, Valentina and Hyun Song Shin (2015b) "Cross-Border Banking and Global Liquidity" Review of Economic Studies 82, 535-564.

Calderón, César and Megumi Kubota (2013) "Sudden stops: Are Global and Local Investors Alike?" Journal of International Economics 89, 122-142.

Calvo, Guillermo, Leonardo Leiderman, and Carmen Reinhart (1993) "Capital Inflows and Real Exchange Rate Appreciation in Latin America: The Role of External Factors" IMF Staff Papers 40, 108-51.

Calvo, Guillermo, Leonardo Leiderman, and Carmen Reinhart (1996) “Inflows of Capital to Developing Countries in the 1990s" Journal of Economic Perspectives 10, 123-39. 
Cerutti, Eugenio, Stijn Claessens, and Damien Puy (2015) "Push Factors and Capital Flows to Emerging Markets: Why Knowing Your Lender Matters More Than Variables, IMF Working Paper 15/267.

Cerutti, Eugenio, Stijn Claessens and Lev Ratnovski (2017) “Global Liquidity and Cross-Border Bank Flows" Economic Policy, 32(89), 81-125.

Cerutti, Eugenio and Gee Hee Hong (2017) “Portfolio Inflows Eclipsing Banking Inflows:

Alternative Facts?" Forthcoming, IMF Working Paper.

Claessens, Stijn, Michael P. Dooley, and Andrew Warner (1995). "Portfolio Capital Flows: Hot Or Cold?" World Bank Economic Review, 9(1), 153-174.

Correa, Ricardo, Teodora Paligorova, Horacio Sapriza, and Andrei Zlate (2016), “Cross-Border Bank Flows and Monetary Policy," mimeo, Federal Reserve Board.

Contessi, Silvio, Pierangelo De Pace and Johanna Francis (2013) "The cyclical properties of disaggregated capital flows." Journal of International Money and Finance, 32, 528-555.

Deniz, Igan and Zhibo Tan (2015). "Capital Inflows, Credit Growth, and Financial Systems," IMF Working Paper, WP/15/193.

Eichengreen, Barry, and Poonam Gupta (2014) "Tapering Talk: The Impact of Expectations of Reduced Federal Reserve Security Purchases on Emerging Markets" World Bank Policy Research Working Paper Series 6,754.

Forbes, Kristin J., and Francis E. Warnock (2012) "Capital Flow Waves: Surges, Stops, Flight, and Retrenchment" Journal of International Economics 88, 235-251.

Fratzscher, Marcel (2012) "Capital Flows, Push versus Pull Factors and the Global Financial Crisis" Journal of International Economics 88, 341-356.

Ghosh, Atish R., Mahvash S. Qureshi, Jun II Kim, and Juan Zalduendo (2014) "Surges" Journal of International Economics 92, 266-285.

Han, Xuehui, and Shang-Jin Wei (2016) International transmissions of monetary shocks:

Between a trilemma and a dilemma" NBER WP 22,812.

IMF (2013) "The Yin and Yang of Capital Flow Management: Balancing Capital Inflows with Capital Outflows," by Jaromir Benes, Jaime Guajardo, Damiano Sandri, and John Simon, World Economic Outlook, Chapter 4, Fall.

IMF (2014) "Global Liquidity: Issues for Surveillance" by Luis Brandao Marques, Eugenio Cerutti, Stijn Claessens, Sally Chen, Pragyan Deb, Gaston Gelos, Brenda Gonzalez-Hermosillo, Vikram Haksar, Shuntaro Hara, Lev Ratnovski, Andrew Tiffin, Edouard Vidon, and Yuanyan Sophia Zhang available at https://www.imf.org/external/np/pp/eng/2014/031114.pdf. 
IMF (2016) "Understanding The Slowdown In Capital Flows To Emerging Markets," by Rudolfs Bems, Luis Catão, Zsóka Kóczán, Weicheng Lian, and Marcos Poplawski-Ribeiro, World Economic Outlook, Chapter 2, Spring.

Jotikasthira, Chotibhak, Christian Lundblad, and Tarun Ramadorai (2012) "Asset Fire Sales and Purchases and the International Transmission of Funding Shocks" Journal of Finance 67, 2015050.

Koepke, Robin (2015) "What Drives Capital Flows to Emerging Markets: A Survey of the Empirical Literature" IIF Working Paper, Washington, D.C.

Lane, Philip R., and Gian Maria Milesi Ferretti (2017), "International Financial Integration in the Aftermath of the Global Financial Crisis," mimeo, Central Bank of Ireland and IMF.

Lane, Phillip, and Peter McQuade (2013), "Domestic Credit Growth and International Capital Flows," The Scandinavian Journal of Economics 116 (1), 218-52.

Miranda Agrippino, Silvia and Hélène Rey (2015) "World Asset Markets and the Global Financial Cycle" CEPR Discussion Paper No. 10,591.

Milesi-Ferretti, Gian Maria, and Cédric Tille (2011) "The Great Retrenchment: International Capital Flows during the Global Financial Crisis," Economic Policy, 26(66), 285-342.

Obstfeld, Maurice, Jonathan Ostry, and Mahvash Qureshi (2017) "A Tie That Binds: Revisiting the Trilemma in Emerging Market Economies," IMF WP 17/130.

Passari, Evgenia and Hélène Rey (2015) "Financial Flows and the International Monetary System" Economic Journal 125, 675-698.

Prachi, Mishra, Kenji Moriyama, Papa N'Diaye, and Lam Nguyen (2014) "Impact of Fed Tapering Announcements on Emerging Markets" IMF WP 14/109.

Puy, Damien (2016) "Mutual Fund Flows and the Geography of Contagion" Journal of International Money and Finance 60, 73-93.

Raddatz, Claudio, and Sergio L. Schmukler (2012) "On the International Transmission of Shocks: Micro-evidence from Mutual Fund Portfolios" Journal of International Economics 88, 357-74.

Rey, Hélène (2013) "Dilemma not Trilemma: The Global Financial Cycle and Monetary Policy Independence" in Proceedings of the 2013 Federal Reserve Bank of Kansas City Economic Symposium at Jackson Hole, 285-333

Rey, Hélène (2015) "International Channels of Transmission of Monetary Policy and the Mundellian Trilemma," Mundell Fleming lecture, IMF Economic Review, May, 64(1), 6-35.

Sahay, Ratna, Vivek Arora, Thanos Arvanitis, Hamid Faruqee, Papa N'Diaye, Tommaso ManciniGriffoli, and an IMF Team (2014) "Emerging Market Volatility: Lessons from the Taper Tantrum" 
IMF Staff Discussion Note SDN 14/09, September.

Shin, Hyun Song (2012) "Global Banking Glut and Loan Risk Premium" Mundell-Fleming Lecture, IMF Economic Review 60, 155-92.

Shin, Hyun Song (2013) "Second Phase of Global Liquidity and Its Impact on Emerging Economies" In Proceedings of the Keynote Address at Federal Reserve Bank of San Francisco Asia Economic Policy Conference, November 3-5, 2013.

Shin, Hyun Song (2016) "The Bank/Capital Markets Nexus Goes Global" Speech the London School of Economics and Political Science, 15 November 2016. Available at http://www.bis.org/speeches/sp161115.htm 
Table 1 Importance of Common Phenomena for Goodness of Fit in Panel Regressions

\begin{tabular}{|l|l|c|c|c|c|c|c|}
\hline & Time Span & \multicolumn{2}{c|}{ 1990Q1-2015Q4 } & \multicolumn{2}{c|}{ 1996Q1-2015Q4 } & \multicolumn{2}{c|}{ 1990Q1-2015Q4 } \\
\hline & Country Span & \multicolumn{2}{|c|}{ All } & \multicolumn{2}{c|}{ All } & \multicolumn{2}{c|}{ Small } \\
\hline & R Measure & Within & Overall & Within & Overall & Within & Overall \\
\hline Inflow & FDI & .06 & .05 & .06 & .05 & .08 & .07 \\
\hline Inflow & Portfolio Debt & .10 & .09 & .10 & .09 & .07 & .07 \\
\hline Inflow & Portfolio Equity & .05 & .03 & .05 & .03 & .11 & .10 \\
\hline Inflow & Credit & .10 & .09 & .10 & .09 & .07 & .06 \\
\hline Outflow & FDI & .08 & .07 & .08 & .07 & .08 & .07 \\
\hline Outflow & Portfolio Debt & .07 & .06 & .07 & .06 & .09 & .09 \\
\hline Outflow & Portfolio Equity & .08 & .06 & .08 & .06 & .07 & .07 \\
\hline Outflow & Credit & .11 & .11 & .11 & .11 & .07 & .06 \\
\hline
\end{tabular}

Panel regressions with time- and country-specific fixed effects; data pooled across countries with series continuously available over relevant sample.

Table 2: Importance of Common Phenomena for Goodness of Fit in Panel Regressions

\begin{tabular}{|l|l|c|c|c|c|}
\hline & Within/Overall $\mathrm{R}^{2}$ & & MAR factors & & \\
\hline & Lags of 8 US vars: & None & None & Add 1 lag & Add 4 lags \\
\hline Inflow & FDI & $.05 / .04$ & $.07 / .06$ & $.05 / .04$ & $.06 / .06$ \\
\hline Inflow & Portfolio Debt & $.04 / .04$ & $.05 / .04$ & $.05 / .04$ & $.06 / .05$ \\
\hline Inflow & Portfolio Equity & $.05 / .05$ & $.05 / .05$ & $.06 / .06$ & $.08 / .08$ \\
\hline Inflow & Credit & $.03 / .03$ & $.04 / .04$ & $.04 / .04$ & $.06 / .06$ \\
\hline Outflow & FDI & $.03 / .03$ & $.04 / .04$ & $.03 / .03$ & $.05 / .05$ \\
\hline Outflow & Portfolio Debt & $.05 / .05$ & $.06 / .06$ & $.05 / .05$ & $.07 / .07$ \\
\hline Outflow & Portfolio Equity & $.01 / .01$ & $.01 / .01$ & $.02 / .02$ & $.05 / .05$ \\
\hline Outflow & Credit & $.03 / .03$ & $.04 / .03$ & $.04 / .03$ & $.05 / .04$ \\
\hline
\end{tabular}

Panel regressions with country-specific fixed effects; data pooled across small countries with series continuously available 1990Q1-2015Q4. Common phenomena include contemporary (and lagged) values of: i) eight US variables: a) VIX; b) real GDP growth rate; c) nominal policy rate; d) real policy rate; e) TED (2m LIBOR/Tbill) spread; f) yield curve (10y/3m treasury) spread; g) REER change; and h) M2 growth; and ii) two dynamic capital flow factors (advanced and emerging), estimated with one lag and specific to direction/type of capital flow. 
Table 3: Country-Heterogeneous Responses to Common Phenomena in Panel Regressions

\begin{tabular}{|l|l|c|c|c|c|c|}
\hline \multicolumn{2}{|c|}{} & Within/Overall R & \multicolumn{5}{c|}{ Add country-specific interactions with: } \\
\hline & $\begin{array}{c}\text { Current } \\
\text { VIX }\end{array}$ & $\begin{array}{c}\text { Current, } \\
\text { 1 lag of } \\
\text { VIX }\end{array}$ & $\begin{array}{c}\text { Current, } \\
\text { 4 lags of } \\
\text { VIX }\end{array}$ & $\begin{array}{c}\text { Current } \\
\text { of } 8 \text { US } \\
\text { vars }\end{array}$ & $\begin{array}{c}\text { Current, } \\
\text { lag of } 8 \\
\text { US vars }\end{array}$ \\
\hline Inflow & FDI & $.05 / .05$ & $.05 / .04$ & $.11 / .02$ & $.35 / .08$ & $.42 / .08$ \\
\hline Inflow & Portfolio Debt & $.09 / .02$ & $.11 / .02$ & $.12 / .01$ & $.25 / .00$ & $.42 / .05$ \\
\hline Inflow & Portfolio Equity & $.04 / .02$ & $.05 / .03$ & $.09 / .05$ & $.26 / .07$ & $.35 / .11$ \\
\hline Inflow & Credit & $.03 / .00$ & $.05 / .00$ & $.11 / .00$ & $.32 / .00$ & $.38 / .00$ \\
\hline Outflow & FDI & $.05 / .01$ & $.06 / .01$ & $.11 / .02$ & $.27 / .01$ & $.36 / .01$ \\
\hline Outflow & Portfolio Debt & $.08 / .00$ & $.11 / .00$ & $.13 / .01$ & $.27 / .02$ & $.37 / .04$ \\
\hline Outflow & Portfolio Equity & $.03 / .03$ & $.05 / .02$ & $.08 / .00$ & $.15 / .00$ & $.33 / .13$ \\
\hline Outflow & Credit & $.07 / .02$ & $.07 / .02$ & $.10 / .03$ & $.27 / .02$ & $.35 / .01$ \\
\hline
\end{tabular}

Panel regressions with country-specific fixed effects and dynamic factors for capital flow factors (advanced and emerging, estimated with one lag and specific to direction/type of capital flow); data pooled across all small countries with series continuously available 1990Q1-2015Q4. Up to eight current and lagged US variables are included, as indicated in the top rows: a) VIX; b) nominal policy rate; c) real policy rate; d) TED (2m LIBOR/Tbill) spread; e) yield curve (10y/3m treasury) spread; f) growth; g) REER change; and h) M2 growth. 


\section{Capital Flows and the VIX}

Capital Flows, \%GDP (y) against VIX (x); 63 small countries 1990Q1-2015Q4
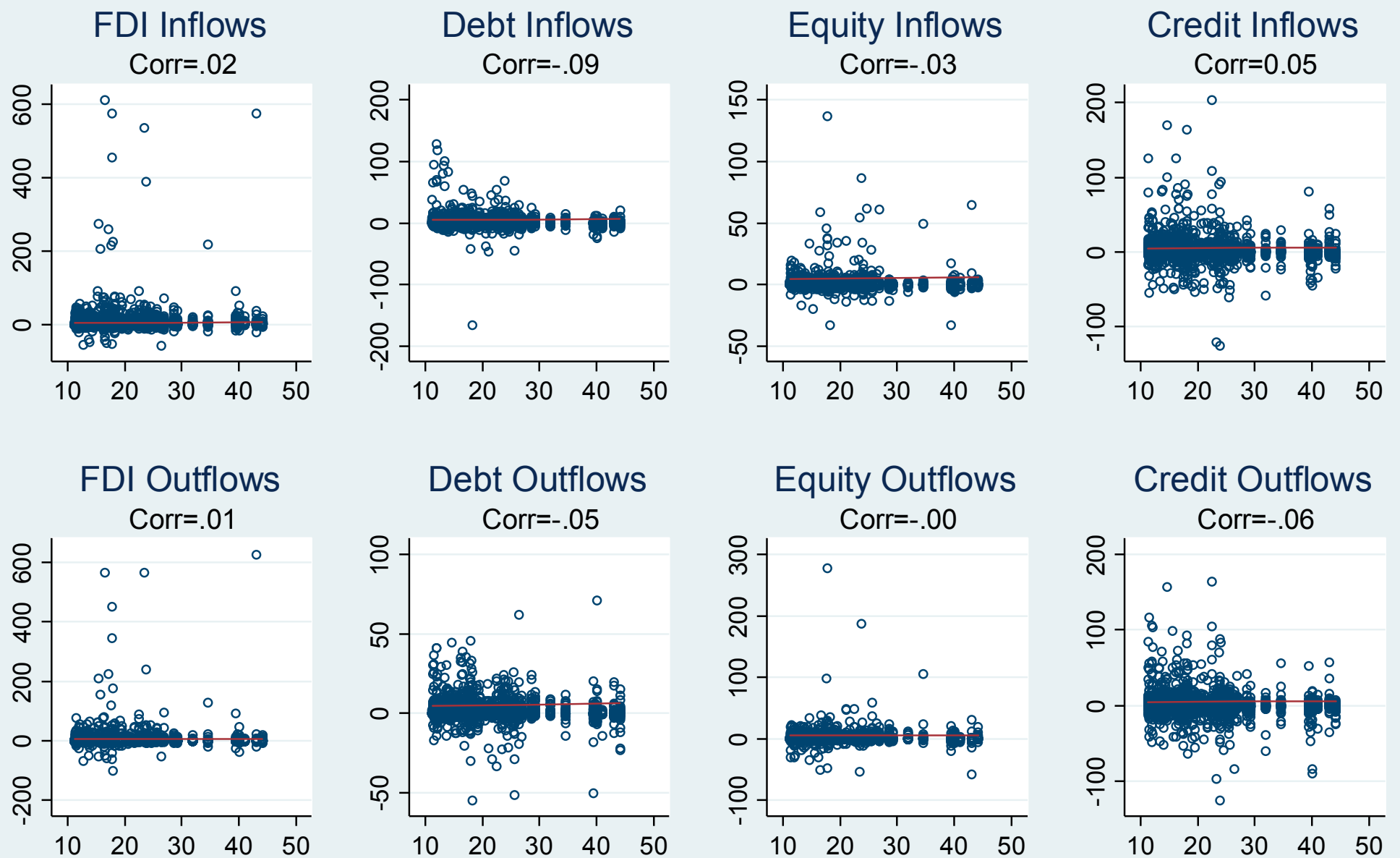

Figure 1 


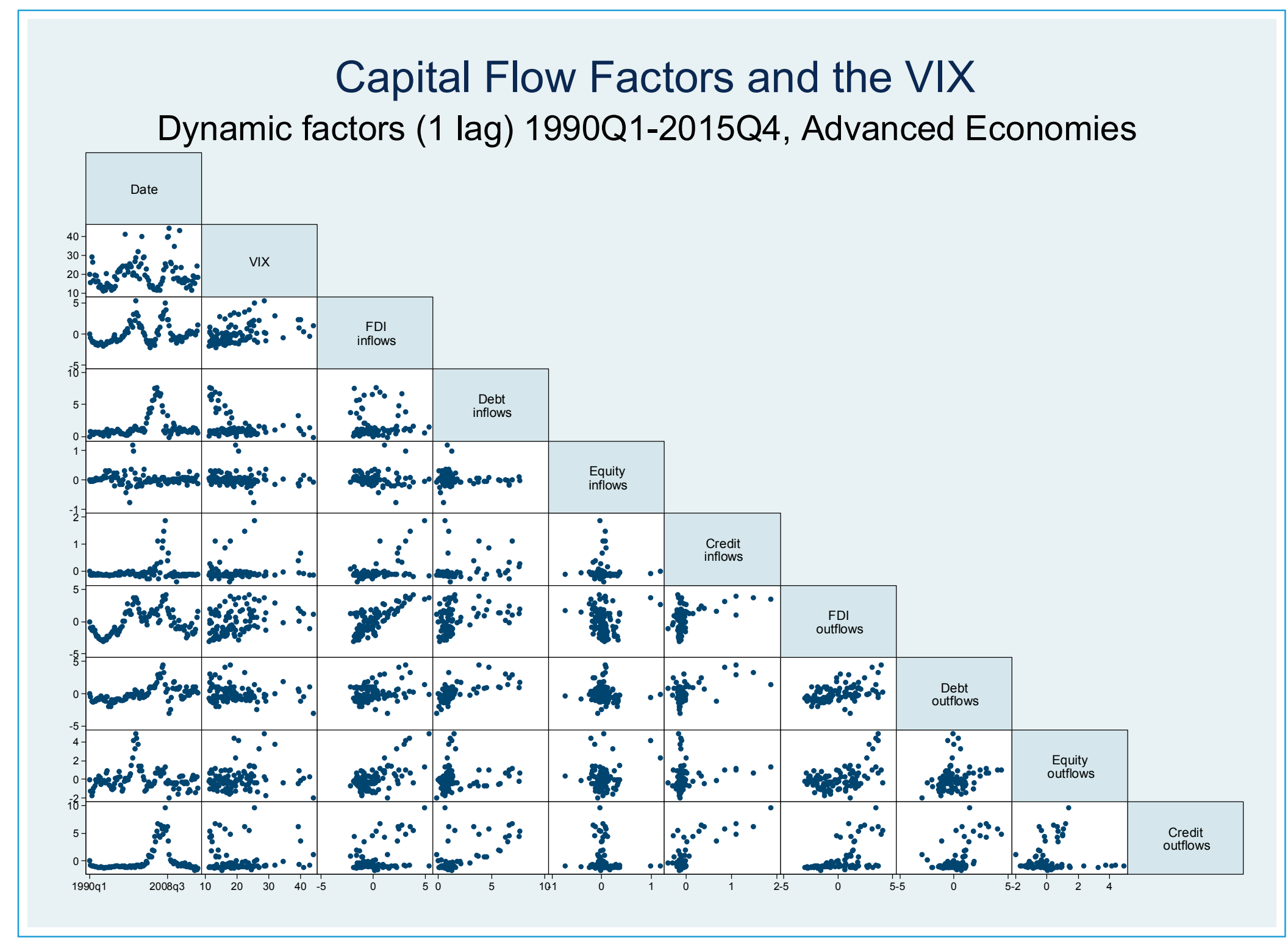

Figure 2 


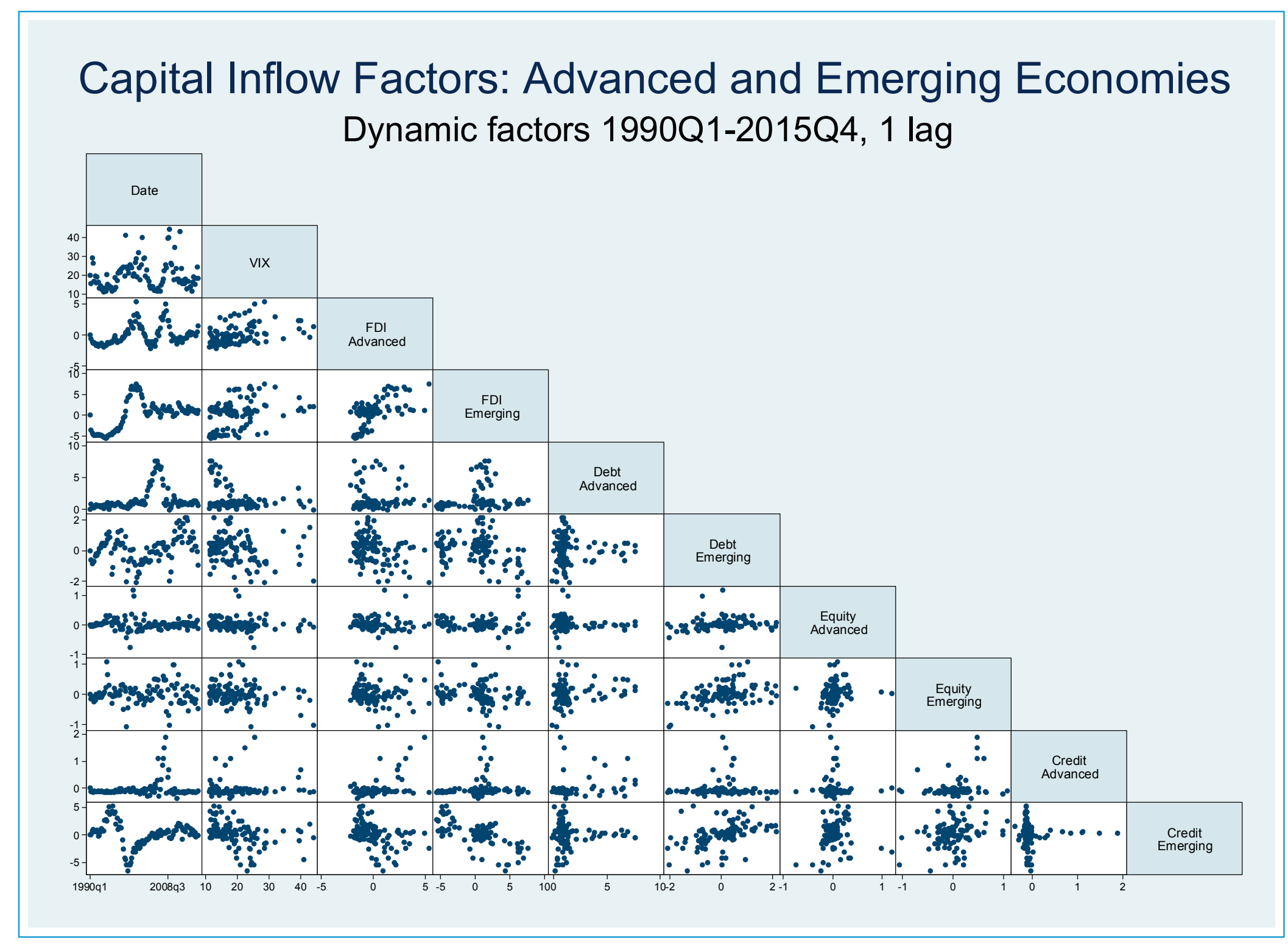

Figure 3 
Fear Measures and Factors from Asset/Commodity Prices

Dynamic factors 1990Q1-2015Q4, 1 lag

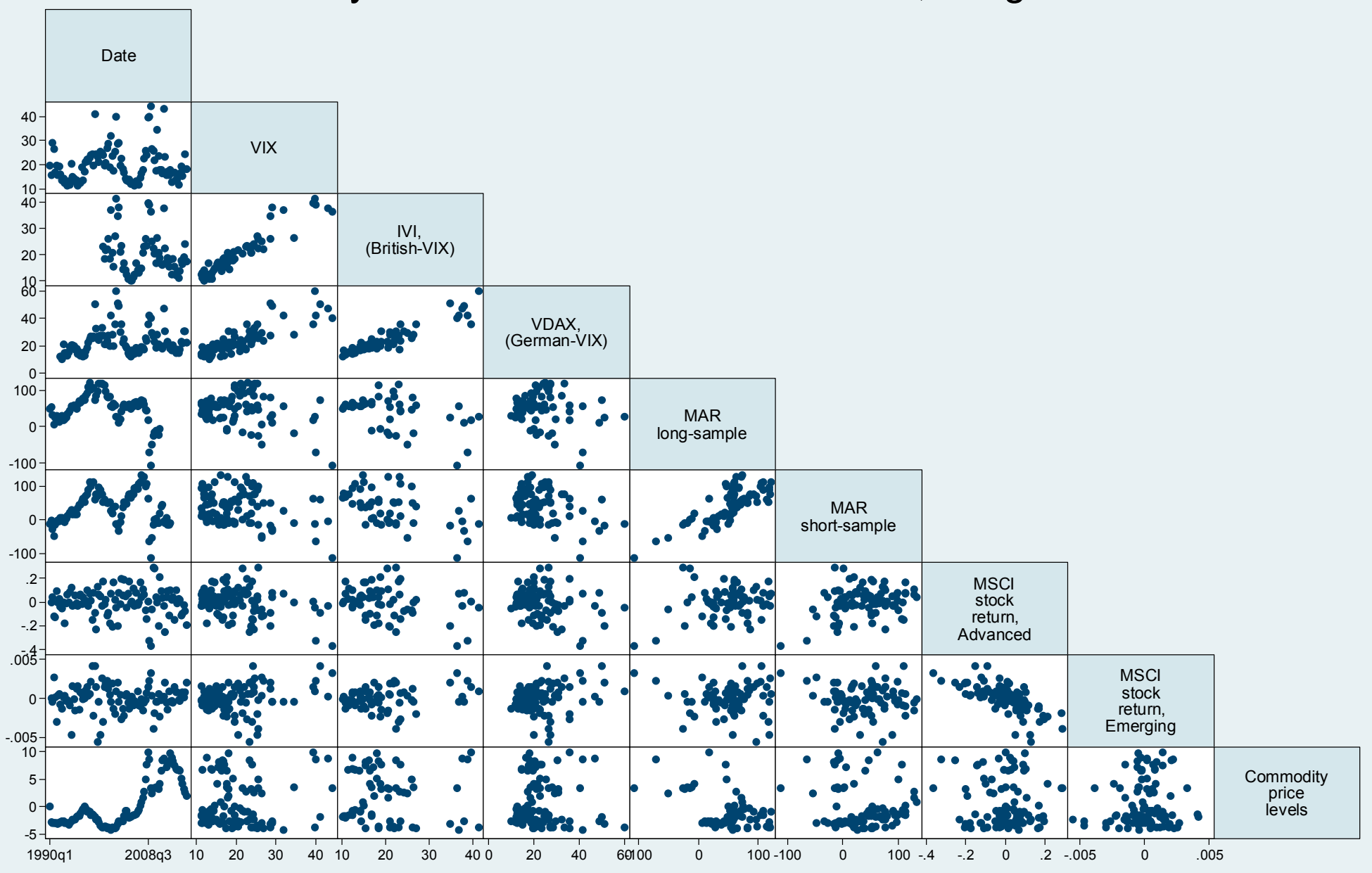

Figure 4 


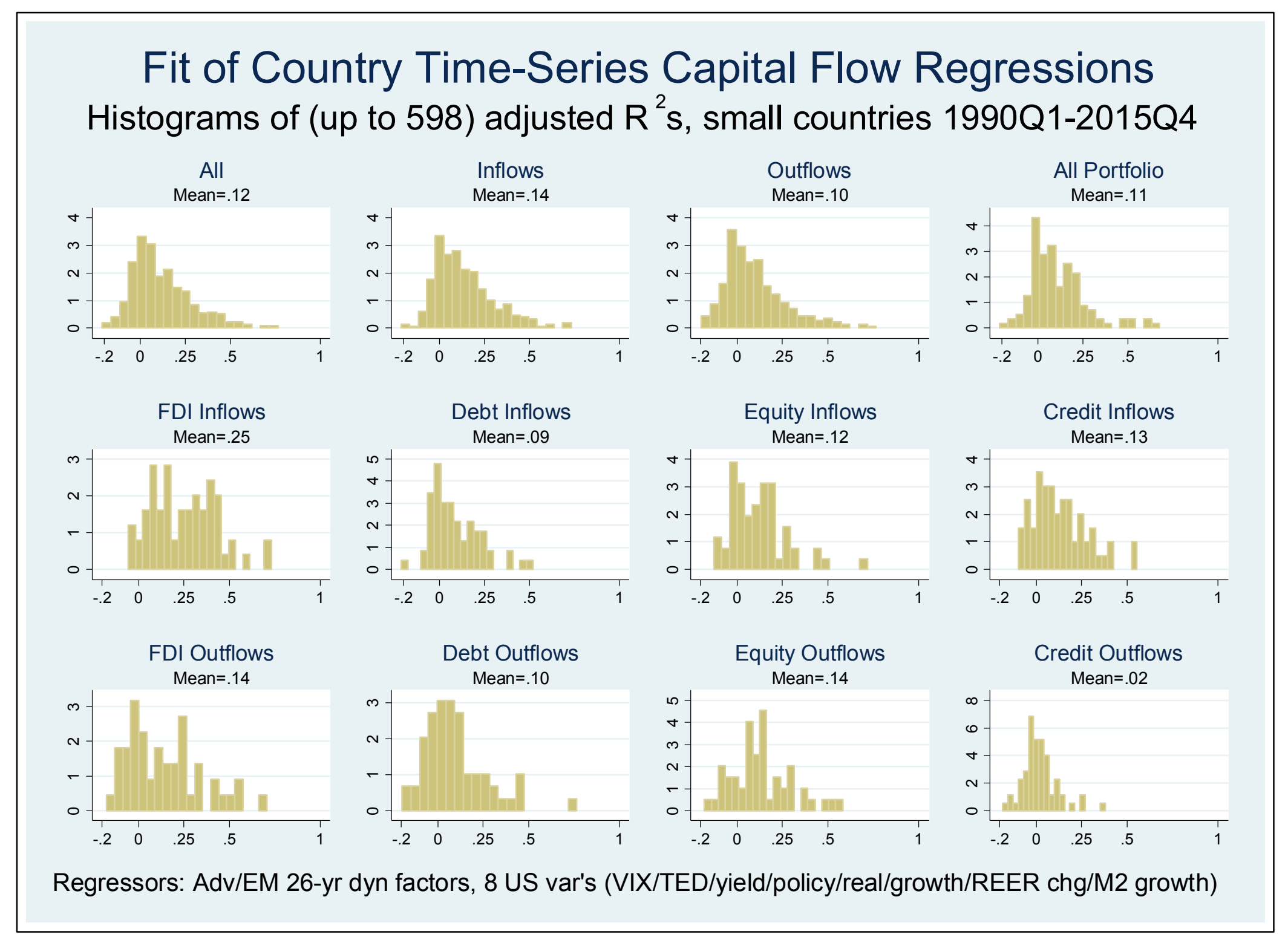

Figure 5 


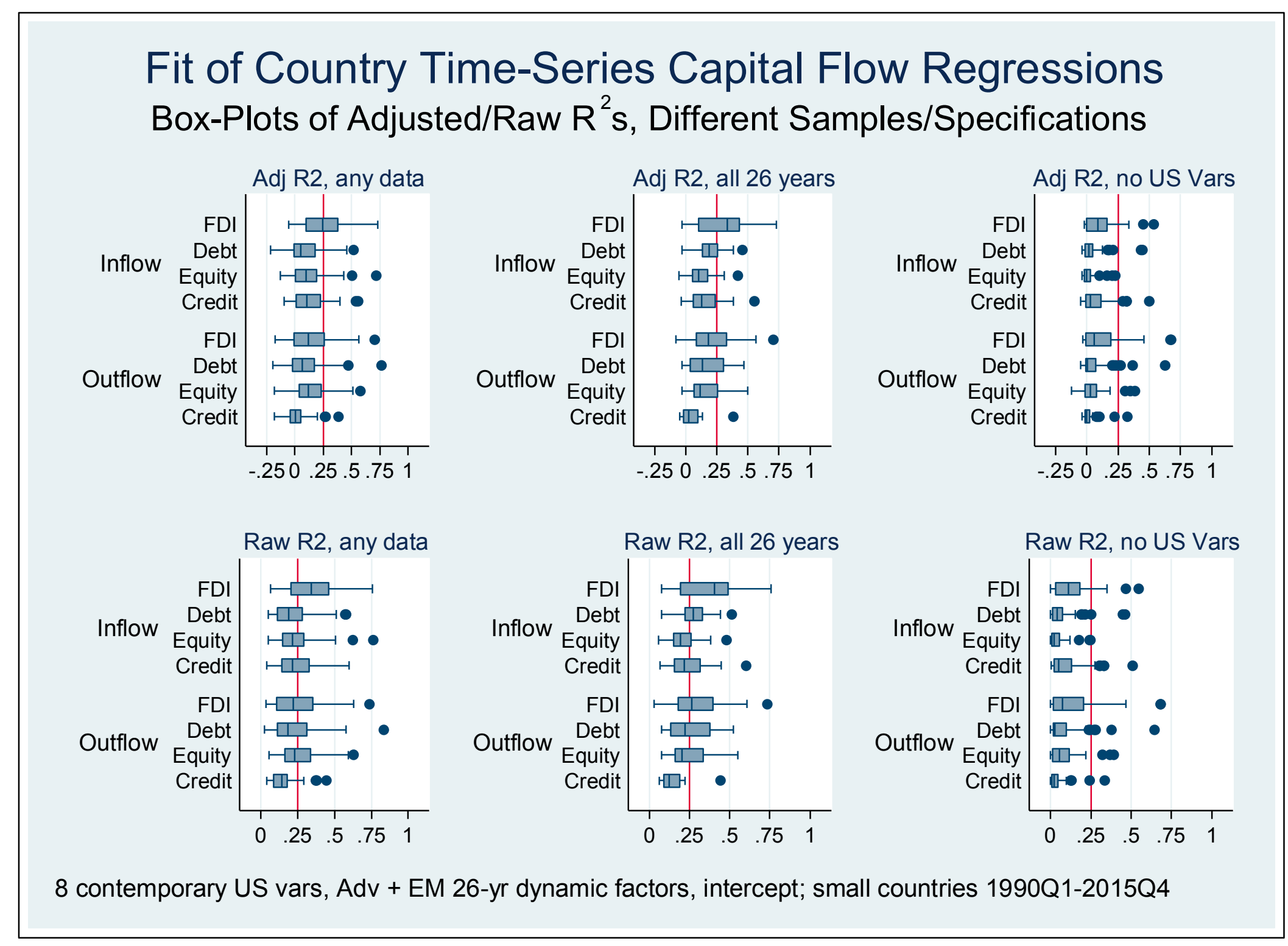

Figure 6 


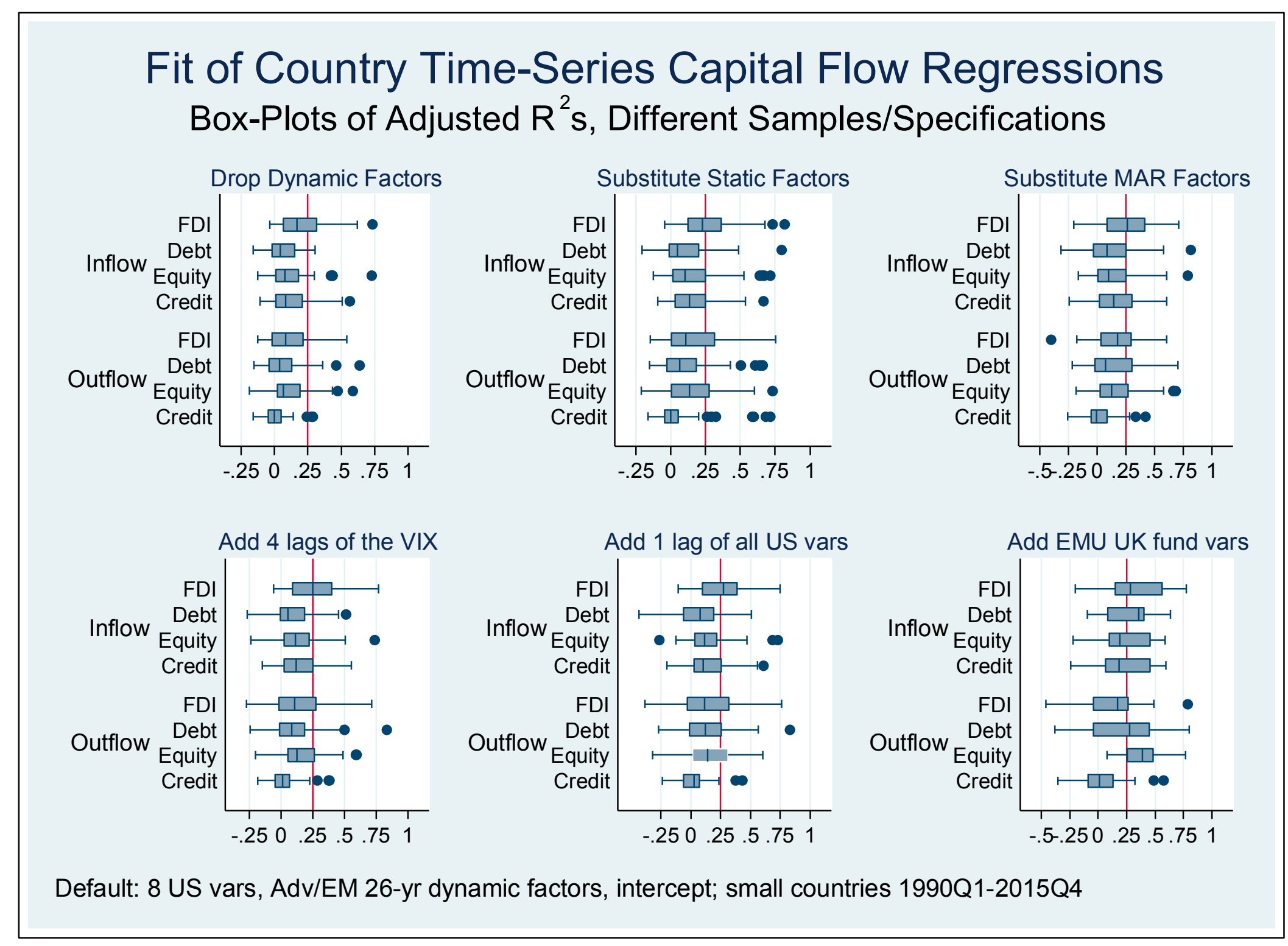

Figure 7 




Figure 8 




Figure 9 


\section{Capital Flows (\%GDP) around quarters when VIX close>30}

8 events
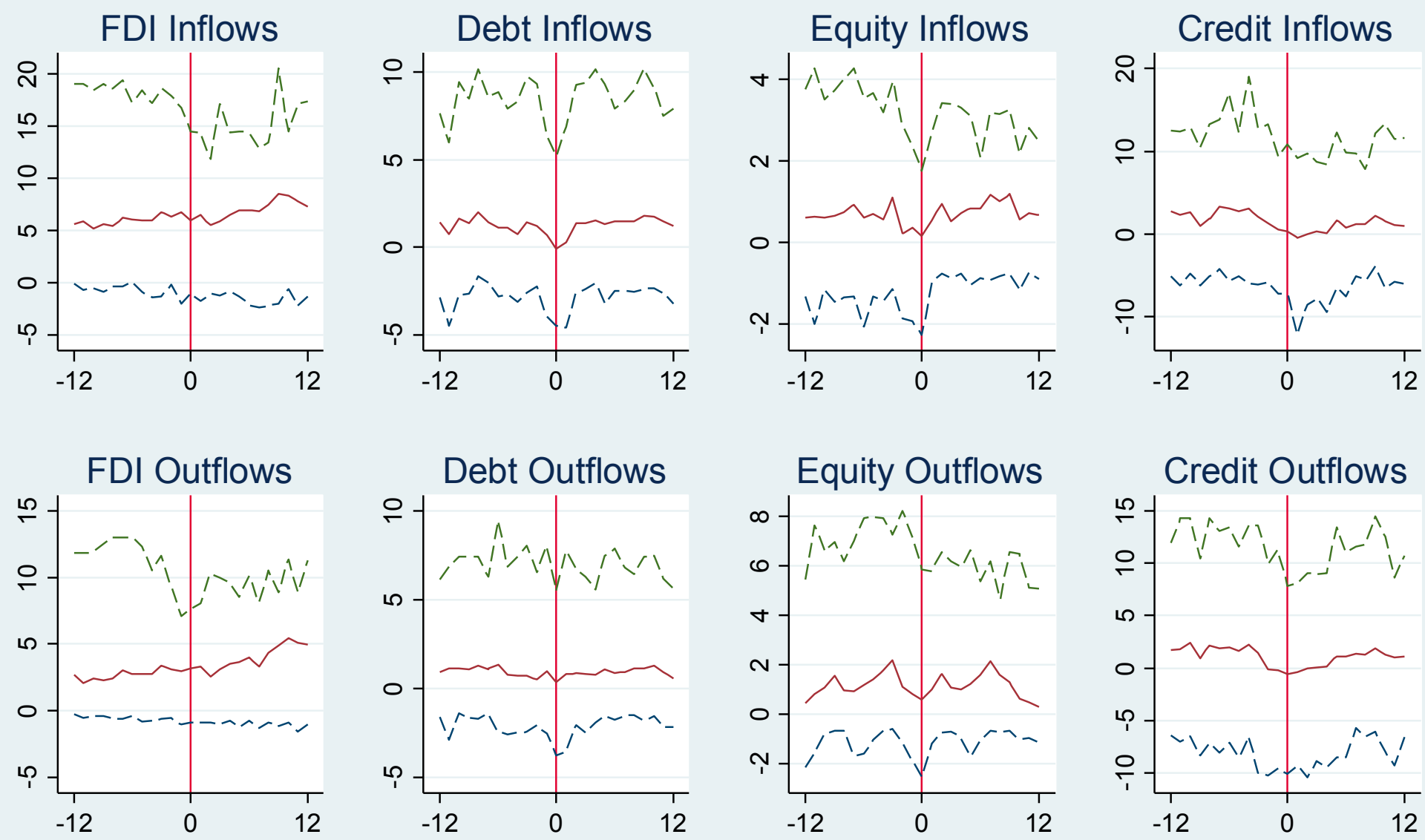

Means with $(5,95)$ confidence interval. 1990Q1-2015Q4 data, 63 small countries. 
Table A1: List of Countries

\begin{tabular}{|c|c|c|c|}
\hline Argentina & Estonia $^{1}$ & Lesotho & Russia $^{4,5}$ \\
\hline Armenia & Finland $^{1}$ & Lithuania $^{1}$ & Slovakia $^{1}$ \\
\hline Australia 3,5 & France $^{1}$ & Luxembourg $^{1}$ & Slovenia $^{1}$ \\
\hline Austria $^{1}$ & Georgia & Macedonia & South Africa ${ }^{4}$ \\
\hline Azerbaijan & Germany $^{1}$ & Malta 1 & Spain $^{1}$ \\
\hline Bangladesh & Greece $^{1}$ & Mauritius & Sri Lanka \\
\hline Belarus & Honduras & Mexico $^{4,5}$ & Suriname \\
\hline Belgium $^{1}$ & Hong Kong & Moldova & Sweden $^{3}$ \\
\hline Bolivia & Hungary & Mongolia & Switzerland $^{5}$ \\
\hline Brazil $^{4,5}$ & Iceland $^{3}$ & Namibia & Thailand $^{4}$ \\
\hline Bulgaria & Indonesia ${ }^{4,5}$ & Netherlands $^{1}$ & Turkey $^{4,5}$ \\
\hline Cabo Verde & Ireland $^{1}$ & New Zealand ${ }^{3}$ & Uganda \\
\hline Canada ${ }^{3,5}$ & Israel & Nicaragua & Ukraine \\
\hline Chile $^{4}$ & Italy ${ }^{1}$ & Norway $^{3}$ & $U^{2}$ \\
\hline China $^{4}$ & Japan $^{2}$ & Pakistan & USA $^{2}$ \\
\hline Colombia & Jordan & Panama & Uruguay \\
\hline Costa Rica & Kazakhstan & Paraguay & Venezuela \\
\hline Croatia & Korea $^{4,5}$ & Peru & Viet Nam \\
\hline Cyprus $^{1}$ & Kyrgyzstan & Philippines $^{4}$ & Zambia \\
\hline Czech Republic & Laos & Poland $^{4}$ & \\
\hline Denmark & Latvia $^{1}$ & Portugal $^{1}$ & \\
\hline Ecuador & Lebanon & Romania & \\
\hline
\end{tabular}

1 EMU member 2017; 2 large non-Euro economy; 3 used to generate advanced economy factors; 4 used to generate emerging market factors; 5 used to generate advanced/emerging factors. 
Table A2: Goodness of Fit for Panel Forbes-Warnock Capital Flow Event Equations

\begin{tabular}{|l|l|c|c|c|c|}
\hline $\begin{array}{l}\text { Estimator, } \\
\text { country effects }\end{array}$ & Regressors & $\begin{array}{c}\text { Flight } \\
\text { (Increased } \\
\text { Outflow) }\end{array}$ & $\begin{array}{c}\text { Retrenchment } \\
\text { (Decreased } \\
\text { Outflow) }\end{array}$ & $\begin{array}{c}\text { Stop } \\
\text { (Decreased } \\
\text { Inflow) }\end{array}$ & $\begin{array}{c}\text { Surge } \\
\text { (Increased } \\
\text { Inflow) }\end{array}$ \\
\hline Probit, random & Time-Effects & .01 & .00 & .00 & .01 \\
\hline Logit, fixed & Time-Effects & .07 & .17 & .21 & .12 \\
\hline LS, fixed & Time-Effects & .06 & .16 & .21 & .08 \\
\hline Probit, random & 8 US Variables & .01 & .00 & .00 & .01 \\
\hline Logit, fixed & 8 US Variables & .04 & .12 & .15 & .07 \\
\hline LS, fixed & 8 US Variables & .03 & .12 & .16 & .04 \\
\hline
\end{tabular}

Quasi $R^{2}$ (probit/logit) or within $R^{2}$ (LS). Panel estimates with country random/fixed effects as marked. 53 countries, 1990Q1-2009Q4. 
Table A3: Signs of Coefficients, Selected Capital Inflow Equations

\begin{tabular}{|c|c|c|c|c|c|c|c|c|c|}
\hline \multirow[b]{2}{*}{ Recipient } & \multirow[b]{2}{*}{ Type } & \multicolumn{8}{|c|}{ Effects of US Fundamental Variables } \\
\hline & & VIX & $\begin{array}{c}\text { GDP } \\
\text { Growth }\end{array}$ & $\begin{array}{c}\text { M2 } \\
\text { growth }\end{array}$ & $\begin{array}{c}\text { Nominal } \\
\text { Interest }\end{array}$ & $\begin{array}{c}\text { Real } \\
\text { Interest }\end{array}$ & REER & $\begin{array}{c}\text { TED } \\
\text { Spread }\end{array}$ & $\begin{array}{c}\text { Yield } \\
\text { Spread }\end{array}$ \\
\hline $\begin{array}{l}\text { South } \\
\text { Africa }\end{array}$ & FDI & $\begin{array}{l}-.08 \\
(.05)\end{array}$ & $\begin{array}{l}-.20 \\
(.18)\end{array}$ & $\begin{array}{c}.08 \\
(.14)\end{array}$ & $\begin{array}{c}.18 \\
(.47)\end{array}$ & $\begin{array}{l}-.08 \\
(.24)\end{array}$ & $\begin{array}{c}4.2 \\
(13.5)\end{array}$ & $\begin{array}{c}.27 \\
(1.11)\end{array}$ & $\begin{array}{c}.44 \\
(.61)\end{array}$ \\
\hline Brazil & FDI & $\begin{array}{l}.01 \\
(.02)\end{array}$ & $\begin{array}{l}.23 \\
(.07)\end{array}$ & $\begin{array}{l}.07 \\
(.07)\end{array}$ & $\begin{array}{l}-.42 \\
(.12)\end{array}$ & $\begin{array}{l}.19 \\
(.10)\end{array}$ & $\begin{array}{c}-.0 \\
(4.8)\end{array}$ & $\begin{array}{c}.38 \\
(.33)\end{array}$ & $\begin{array}{l}-.24 \\
(.16)\end{array}$ \\
\hline Chile & FDI & $\begin{array}{l}-.03 \\
(.06)\end{array}$ & $\begin{array}{c}.39 \\
(.23)\end{array}$ & $\begin{array}{c}.26 \\
(.31)\end{array}$ & $\begin{array}{l}-1.17 \\
(.44)\end{array}$ & $\begin{array}{c}.30 \\
(.46)\end{array}$ & $\begin{array}{c}17.4 \\
(15.7)\end{array}$ & $\begin{array}{c}2.49 \\
(1.08)\end{array}$ & $\begin{array}{l}-1.01 \\
(.65)\end{array}$ \\
\hline Mexico & FDI & $\begin{array}{c}.01 \\
(.02) \\
\end{array}$ & $\begin{array}{c}.07 \\
(.07) \\
\end{array}$ & $\begin{array}{c}.02 \\
(.08)\end{array}$ & $\begin{array}{l}-.09 \\
(.15)\end{array}$ & $\begin{array}{c}.08 \\
(.10)\end{array}$ & $\begin{array}{l}-2.1 \\
(3.4)\end{array}$ & $\begin{array}{l}-.37 \\
(.45) \\
\end{array}$ & $\begin{array}{l}-.01 \\
(.21) \\
\end{array}$ \\
\hline Indonesia & FDI & $\begin{array}{l}-.05 \\
(.02) \\
\end{array}$ & $\begin{array}{l}-.03 \\
(.07)\end{array}$ & $\begin{array}{c}.02 \\
(.08)\end{array}$ & $\begin{array}{l}-.59 \\
(.08)\end{array}$ & $\begin{array}{l}-.07 \\
(.08)\end{array}$ & $\begin{array}{l}-2.1 \\
(4.0)\end{array}$ & $\begin{array}{l}1.05 \\
(.26)\end{array}$ & $\begin{array}{l}-.71 \\
(.16) \\
\end{array}$ \\
\hline $\begin{array}{l}\text { South } \\
\text { Africa }\end{array}$ & Debt & $\begin{array}{l}-.09 \\
(.05) \\
\end{array}$ & $\begin{array}{c}.02 \\
(.18)\end{array}$ & $\begin{array}{c}.24 \\
(.18) \\
\end{array}$ & $\begin{array}{c}.00 \\
(.21)\end{array}$ & $\begin{array}{c}.28 \\
(.25)\end{array}$ & $\begin{array}{l}-13.5 \\
(10.8) \\
\end{array}$ & $\begin{array}{l}-.06 \\
(.61)\end{array}$ & $\begin{array}{c}.47 \\
(.41) \\
\end{array}$ \\
\hline Brazil & Debt & $\begin{array}{l}-.05 \\
(.03) \\
\end{array}$ & $\begin{array}{c}.14 \\
(.19) \\
\end{array}$ & $\begin{array}{l}-.10 \\
(.11) \\
\end{array}$ & $\begin{array}{l}-.16 \\
(.18) \\
\end{array}$ & $\begin{array}{l}.59 \\
(.44) \\
\end{array}$ & $\begin{array}{l}-6.9 \\
(9.7) \\
\end{array}$ & $\begin{array}{l}1.35 \\
(.93) \\
\end{array}$ & $\begin{array}{c}.75 \\
(.88) \\
\end{array}$ \\
\hline Chile & Debt & $\begin{array}{l}.02 \\
(.04) \\
\end{array}$ & $\begin{array}{c}.30 \\
(.15) \\
\end{array}$ & $\begin{array}{c}.16 \\
(.14) \\
\end{array}$ & $\begin{array}{l}-.31 \\
(.26) \\
\end{array}$ & $\begin{array}{l}-.02 \\
(.24) \\
\end{array}$ & $\begin{array}{l}-8.9 \\
(9.4) \\
\end{array}$ & $\begin{array}{l}-.62 \\
(.96) \\
\end{array}$ & $\begin{array}{l}-.04 \\
(.37) \\
\end{array}$ \\
\hline Mexico & Debt & $\begin{array}{c}.09 \\
(.03) \\
\end{array}$ & $\begin{array}{l}.14 \\
(.13) \\
\end{array}$ & $\begin{array}{c}.21 \\
(.18) \\
\end{array}$ & $\begin{array}{l}-.04 \\
(.15) \\
\end{array}$ & $\begin{array}{l}-.43 \\
(.21) \\
\end{array}$ & $\begin{array}{c}-9.2 \\
(8.4) \\
\end{array}$ & $\begin{array}{c}-12 \\
(.46) \\
\end{array}$ & $\begin{array}{l}.10 \\
(.44) \\
\end{array}$ \\
\hline Indonesia & Debt & $\begin{array}{l}-.07 \\
(.02) \\
\end{array}$ & $\begin{array}{l}-.10 \\
(.08) \\
\end{array}$ & $\begin{array}{l}-.00 \\
(.08) \\
\end{array}$ & $\begin{array}{l}-.47 \\
(.13) \\
\end{array}$ & $\begin{array}{c}.39 \\
(.18) \\
\end{array}$ & $\begin{array}{l}-8.9 \\
(6.0) \\
\end{array}$ & $\begin{array}{c}.28 \\
(.40) \\
\end{array}$ & $\begin{array}{l}-.23 \\
(.17) \\
\end{array}$ \\
\hline $\begin{array}{l}\text { South } \\
\text { Africa }\end{array}$ & Equity & $\begin{array}{l}-.03 \\
(.05)\end{array}$ & $\begin{array}{c}.38 \\
(.18)\end{array}$ & $\begin{array}{c}.11 \\
(.18)\end{array}$ & $\begin{array}{l}-.87 \\
(.35)\end{array}$ & $\begin{array}{l}1.11 \\
(.28)\end{array}$ & $\begin{array}{l}-12.5 \\
(12.3)\end{array}$ & $\begin{array}{l}1.09 \\
(.86)\end{array}$ & $\begin{array}{l}-.78 \\
(.40)\end{array}$ \\
\hline Brazil & Equity & $\begin{array}{c}-.04 \\
(.02)\end{array}$ & $\begin{array}{l}-.09 \\
(.07)\end{array}$ & $\begin{array}{l}-.00 \\
(.05) \\
\end{array}$ & $\begin{array}{c}-.13 \\
(.08)\end{array}$ & $\begin{array}{l}.18 \\
(.11)\end{array}$ & $\begin{array}{l}-9.7 \\
(4.0)\end{array}$ & $\begin{array}{l}-.05 \\
(.24)\end{array}$ & $\begin{array}{l}.08 \\
(.12)\end{array}$ \\
\hline Chile & Equity & $\begin{array}{l}.03 \\
(.02) \\
\end{array}$ & $\begin{array}{c}.11 \\
(.06) \\
\end{array}$ & $\begin{array}{c}.04 \\
(.07) \\
\end{array}$ & $\begin{array}{c}.03 \\
(.11) \\
\end{array}$ & $\begin{array}{c}.11 \\
(.11) \\
\end{array}$ & $\begin{array}{c}5.8 \\
(4.4) \\
\end{array}$ & $\begin{array}{c}.50 \\
(.39) \\
\end{array}$ & $\begin{array}{c}.12 \\
(.18) \\
\end{array}$ \\
\hline Mexico & Equity & $\begin{array}{c}-.03 \\
(.01) \\
\end{array}$ & $\begin{array}{c}-.08 \\
(.06) \\
\end{array}$ & $\begin{array}{c}.03 \\
(.05) \\
\end{array}$ & $\begin{array}{c}.18 \\
(.08)\end{array}$ & $\begin{array}{c}.03 \\
(.07) \\
\end{array}$ & $\begin{array}{c}4.6 \\
(3.3) \\
\end{array}$ & $\begin{array}{c}-25 \\
(.29) \\
\end{array}$ & $\begin{array}{c}.33 \\
(.12) \\
\end{array}$ \\
\hline Indonesia & Equity & $\begin{array}{l}.03 \\
(.02) \\
\end{array}$ & $\begin{array}{l}-18 \\
(.11) \\
\end{array}$ & $\begin{array}{l}-.08 \\
(.06) \\
\end{array}$ & $\begin{array}{c}.15 \\
(.10) \\
\end{array}$ & $\begin{array}{l}-32 \\
(.19) \\
\end{array}$ & $\begin{array}{c}-12.9 \\
(7.6) \\
\end{array}$ & $\begin{array}{c}-.01 \\
(.31) \\
\end{array}$ & $\begin{array}{c}.01 \\
(.15) \\
\end{array}$ \\
\hline $\begin{array}{l}\text { South } \\
\text { Africa }\end{array}$ & Credit & $\begin{array}{c}-.03 \\
(.02) \\
\end{array}$ & $\begin{array}{c}.26 \\
(.12)\end{array}$ & $\begin{array}{c}.02 \\
(.11)\end{array}$ & $\begin{array}{c}-18 \\
(.18)\end{array}$ & $\begin{array}{l}-15 \\
(.17)\end{array}$ & $\begin{array}{l}-5.0 \\
(6.9)\end{array}$ & $\begin{array}{c}.29 \\
(.48)\end{array}$ & $\begin{array}{c}-.44 \\
(.25)\end{array}$ \\
\hline Brazil & Credit & $\begin{array}{l}-.03 \\
(.03) \\
\end{array}$ & $\begin{array}{l}-.08 \\
(.11) \\
\end{array}$ & $\begin{array}{l}-.01 \\
(.09) \\
\end{array}$ & $\begin{array}{c}.12 \\
(.11) \\
\end{array}$ & $\begin{array}{l}-.13 \\
(.13) \\
\end{array}$ & $\begin{array}{c}1.4 \\
(8.0) \\
\end{array}$ & $\begin{array}{l}-.55 \\
(.72) \\
\end{array}$ & $\begin{array}{l}-.11 \\
(.20) \\
\end{array}$ \\
\hline Chile & Credit & $\begin{array}{c}.02 \\
(.03) \\
\end{array}$ & $\begin{array}{c}.08 \\
(.19)\end{array}$ & $\begin{array}{c}-.13 \\
(.15)\end{array}$ & $\begin{array}{c}.09 \\
(.24) \\
\end{array}$ & $\begin{array}{c}-19 \\
(.22)\end{array}$ & $\begin{array}{c}-22.1 \\
(8.8)\end{array}$ & $\begin{array}{l}-.90 \\
(.54)\end{array}$ & $\begin{array}{c}.41 \\
(.32) \\
\end{array}$ \\
\hline Mexico & Credit & $\begin{array}{c}.01 \\
(.05) \\
\end{array}$ & $\begin{array}{l}-17 \\
(.13)\end{array}$ & $\begin{array}{l}-.30 \\
(.14)\end{array}$ & $\begin{array}{c}.26 \\
(.19)\end{array}$ & $\begin{array}{c}-.26 \\
(.20)\end{array}$ & $\begin{array}{l}-1.5 \\
(6.9) \\
\end{array}$ & $\begin{array}{r}-1.49 \\
(.58) \\
\end{array}$ & $\begin{array}{c}.03 \\
(.29) \\
\end{array}$ \\
\hline Indonesia & Credit & $\begin{array}{c}-.01 \\
(.01)\end{array}$ & $\begin{array}{c}-.04 \\
(.05) \\
\end{array}$ & $\begin{array}{l}.08 \\
(.05)\end{array}$ & $\begin{array}{c}-.12 \\
(.07) \\
\end{array}$ & $\begin{array}{l}-.06 \\
(.08)\end{array}$ & $\begin{array}{l}-3.3 \\
(2.5) \\
\end{array}$ & $\begin{array}{c}.44 \\
(.31) \\
\end{array}$ & $\begin{array}{c}-.14 \\
(.11)\end{array}$ \\
\hline
\end{tabular}

Each row tabulates coefficients (with robust standard errors); regressand is capital inflow of given type, as percentage of domestic GDP. LS estimation, 1990Q1-2015Q4 (with some gaps). Intercept and advanced/emerging market factors included but not reported. 


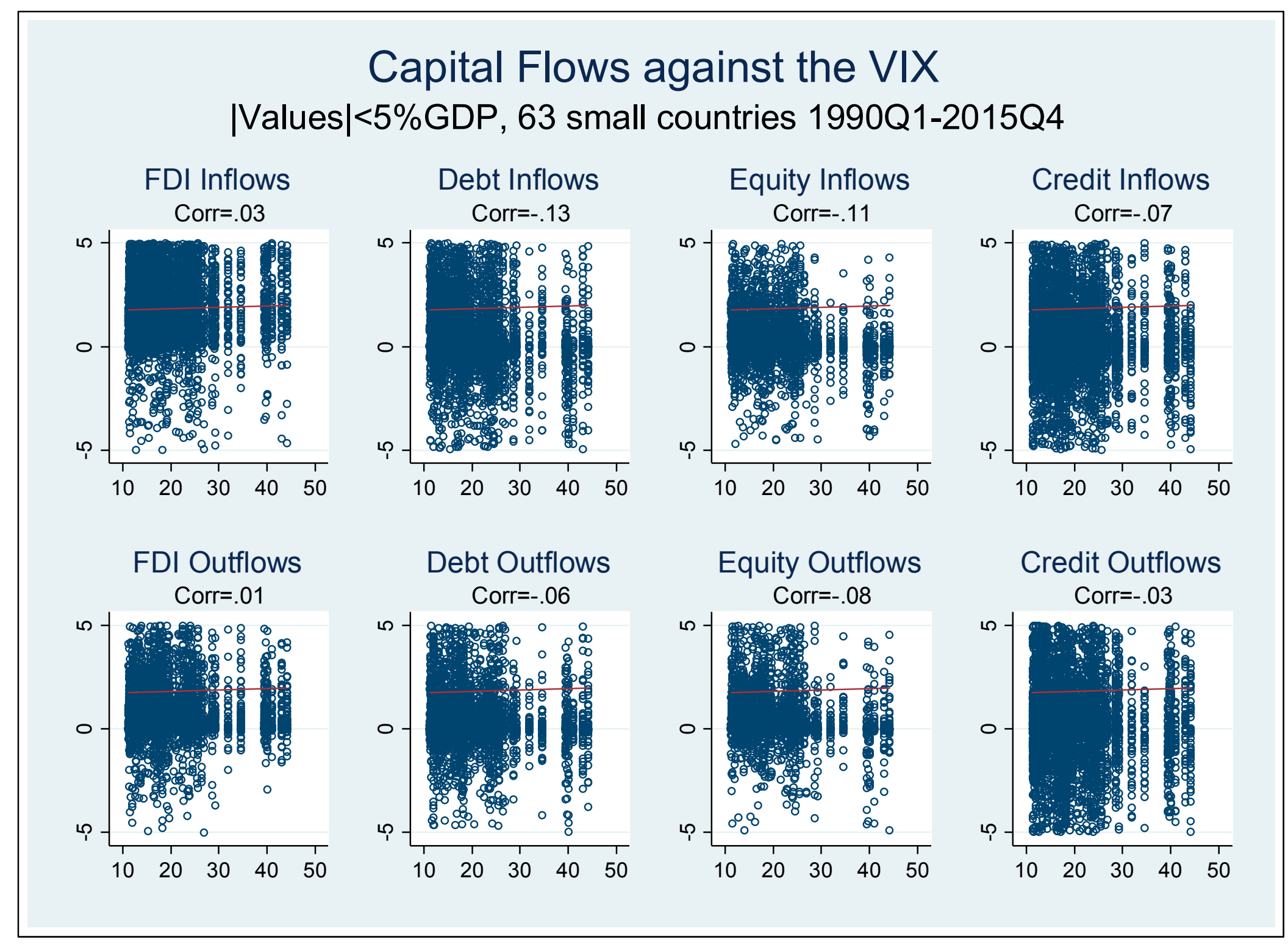

Figure A1 


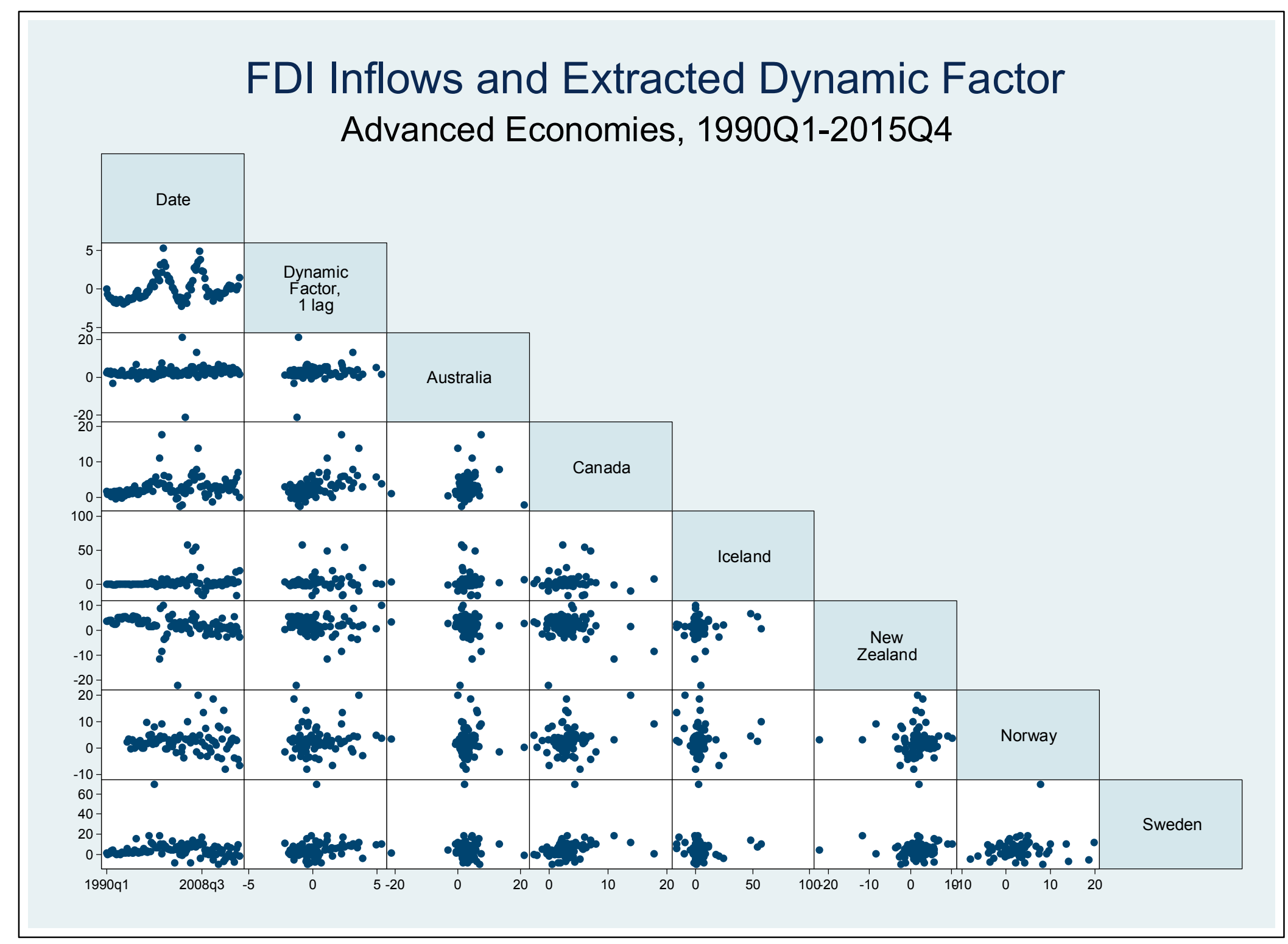

Figure A2 


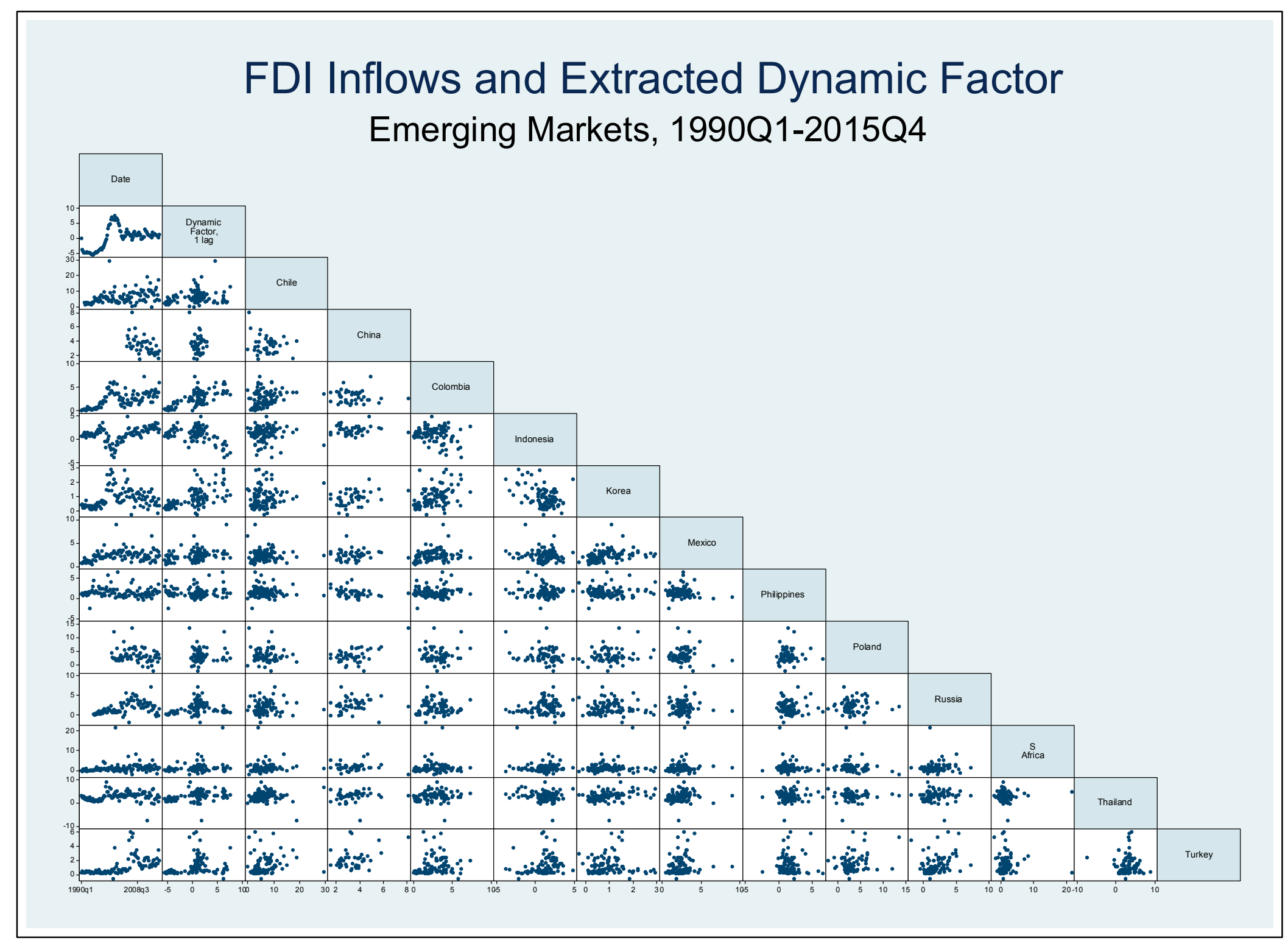

Figure A3 


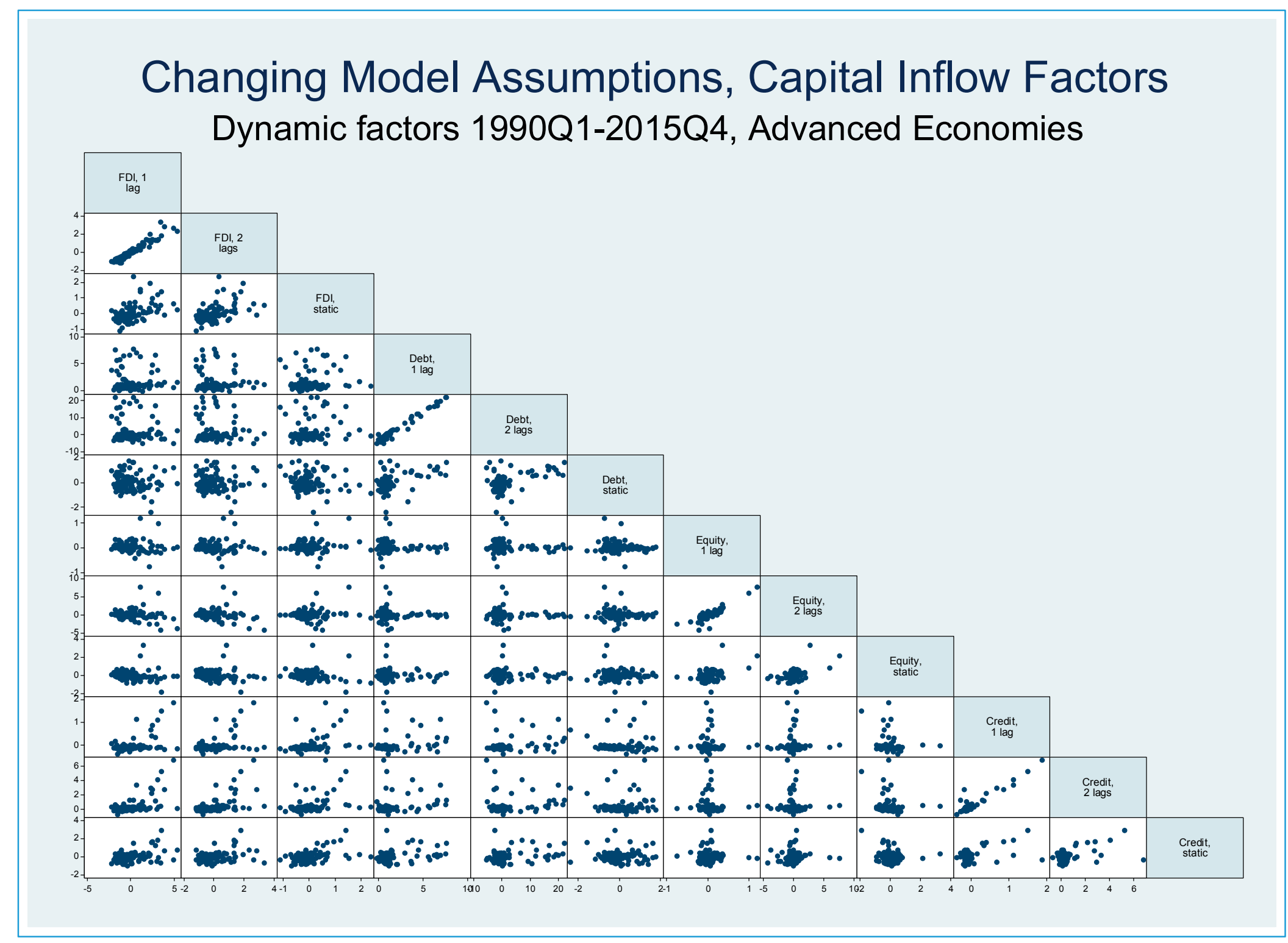




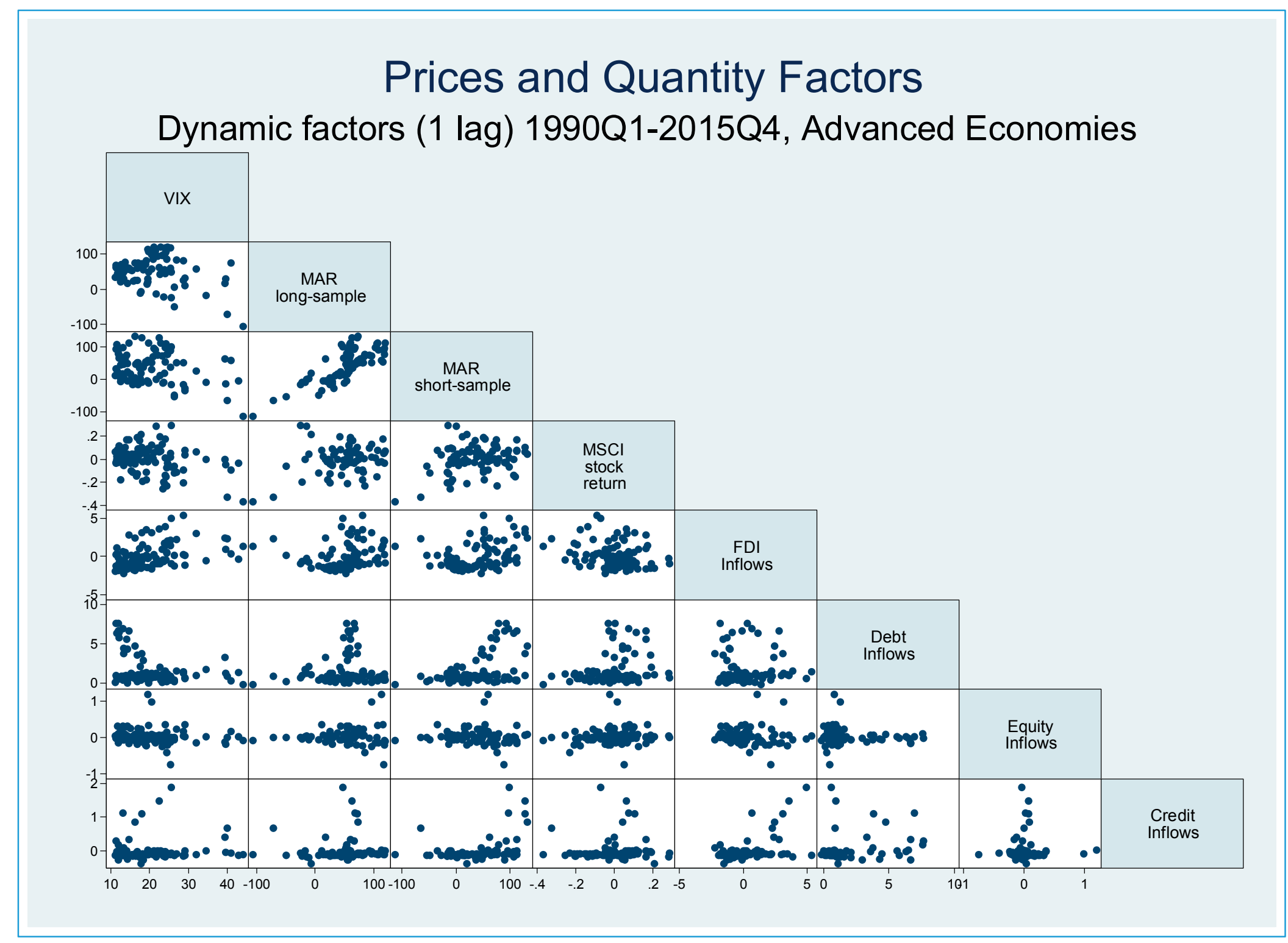

Figure A5 


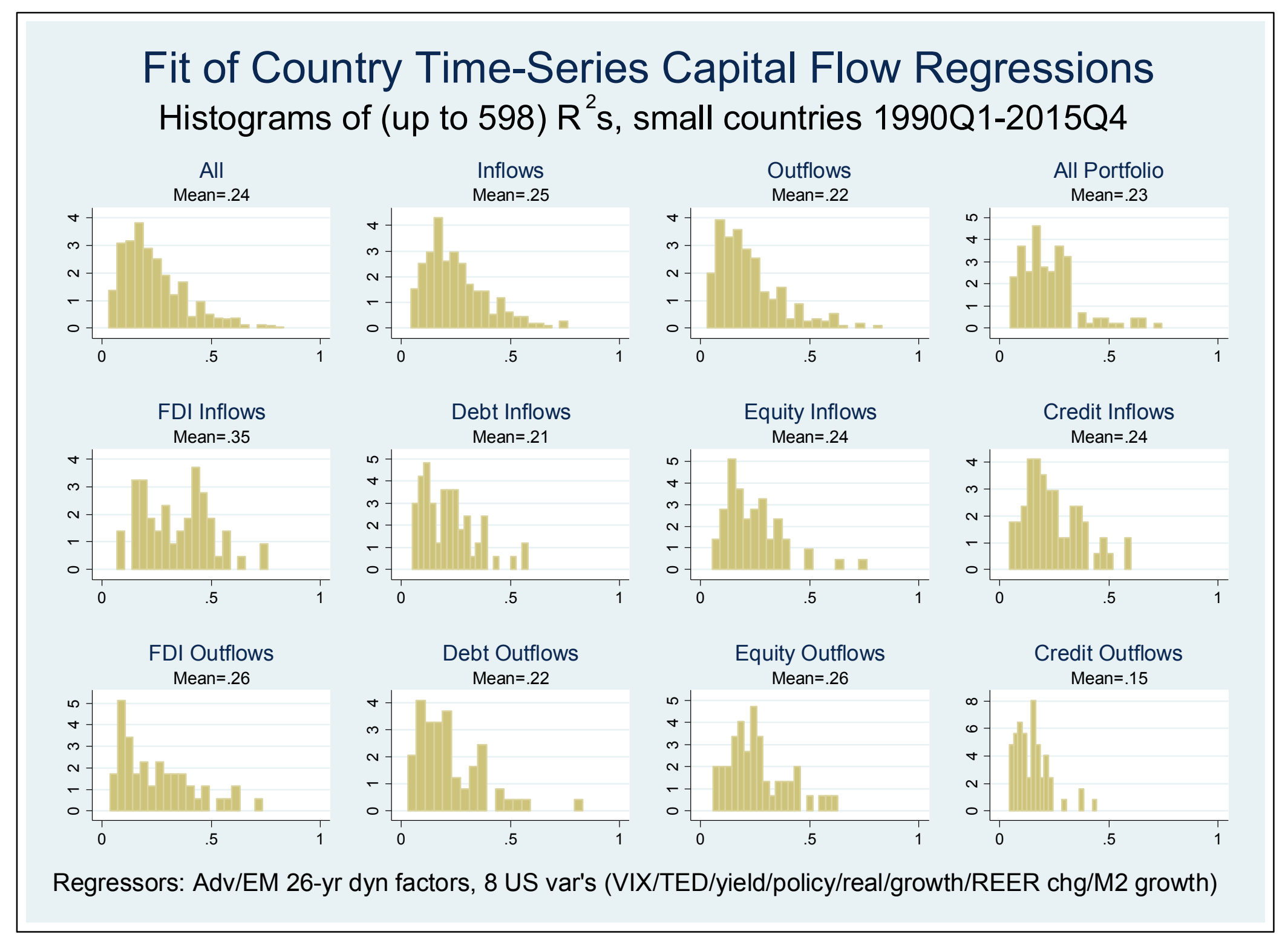

Figure A6 


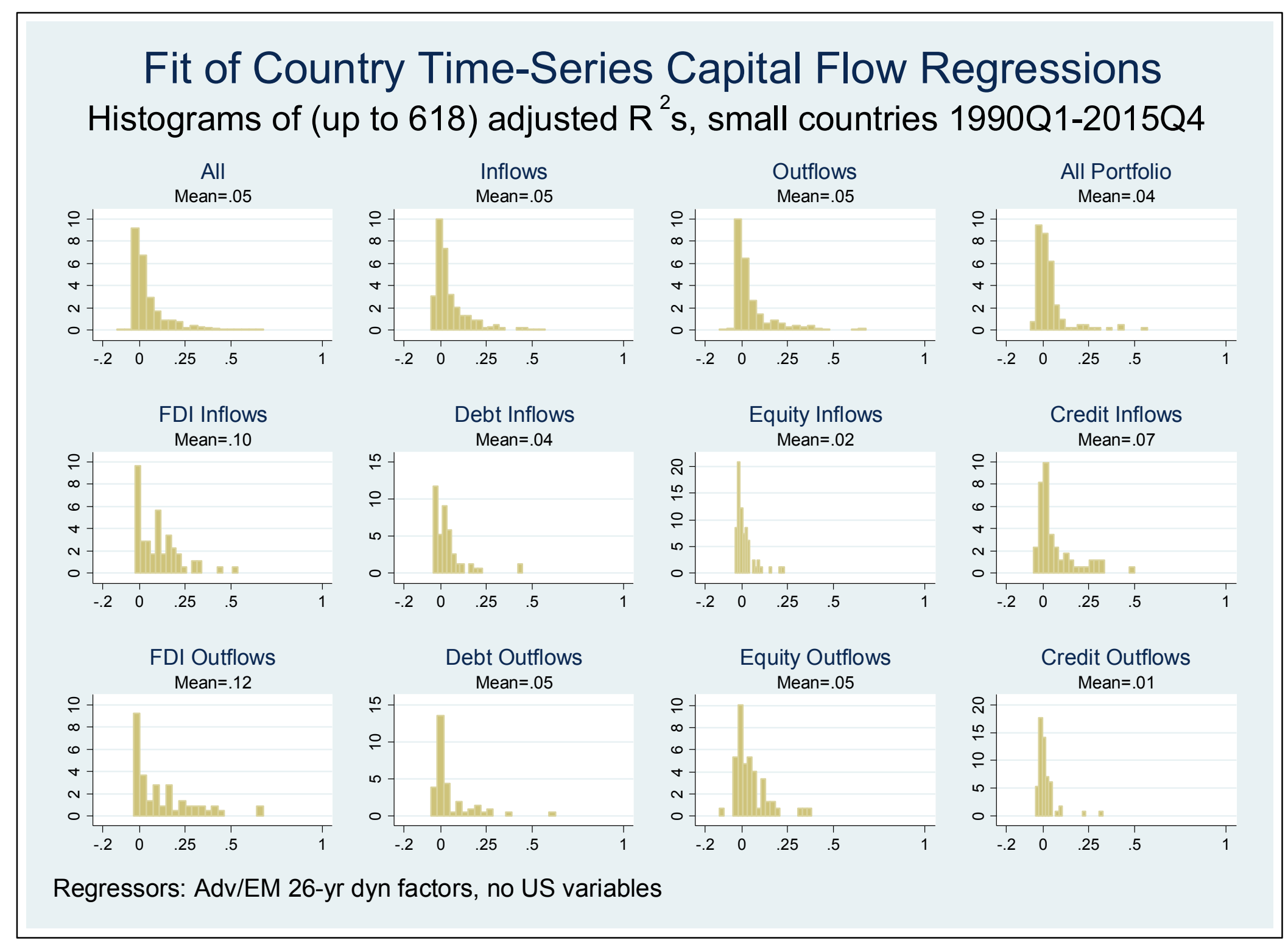

Figure A7 


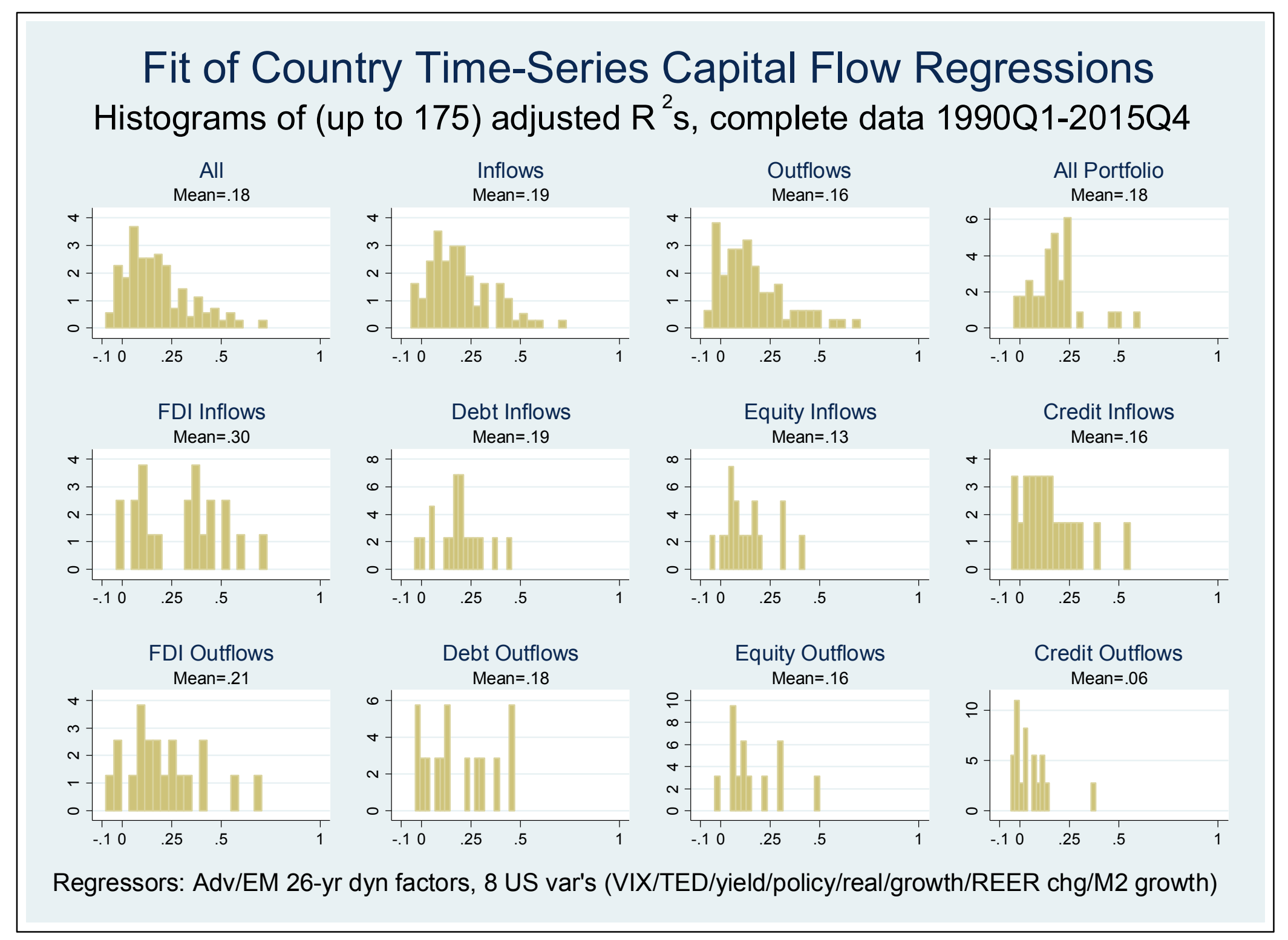

Figure A8 


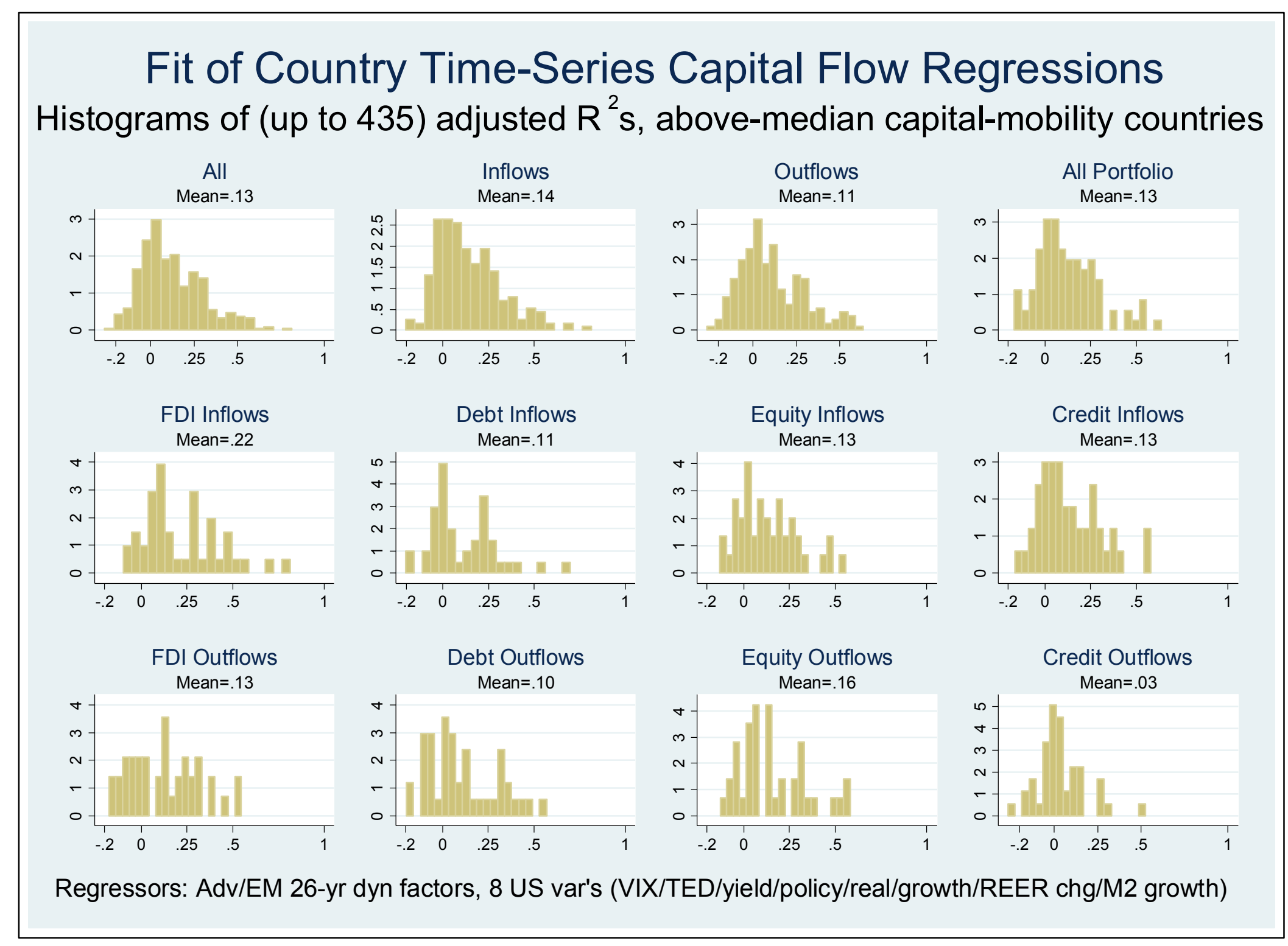

Figure A9 


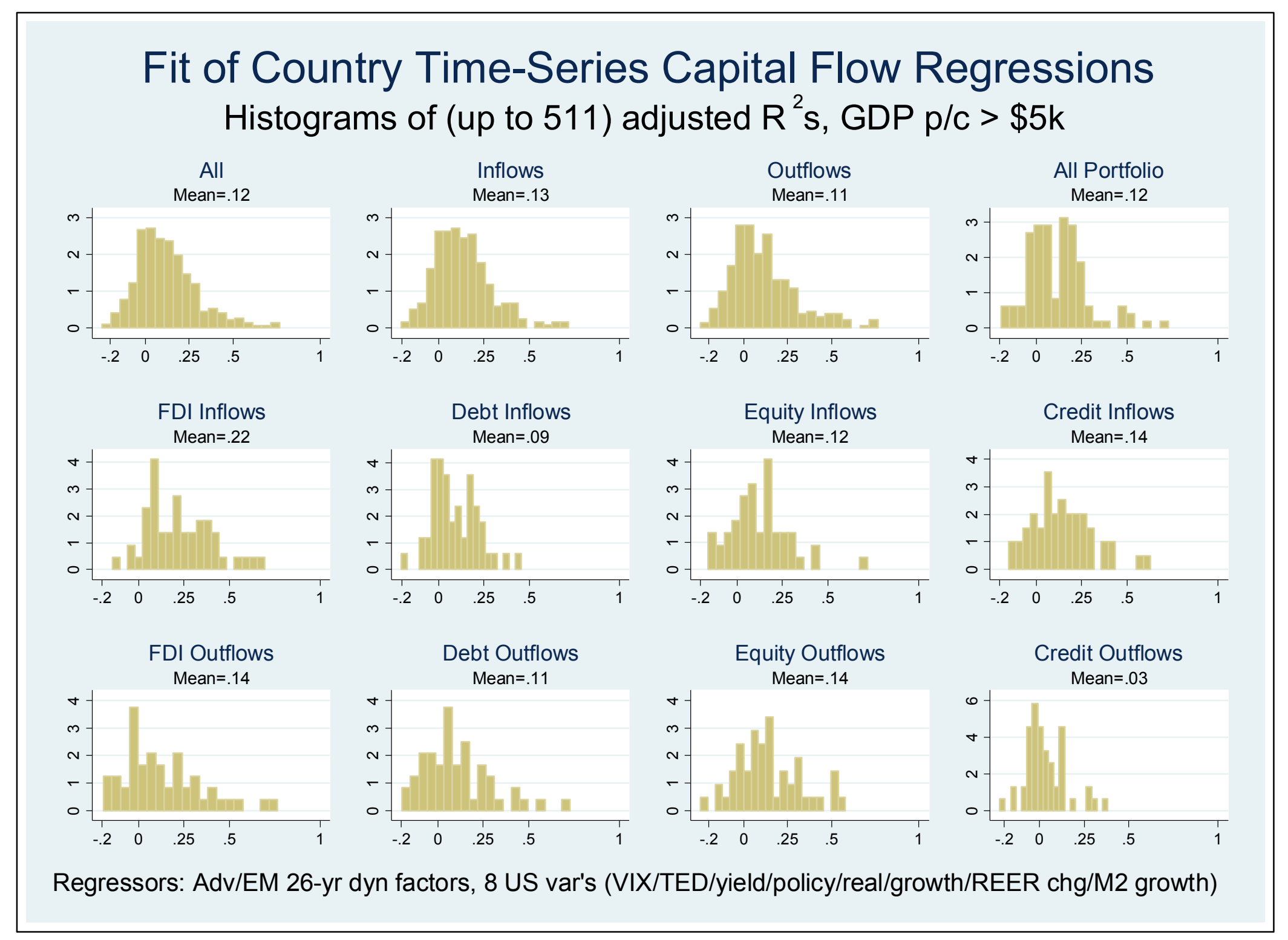

Figure A10 


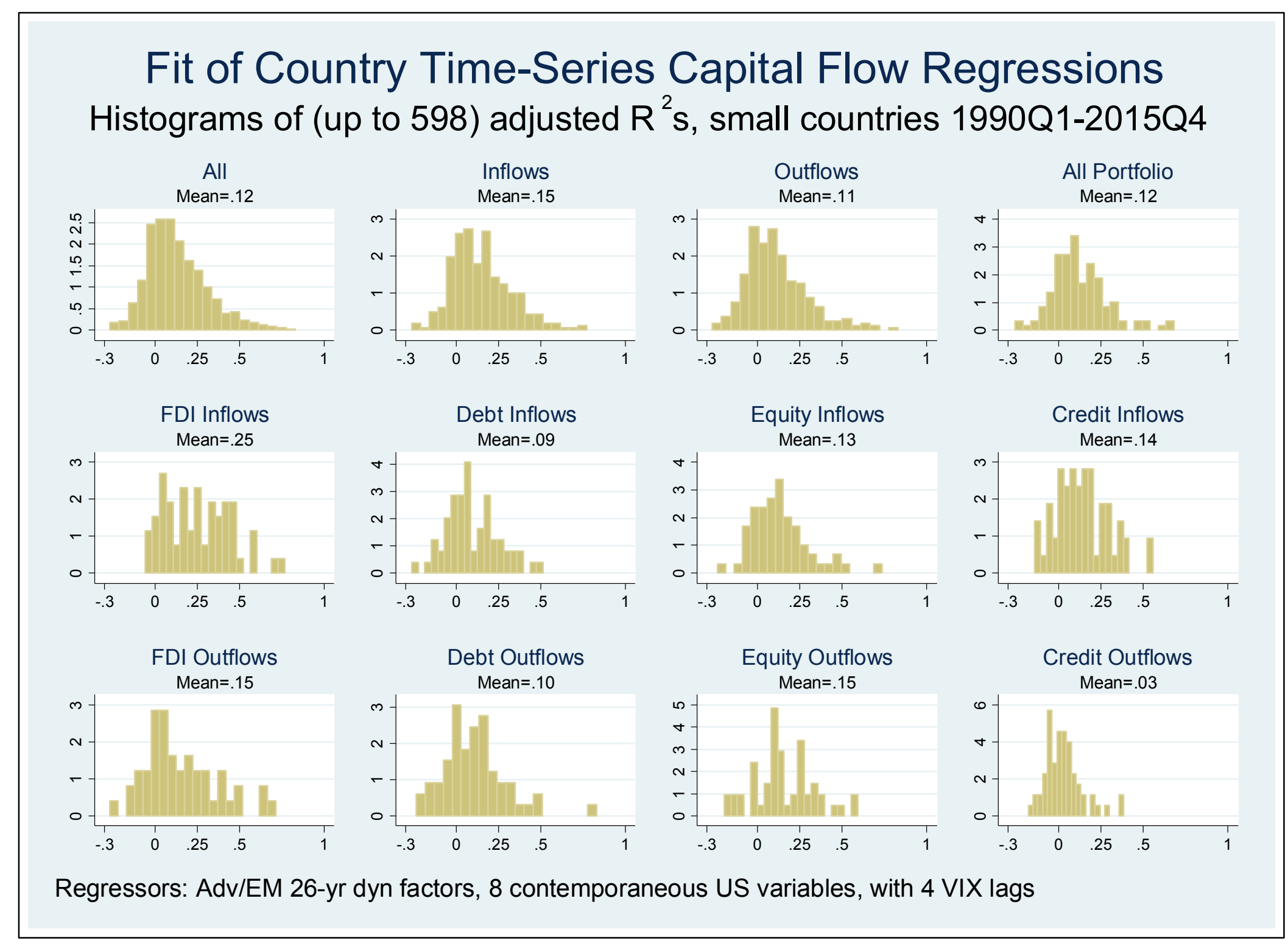

Figure A11 




Figure A12 


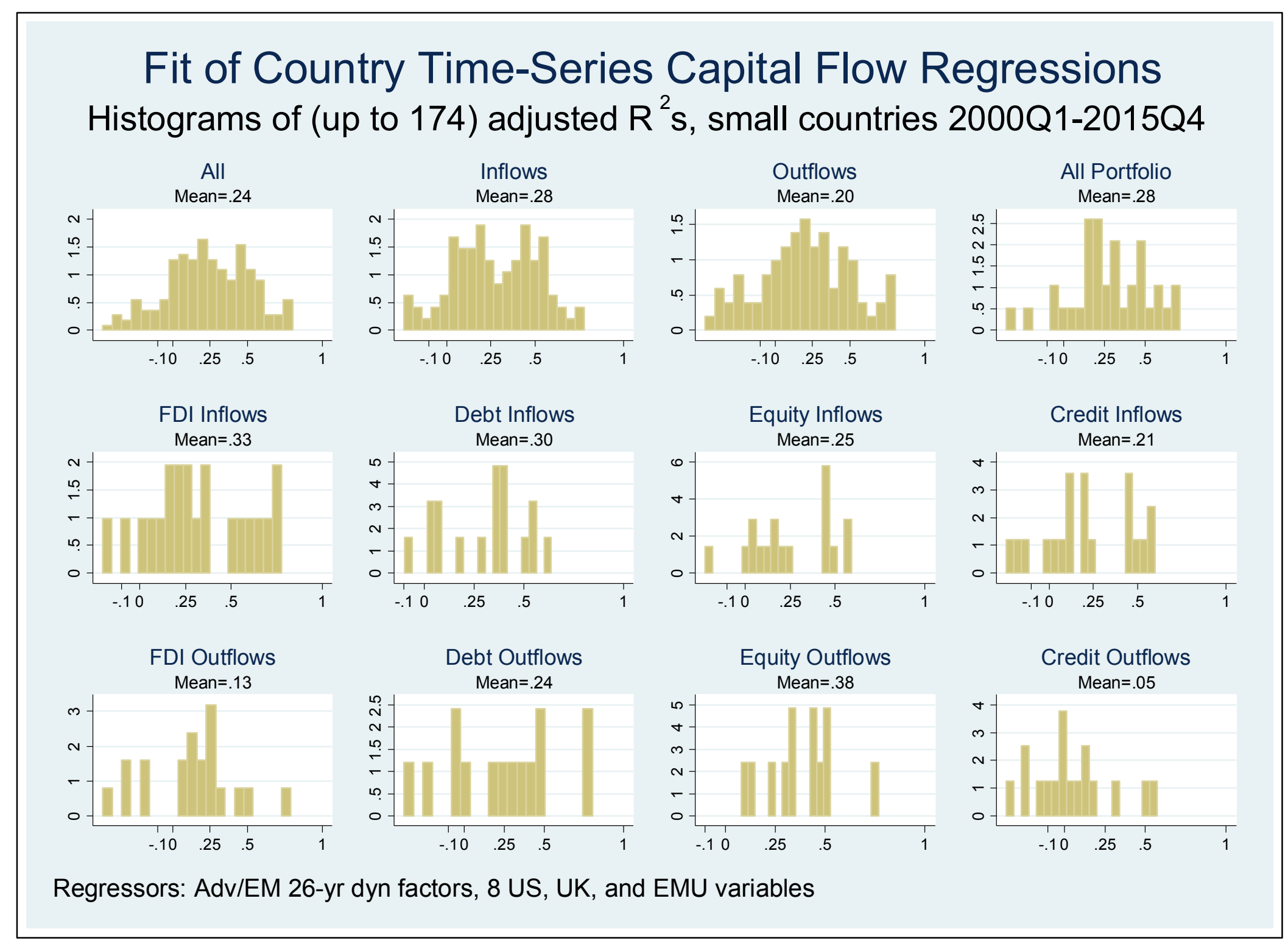

Figure A13 


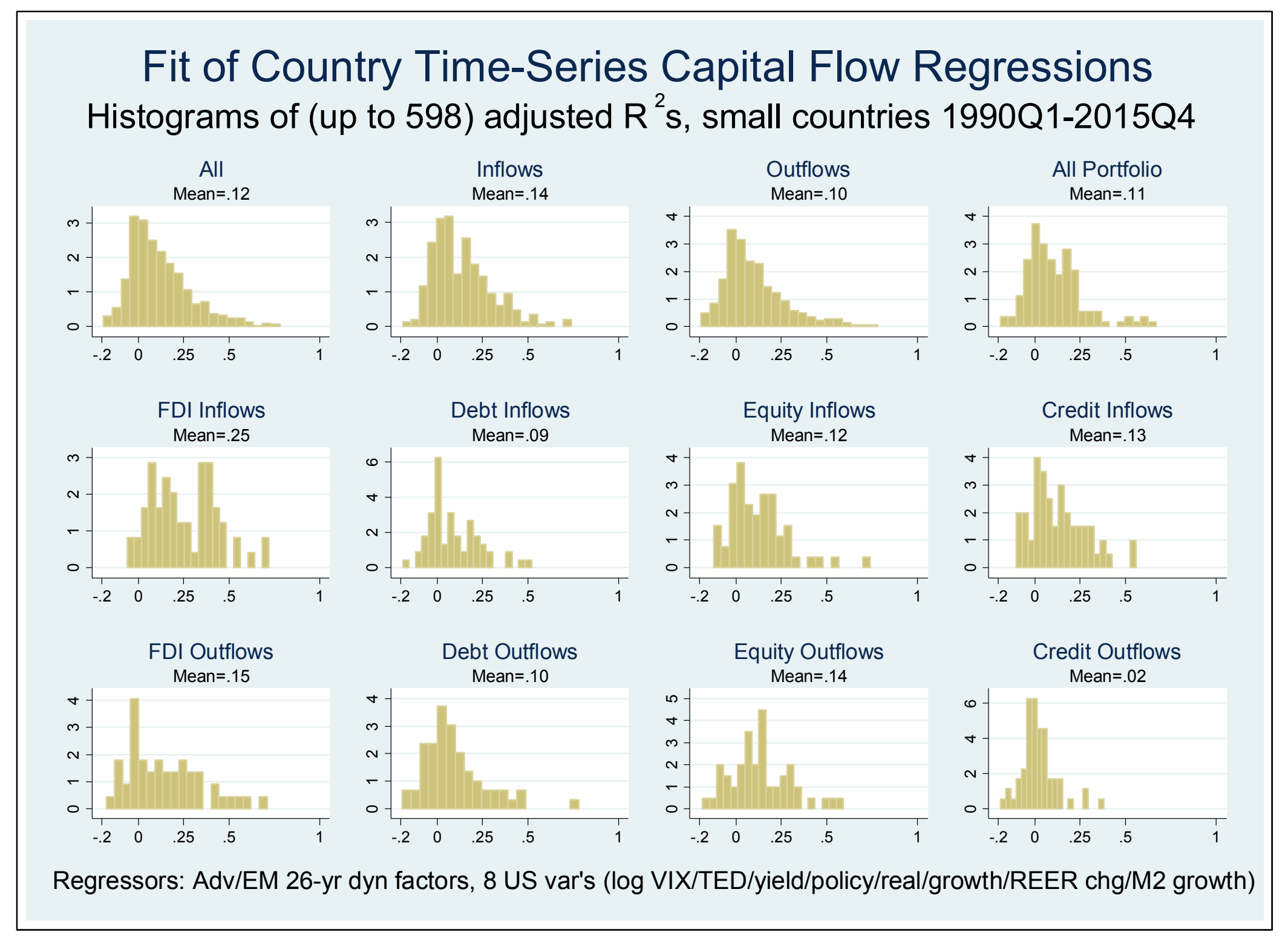

Figure A14 


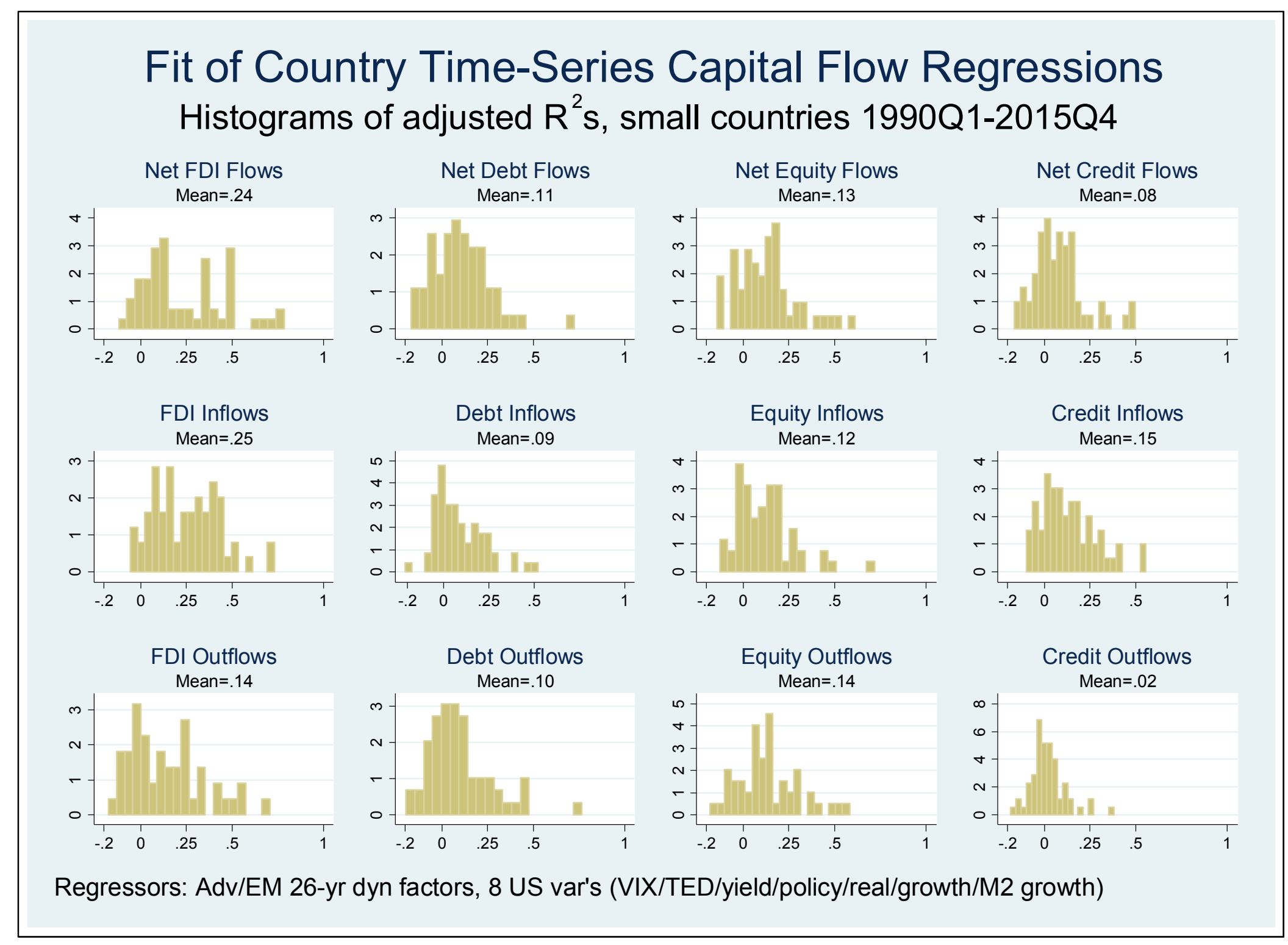

Figure A15 


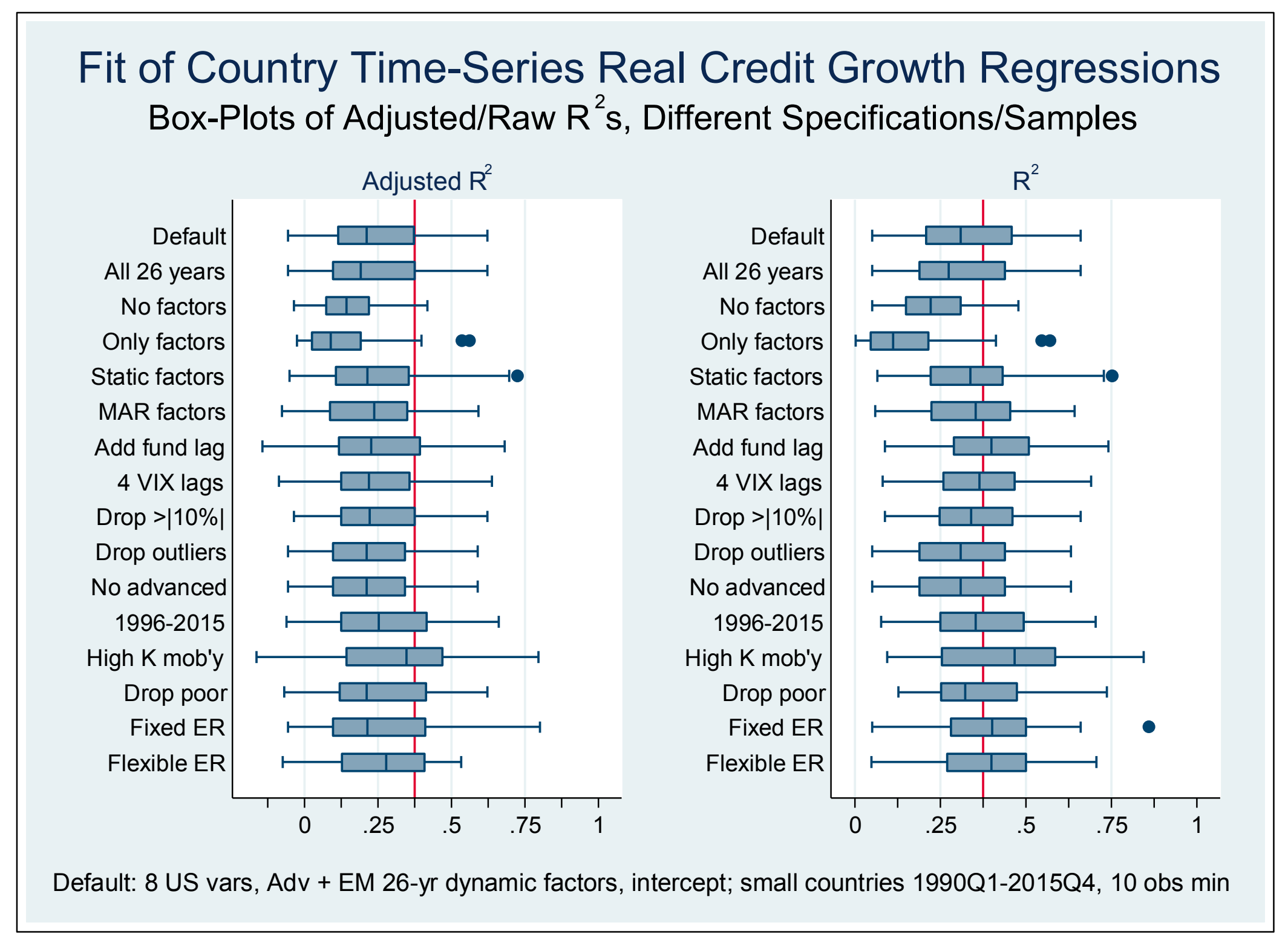

Figure A16 


\section{Capital Flows (\%GDP) around quarters when VIX close>25}

19 events
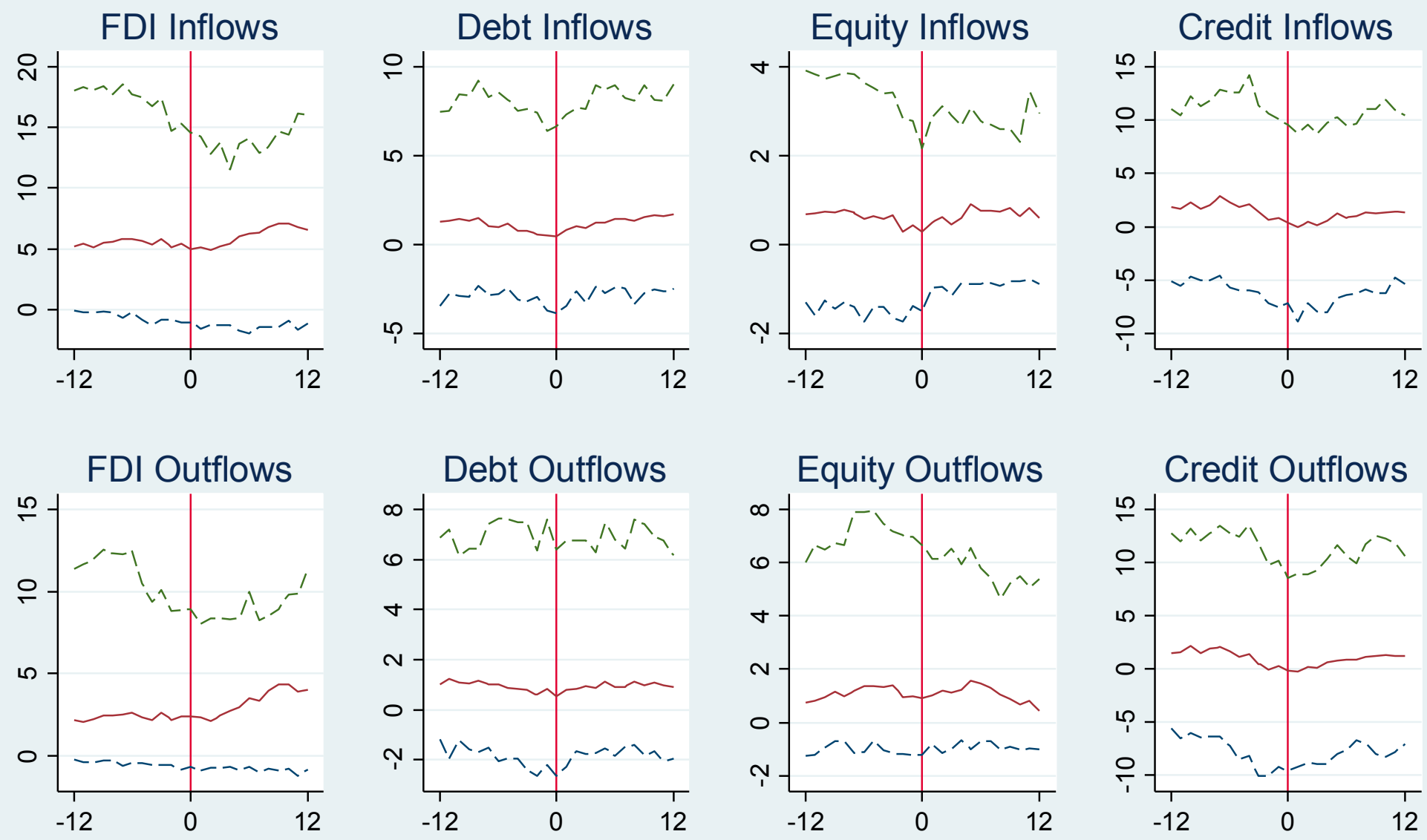

Means with $(5,95)$ confidence interval. 1990Q1-2015Q4 data, 63 small countries. 


\section{Capital Flows (\%GDP) around quarters when final VIX rises $>5$}

12 events
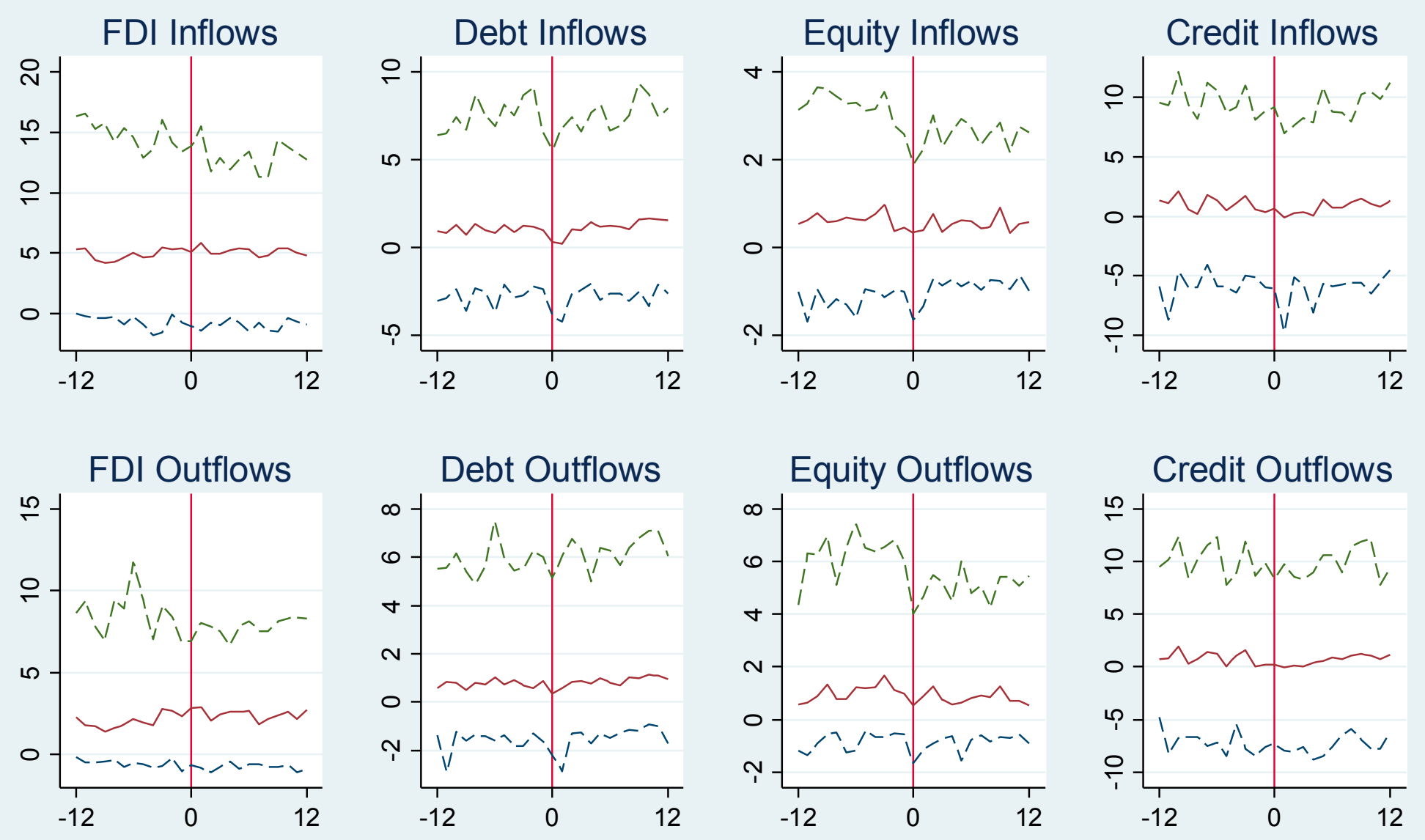

Means with $(5,95)$ confidence interval. 1990Q1-2015Q4 data, 63 small countries. 


\section{Capital Flows (\%GDP) around quarters when VIX average $>30$}

7 events
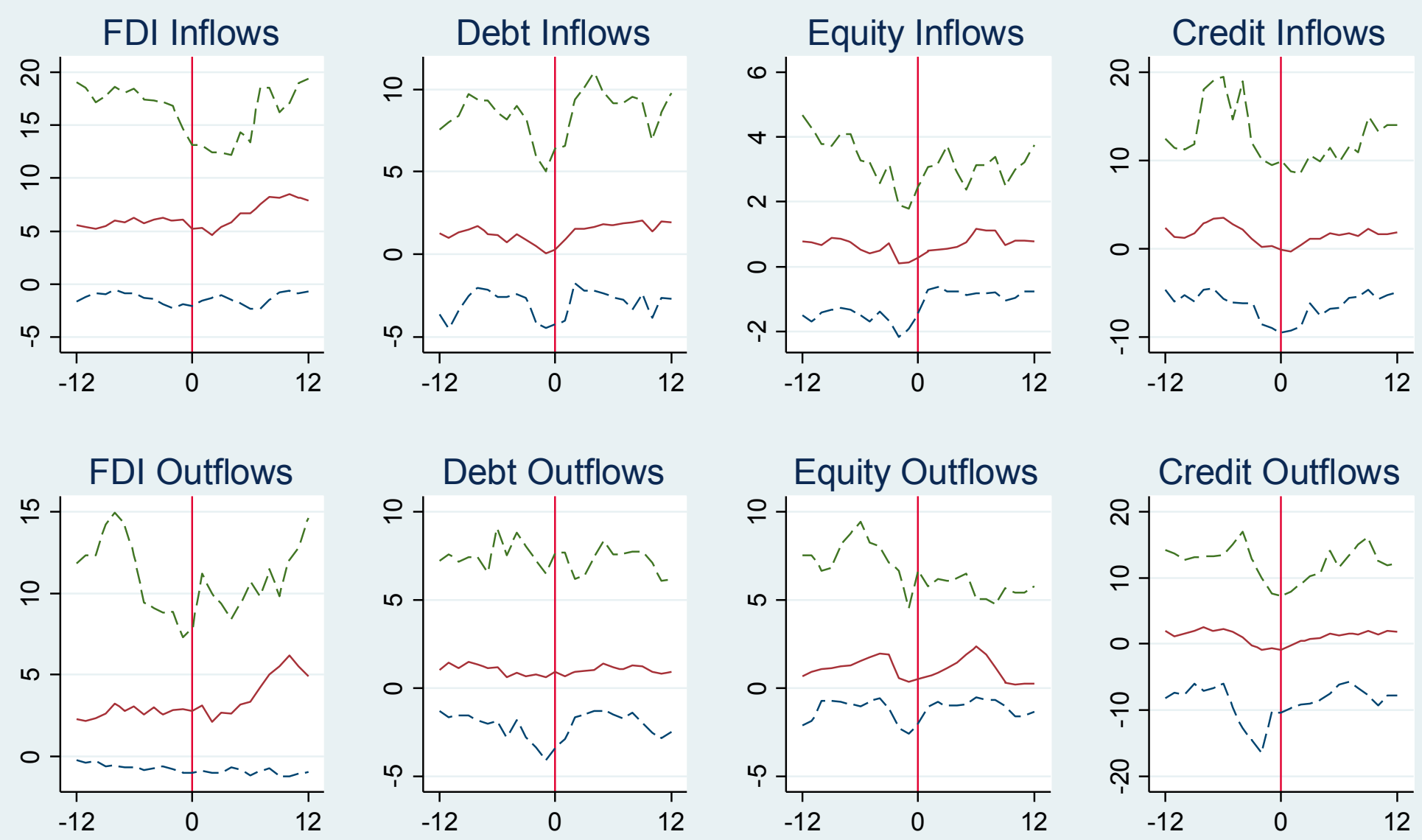

Means with $(5,95)$ confidence interval. 1990Q1-2015Q4 data, 63 small countries. 


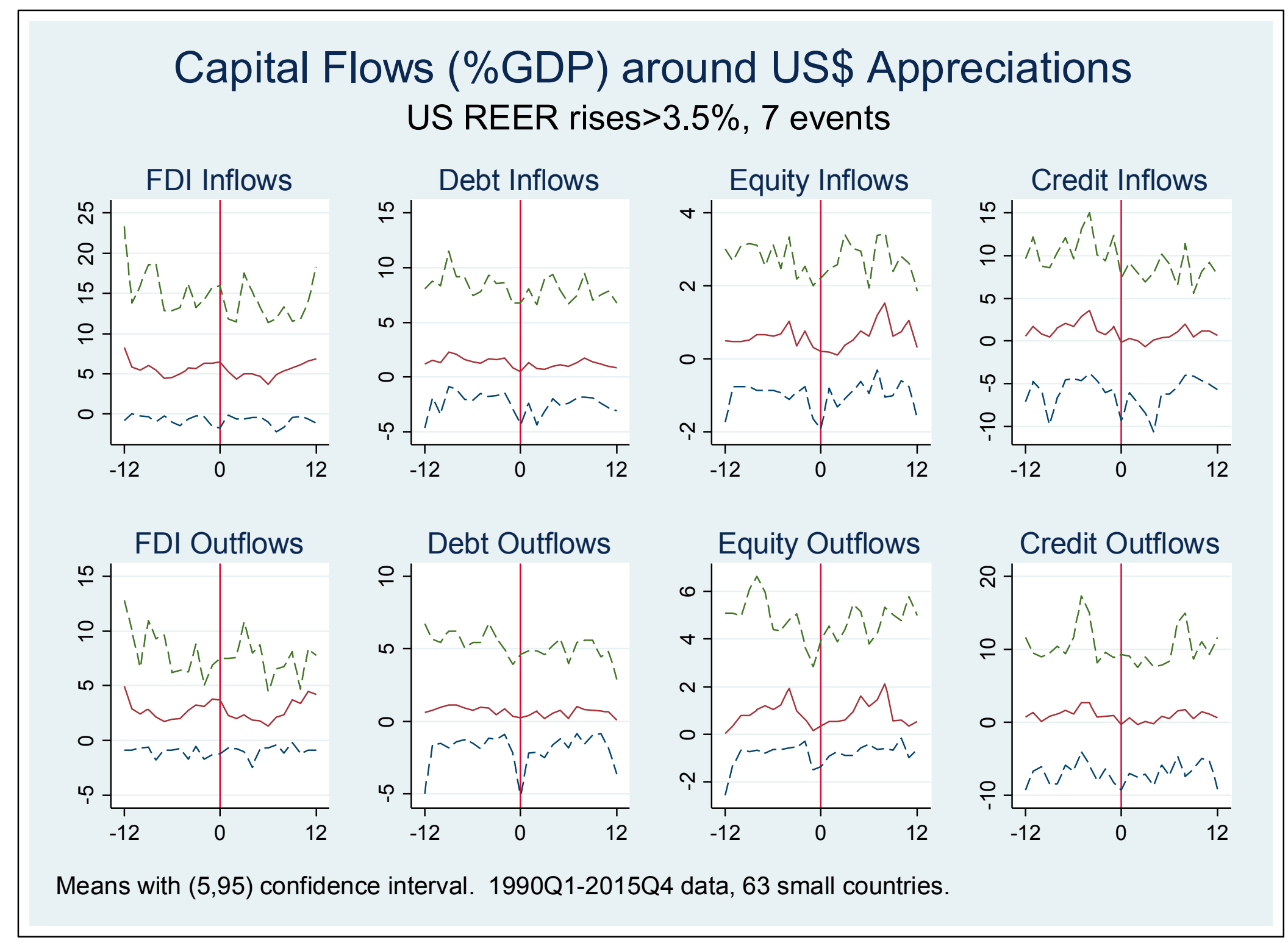

Figure A20 


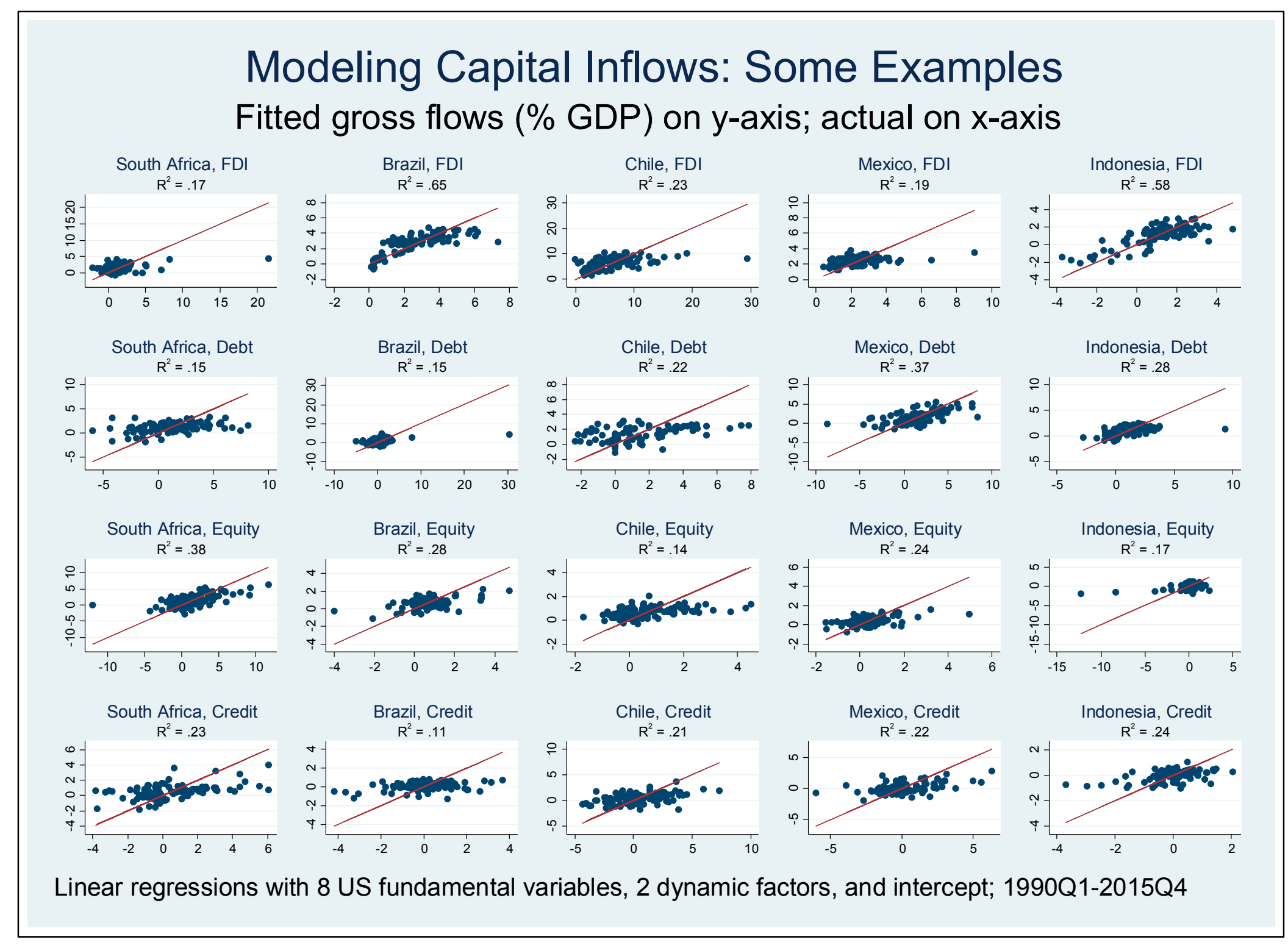

Figure A21 